\title{
INVESTIGATION OF BACILLUS SUBTILIS AS A BIOPESTICIDE AGAINST BOTRYTIS CINEREA
}

\author{
A Thesis presented \\ to the Faculty of \\ California Polytechnic State University
}

In Partial Fulfillment

of the Requirements for the Degree

Master of Science in General Engineering - Biochemical Engineering

by

Kenneth Ng

April 2012 
(C) 2012

Kenneth K Ng

ALL RIGHTS RESERVED 


\section{COMMITTEE MEMBERSHIP}

TITLE:

AUTHOR:

DATE SUBMITTED:
INVESTIGATION OF BACILLUS SUBTILIS AS A

BIOPESTICIDE AGAINST BOTRYTIS CINEREA

KENNETH K. NG

APRIL 2012

COMMITTEE CHAIR: Dr. Nirupam Pal, Professor

COMMITTEE MEMBER: Dr. Yarrow Nelson, Professor

COMMITTEE MEMBER: Dr. Christopher Kitts, Professor 


\section{ABSTRACT \\ INVESTIGATION OF BACILLUS SUBTILIS AS A BIOPESTICIDE AGAINST \\ BOTRYTIS CINEREA \\ KENNETH NG}

The objective of this thesis was to investigate $\mathrm{BiOWiSH}^{\mathrm{TM}}$-Aqua, a commercial dry solid formulation containing a consortium of bacteria and yeast, as a biopesticide for treatment of Botrytis cinerea, a gray mold that affects strawberries. BiOWiSH ${ }^{\mathrm{TM}}$-Aqua was compared with another commercial product specifically used as a fungicide and bacteriocide, Serenade ${ }^{\circledR}$ Garden Disease Control Spray (concentrated Bacillus subtilis strain QST 713). Both laboratory tests as well as in vivo lab tests were conducted. $\mathrm{BiOWiSH}^{\mathrm{TM}}$-Aqua results varied widely from plate to plate, regardless of experimental conditions. In some of these plates, inhibition zones were observed around colonies from $\mathrm{BiOWiSH}^{\mathrm{TM}}$-Aqua, indicating efficacy. The organism responsible for the inhibition zones of $B$. cinerea growth was isolated from $\mathrm{BiOWiSH}^{\mathrm{TM}}$-Aqua, and 16s rRNA analysis identified this culture as a strain of $B$. subtilis. This strain was designated as $B$. subtilis ssp. KLB. The $B$. subtilis KLB concentration required to completely inhibit $B$. cinerea was $9.1 \times 10^{4} \mathrm{CFU} / \mathrm{mL}$ when $B$. subtilis $\mathrm{KLB}$ was inoculated 48 hours before $B$. cinerea, $1.3 \times 10^{5} \mathrm{CFU} / \mathrm{mL}$ at 24 hours, and $3.2 \times 10^{6} \mathrm{CFU} / \mathrm{mL}$ when both were inoculated at the same time. Various preliminary experiments using $B$. subtilis KLB were also conducted to investigate its economic feasibility, to characterize the organism, and to test its postharvest in vivo viability. B. subtilis $\mathrm{KLB}$ cell concentration was $1.6 \times 10^{9} \mathrm{CFU} / \mathrm{mL}$ in a bioreactor with LB at the end of the log growth phase. B. subtilis KLB achieved cell concentrations as high as $5 \times 10^{9} \mathrm{CFU} / \mathrm{mL}$ in shake flasks with food-grade tapioca as a carbon source. Inoculation of B. subtilis KLB on post-harvest strawberries did not have an effect on Botrytis infection rates compared to the negative control. These various experiments were the first step in research to potentially produce $B$. subtilis KLB on a commercial scale. 


\section{TABLE OF CONTENTS}

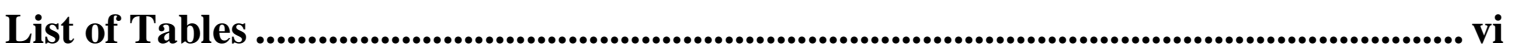

List of Figures................................................................................................................................... ix

CHAPTER 1: INTRODUCTION............................................................................ 1

CHAPTER 2: BACKGROUND ......................................................................................... 4

CHAPTER 3: MATERIALS AND METHODS ................................................. 9

3.1 Source and Culturing of Pathogen and Biopesticide ........................................... 9

3.2 In Vitro Experiments on PDA Plates ............................................................... 12

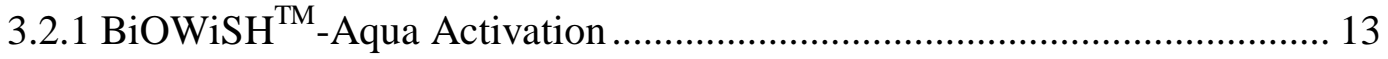

3.2.2 Microscope Enumeration of Botrytis conidia ............................................ 13

3.3 In Vitro Experiments of Biopesticide vs. Pathogen ............................................ 16

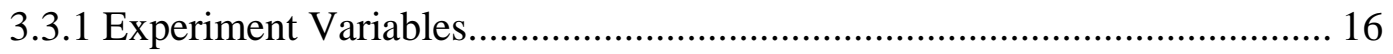

3.3.2 Fixed Experiment Parameters .................................................................... 18

3.3.3 Initial Inhibition Experiments Using BiOWiSH ${ }^{\mathrm{TM}}$-Aqua............................ 19

3.3.4 B. subtilis KLB Isolation..................................................................... 23

3.3.5 Inhibition Experiments Using B. subtilis KLB ....................................... 25

3.4 Initial Carbon Source Screening Experiments ................................................. 26

3.5 Growth Curves of B. subtilis KLB and BiOWiSH ${ }^{\mathrm{TM}}$-Aqua ............................... 28

3.6 Effect of B. subtilis KLB in vivo on Strawberry Fruit Bodies ............................ 30

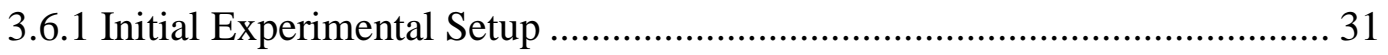

3.6.2 Modification to Initial Experimental Setup ……........................................ 33 


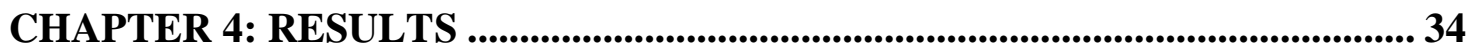

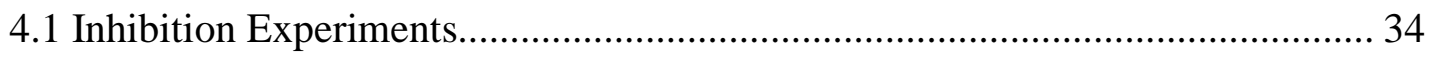

4.1.1 Botrytis Inhibition Results Using BiOWiSH ${ }^{\mathrm{TM}}$-Aqua ……………………... 34

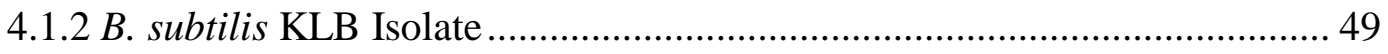

4.2 Initial Carbon Source Screening Results ...................................................... 78

4.3 Botrytis Growth Curve Experiment Results ...................................................... 83

4.4 B. subtilis KLB as Biopesticide on Strawberry Fruit Bodies.............................. 86

CHAPTER 5: CONCLUSIONS ..................................................................................... 89

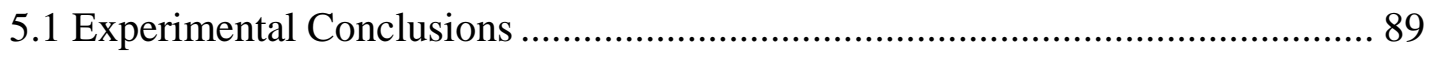

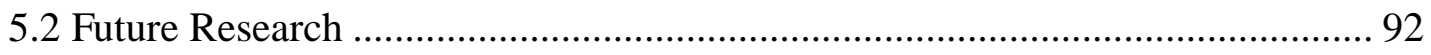

BIBLIOGRAPHY ...................................................................................................................... 94

Appendix A ................................................................................................................ 96

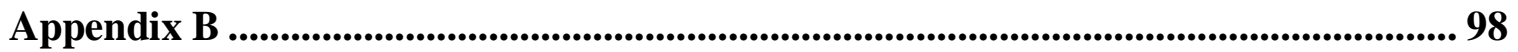




\section{List of Tables}

Table 4-1. Trial 1 data with Botrytis application right after BiOWiSH ${ }^{\mathrm{TM}}$-Aqua spread

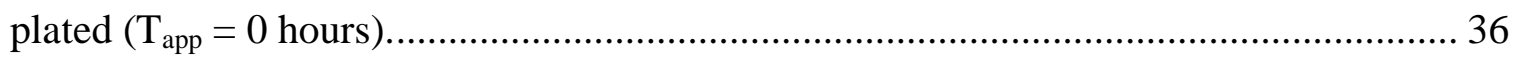

Table 4-2. BiOWiSH ${ }^{\mathrm{TM}}$-Aqua Trial 1 control data of the negative control (no

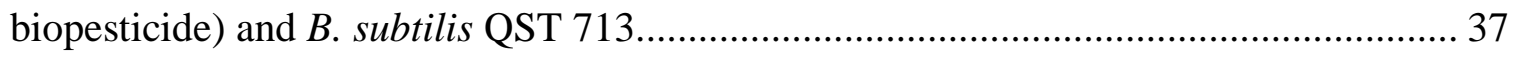

Table 4-3. Trial 1 data with Botrytis application 24 hours after BiOWiSH ${ }^{\mathrm{TM}}$-Aqua

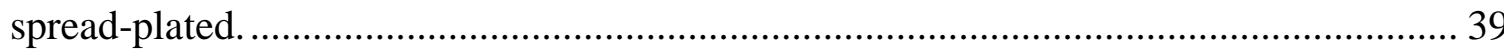

Table 4-4. Trial 1 data with Botrytis application 48 hours after BiOWiSH ${ }^{\mathrm{TM}}$-Aqua

spread-plated.

Table 4-5. Trial 2 data with Botrytis application right after BiOWiSH ${ }^{\mathrm{TM}}$-Aqua spread

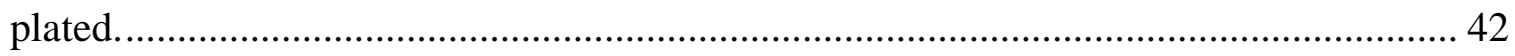

Table 4-6. Trial 2 data with Botrytis application 24 hours after BiOWiSH ${ }^{\mathrm{TM}}$-Aqua

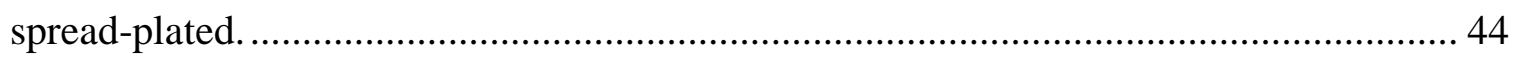

Table 4-7. Trial 3 data with Botrytis application 24 hours after BiOWiSH ${ }^{\mathrm{TM}}$-Aqua

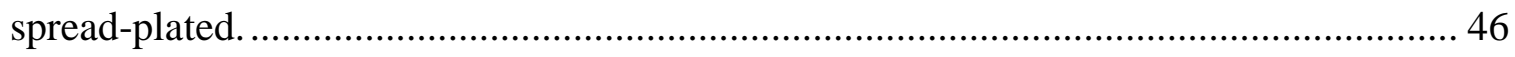

Table 4-8. Trial 4 data with Botrytis application 23 hours after BiOWiSH ${ }^{\mathrm{TM}}$-Aqua

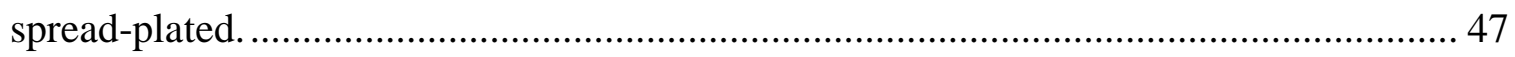

Table 4-9. Trial 1 data with Botrytis application 24 hours after B. subtilis KLB

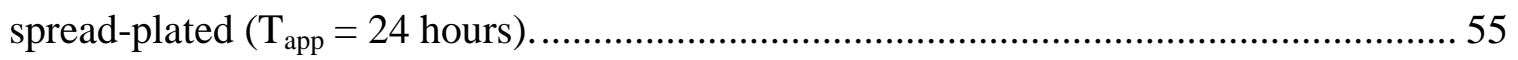

Table 4-10. Trial 2 data with Botrytis application 24 and 48 hours after B. subtilis

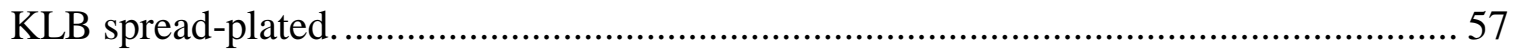


Table 4-11. Trial 3 data with Botrytis application 0 and 24 hours after B. subtilis KLB

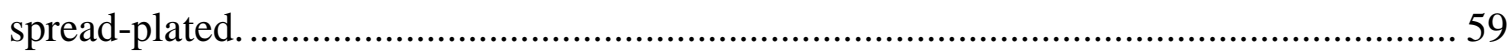

Table 4-12. Trial 4 data with Botrytis application right after B. subtilis KLB spread-

plated

Table 4-13. Trial 5 data with Botrytis application right after B. subtilis KLB spread-

plated.

Table 4-14. Trial 6 data with Botrytis application 24 and 48 hours after B. subtilis

KLB spread-plated. 64

Table 4-15. Trial 7 data with Botrytis application 24 and 48 hours after B. subtilis

KLB spread-plated. 66

Table 4-16. Trial 8 data with Botrytis application 24 and 48 hours after B. subtilis

KLB spread-plated.

Table 4-17. Trial 9 data with Botrytis application 0, 24, and 48 hours after B. subtilis

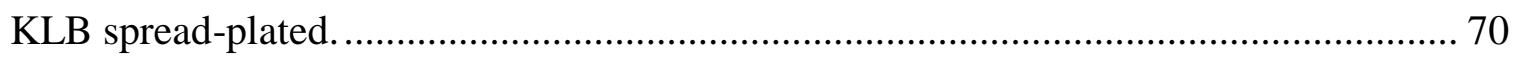

Table 4-18. Cell counts in triplicate for Experiment 1, Trial 1.1................................ 78

Table 4-19. Cell counts in triplicate for Experiment 1, Trial 1.2............................... 79

Table 4-20. Cell counts in triplicate for tapioca, Experiment 2, Trials 2.1-2.4 ............. 81

Table 4-21. Average Botrytis infection rate (\%) four days after biopesticide

inoculation 86 


\section{List of Figures}

Figure 2-1. Botrytis disease cycle on strawberry infection (Burr, 1985)......................... 5

Figure 3-1. Botrytis growth on strawberry after five days....................................... 10

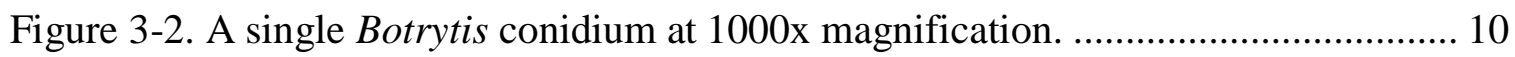

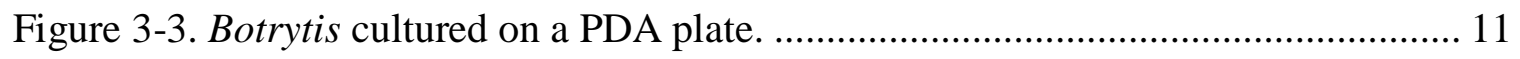

Figure 3-4. BiOWiSH ${ }^{\mathrm{TM}}$-Aqua packaging ........................................................... 12

Figure 3-5. Sample plate with Botrytis growth circled in red.................................... 20

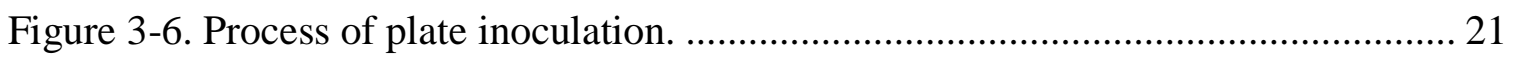

Figure 3-7. B. subtilis KLB biofilm layer in a test tube with LB broth......................... 24

Figure 3-8. Setric Genie 2L laboratory-scale bioreactor. ......................................... 29

Figure 3-9. Chamber for in vivo experiments using strawberry fruit bodies.................. 32

Figure $3-10$. Initial strawberry placement in chamber........................................... 32

Figure 3 -11. Modified strawberry placement in chamber. ......................................... 33

Figure 4-1. Sample plate with typical radial Botrytis growth 48 hours after inoculation.35

Figure 4-2. Sample plate with Botrytis inhibition seen around various areas of the

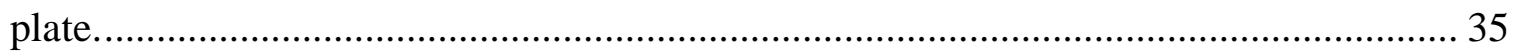

Figure 4-3. Effect of $\mathrm{BiOWiSH}^{\mathrm{TM}}$-Aqua activation time on Botrytis growth at 0 hours

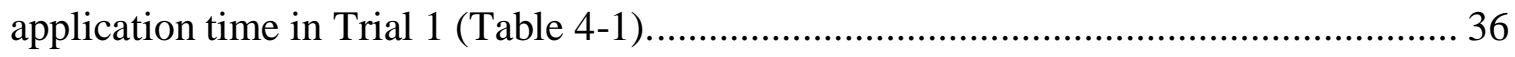

Figure 4-4. Control data of Serenade (B. subtilis QST 713) at three Botrytis application

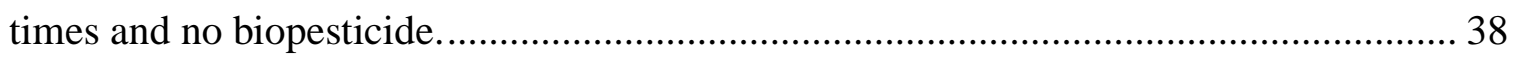


Figure 4-5. Effect of BiOWiSH ${ }^{\mathrm{TM}}$-Aqua activation time on Botrytis growth at 24

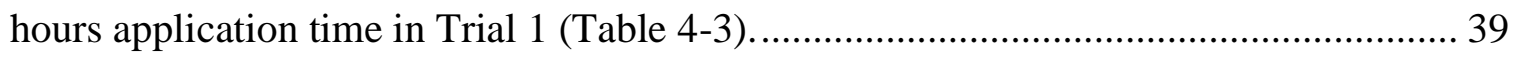

Figure 4-6. Effect of BiOWiSH ${ }^{\mathrm{TM}}$-Aqua activation time on Botrytis growth at 48 hours application time in Trial 1 (Table 4-4) .......................................................... 41

Figure 4-7. Effect of $\mathrm{BiOWiSH}{ }^{\mathrm{TM}}$-Aqua activation time on Botrytis growth at 0 hours

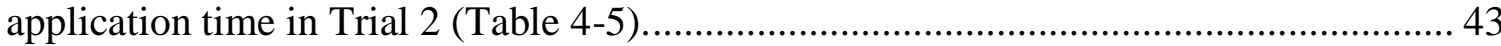

Figure 4-8. Effect of BiOWiSH ${ }^{\mathrm{TM}}$-Aqua activation time on Botrytis growth at 24

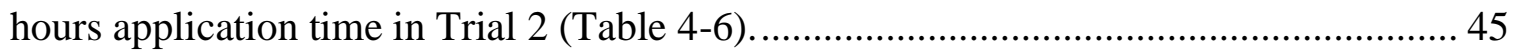

Figure 4-9. Effect of $\mathrm{BiOWiSH}^{\mathrm{TM}}$-Aqua activation time on Botrytis growth at 24

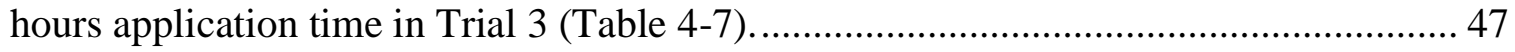
Figure 4-10. Effect of $\mathrm{BiOWiSH}{ }^{\mathrm{TM}}$-Aqua activation time on Botrytis growth at 23

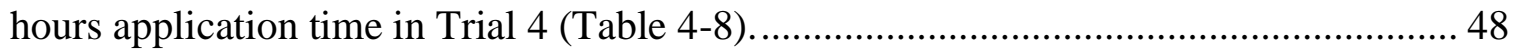
Figure 4-11. PDA plate where B. subtilis KLB completely inhibited Botrytis (the large

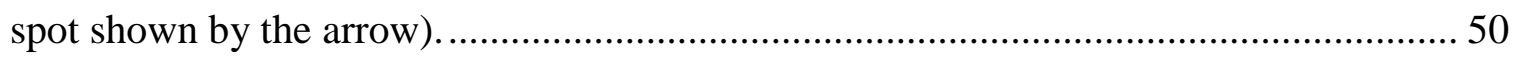

Figure 4-12. 1000x magnification of a Gram-stained slide with B. subtilis KLB.......... 51

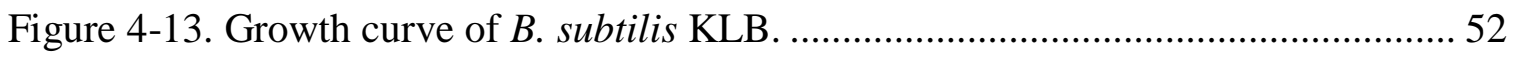

Figure 4-14. Different B. subtilis KLB concentrations at application time of 0 hours..... 53 Figure 4-15. Different B. subtilis KLB concentrations at application time of 24 hours... 54 Figure 4-16. B. subtilis KLB Trial 1 data from Table 4-9........................................ 55

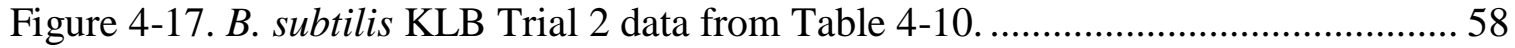

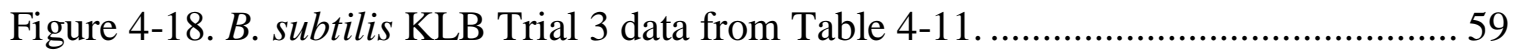


Figure 4-19. Minimal Botrytis growth (2.6 percent) at $6.6 \times 10^{5} \mathrm{CFU} / \mathrm{mL}$ of B. subtilis

KLB in Trial 3

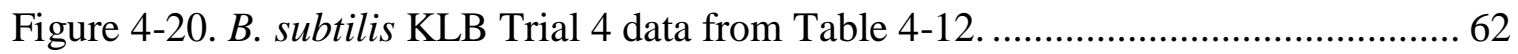

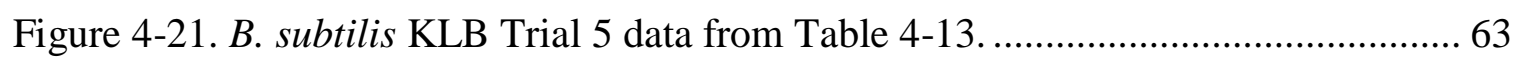

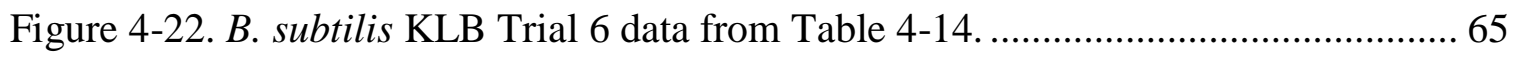

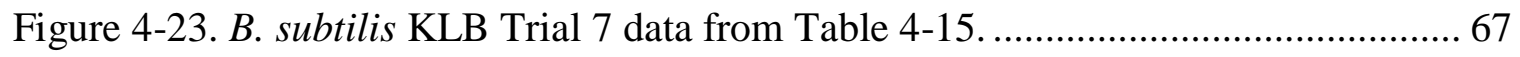

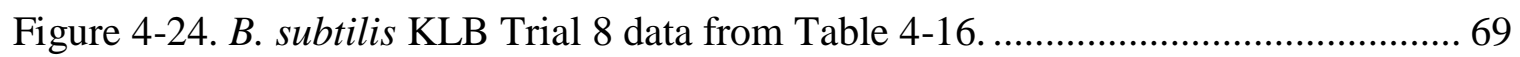

Figure 4-25. B. subtilis KLB Trial 9 data from Table 4-17....................................... 70

Figure 4-26. Linear regression graphs of all three Botrytis application times of 0, 24,

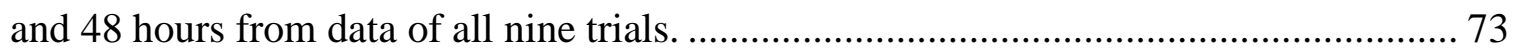

Figure 4-27. Truncated version of Figure 4-26 with only data containing B. subtilis

KLB concentrations greater than $2.5 \times 10^{3} \mathrm{CFU} / \mathrm{mL}$.............................................. 74

Figure 4-28. Linear regression graph with truncated data from application time of 0

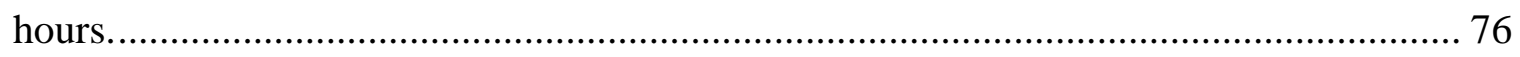

Figure 4-29. Linear regression graph with combined truncated data from application

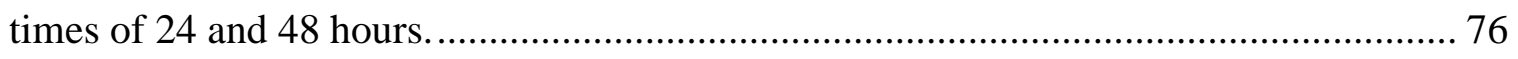

Figure 4-30. Cell counts of KLB grown on molasses and tapioca from Table 4-18

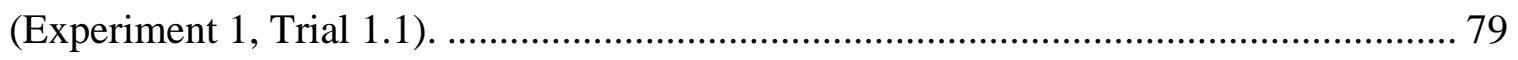

Figure 4-31. Cell counts of KLB grown on molasses and tapioca from Table 4-18

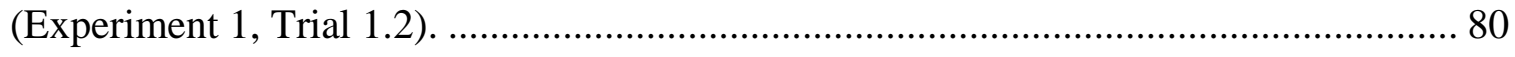

Figure 4-32. Cell counts of KLB grown on tapioca from Table 4-20 …...................... 82 
Figure 4-33. Average cell counts of KLB grown on tapioca from Table 4-20

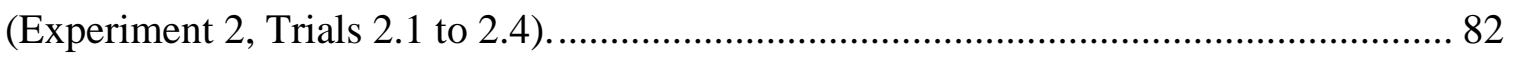

Figure 4-34. The $\mathrm{OD}_{600}$ values of B. subtilis $\mathrm{KLB}$ and $\mathrm{BiOWiSH}^{\mathrm{TM}}$-Aqua with corresponding KLB cell counts.

Figure 4-35. Average Botrytis infection rate (\%) four days after biopesticide

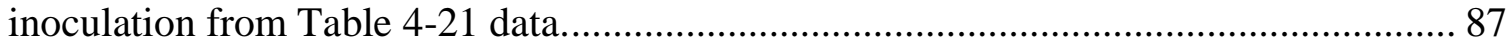




\section{CHAPTER 1: INTRODUCTION}

Methyl bromide (MeBr) is a broad spectrum pesticide used in U.S. agriculture to control pest insects, weeds, and pathogens. In U.S. agriculture, $\mathrm{MeBr}$ is primarily used as a soil fumigant, the process of filling acreage with gaseous pesticides (EPA, 2011). However, $\mathrm{MeBr}$ causes the destruction of the ozone layer and the potential death of human beings. $\mathrm{MeBr}$ causes central nervous system and respiratory system failure in workers directly exposed to the gas (Thomas, 1996). MeBr also depletes the ozone layer by rising into the atmosphere and forming $\mathrm{BrO}$, a powerful ozone-depleting substance (ODS). The result of depleting the ozone layer is UV radiation, which can genetically alter life forms at the cellular level, cause fatal skin cancer, and cause blindness in humans (Morrissey, 2007). In fact, the Montreal Protocol, which is designed to phase out substances that deplete the ozone layer, called for a 100 percent phase-out of MeBr from 2005 onward (EPA, 2011). Despite the consequences of using $\mathrm{MeBr}$, its use as a fumigant is necessary to control agricultural pests for various crops. For example, in the Locascio, 1997 study, no $\mathrm{MeBr}$ alternatives were able to provide the consistent broad spectrum control provided by $\mathrm{MeBr}$ for polyethylene-mulched tomato growth in Florida. For many crops dependent on $\mathrm{MeBr}$ fumigation, there simply is no clear viable alternative.

A major California crop dependent on $\mathrm{MeBr}$ is strawberries. In fact, in 2004, California strawberry producers applied 3.2 million pounds of $\mathrm{MeBr}$ primarily for soil fumigation, accounting for $45 \%$ of the 7.1 million pounds of total MeBr used in California 
(Fennimore, 2008). Organic fields, which do not use chemical pesticides, produce only 25 to 60 percent of conventional yields (USDA, 1999). As a result, parties to the Montreal Protocol and the rulemakings by EPA made an exception for usage of $\mathrm{MeBr}$ in California strawberry production (EPA, 2011).

Fumigation plays a large role in Integrated Pest Management (IPM), an effective and ecological approach to pest management that relies on a combination of common-sense practices including cultural, physical, biological, and chemical practices (Brennan, 2011). One of the longer-term goals of IPM programs is to reduce or even eliminate chemical pesticide usage by encouraging biologically and culturally based alternatives (Cooley, 1996). One of the ways of achieving this is by increasing the role of biological pesticides, or "biopesticides". While strawberries are attacked by a large number of pests, IPM targets key pests within an agroecosystem (Cooley, 1996). The gray mold Botrytis cinerea is the most common and most serious disease of California strawberries (USDA, 1999). In the strawberry industry, IPM could greatly reduce or even potentially eliminate the use of conventional pesticides while minimizing the economic impact of using more natural means.

The purpose of my research is to investigate a biological means for controlling pest growth on strawberries. Specifically, a biopesticide, in this case an organism, will be tested against Botrytis gray mold. Firstly, biopesticide growth conditions for optimal inhibition of Botrytis will be determined in vitro. Secondly, economic feasibility of the 
biopesticide will be explored by using less expensive growth media and by scaling up from flask growth to bioreactor growth. Lastly, in vivo experiments involving direct contact of the biopesticide on strawberry fruit bodies will test possible post-harvest inhibition of Botrytis. 


\section{CHAPTER 2: BACKGROUND}

California produces more than 80 percent of all fresh market and processed strawberries grown in the United States and 20 percent grown in the world (USDA, 1999). Twothirds of this acreage is located in the Santa Maria region alone, which encompasses the coastal regions from Santa Cruz to northern Santa Barbara (USDA, 1999). This amounts to over 1.5 billion pounds of strawberries annually, worth $\$ 750$ million (USDA, 1999). In fact, California is the only state that can grow strawberries at a high enough productivity per acre at 49,000 lbs/acre/year, over four times higher than the United States average (11,000 lbs/acre) (USDA, 1999).

To achieve this productivity, chloropicrin, a highly toxic chemical that affects the respiratory system, is used in conjunction with $\mathrm{MeBr}$ due to cost-effectiveness and efficacy of the combination (Fennimore, 2008). Several weeks before strawberry planting, a plastic tarp is placed over the target acreage in preparation for fumigation. The tarp is usually removed five days after fumigation unless bed fumigation is used, in which the tarp is then removed after the plants are removed. A mulch, typically made of clear polyethylene and used to separate strawberries and plant foliage from the ground, is placed right after planting (USDA, 1999).

A major reason for the necessity of $\mathrm{MeBr}$ is to control the growth of B. cinerea, which causes a major strawberry disease called Botrytis fruit rot, or commonly known as gray 
mold. Gray mold grows not only on the fruit body, but also on petioles, stems, and flowers (Agrios, 1997). In California, Botrytis fruit rot is responsible for fruit losses of 30 to 40 percent where chemical pest management is not practiced (USDA, 1999). The disease cycle starts when $B$. cinerea spores (conidia) overwinter (the process of waiting out the winter to germinate in more favorable conditions) on decayed foliage and fruit as shown in Figure 2-1. In the next spring, during strawberry growing season, increasing temperatures and moisture promote fungal growth and production of conidia. The conidia are then spread through wind and rain onto developing strawberry plants (Burr, 1985).

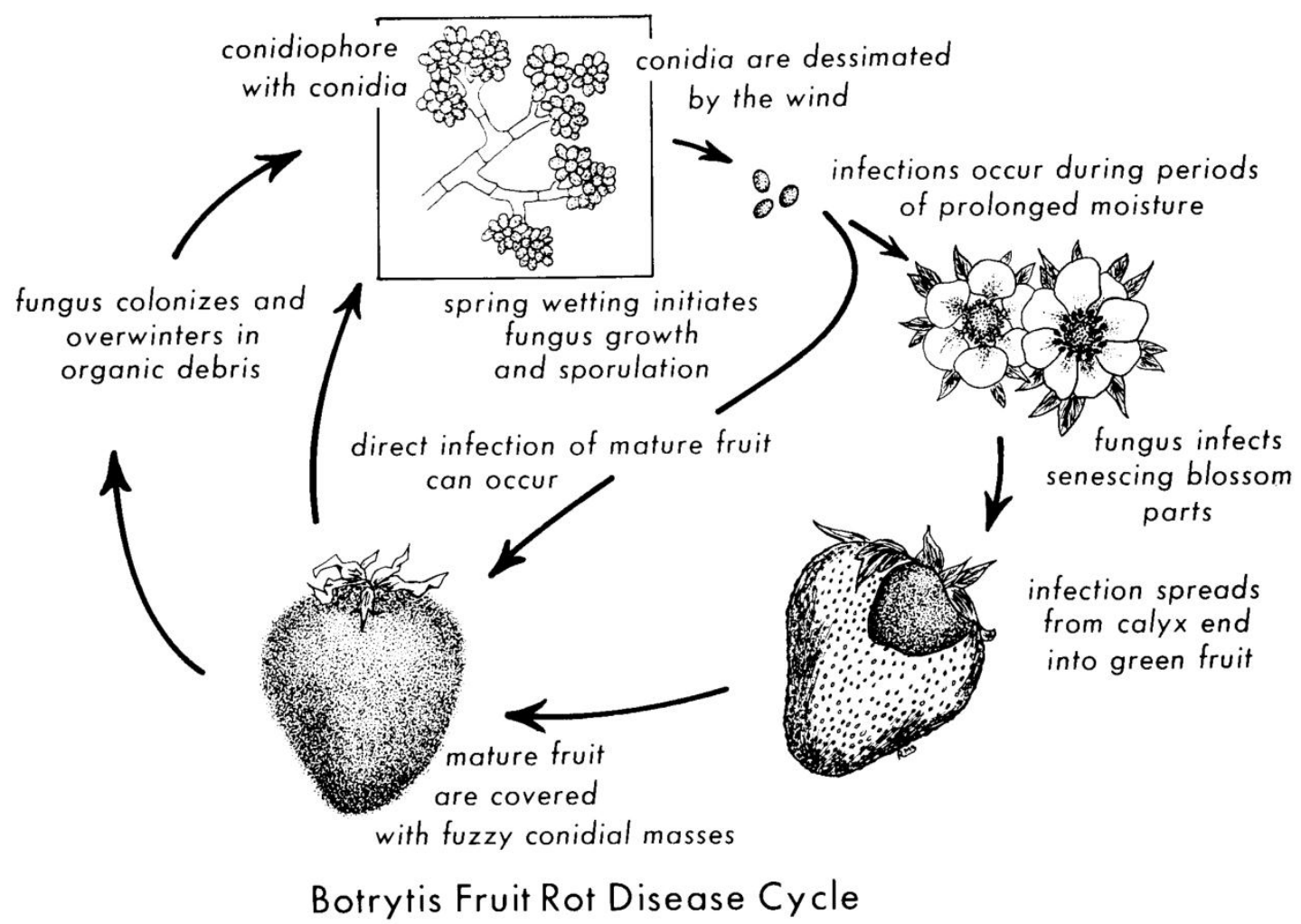

Figure 2-1. Botrytis disease cycle on strawberry infection (Burr, 1985). 
As a potential replacement for $\mathrm{MeBr}$, the EPA approved MeI as a strawberry pesticide in the State of California in December 2010. Although MeI is not an ozone depleting substance, the United States Department of Agriculture (USDA) contends that there are concerns about the environmental fate of MeI after its fumigation. In addition, MeI is carcinogenic and exhibits moderate to high acute toxicity for inhalation and ingestion (Guo, 2009).

The dangers of using chemical pesticides have prompted the use of less toxic alternatives. One method to control pests such as B. cinerea is to limit or to replace the use of conventional pesticides with biopesticides in an integrated pest management program specific to strawberry growth. According to the EPA, biopesticides are derived from natural materials and fall into three major classes: microbial pesticides, PlantIncorporated-Protectants (PIPs), and biochemical pesticides (EPA, 2000). In fact, even in 1990, biopesticide sales were estimated to be increasing 10 to 25 percent each year while the agrochemical market was static or even decreasing (Rodgers, 1993).

The focus of my thesis research is the use of microbial pesticides, which consist of a microorganism such as a bacterium as the active ingredient. Some of the advantages of using biopesticides compared to conventional pesticides include lower toxicity, specificity of pest targets, and effectiveness in small quantities. 
Bacillus sp. are common antibiotic-producing microbial pesticides. In fact, an average of four to five percent of a $B$. subtilis genome is devoted to antibiotic production, including its potential to produce more than two dozen antibiotics (Stein, 2005). The most prominent biopesticide is $B$. thuringiensis (Bt), which accounts for 90 percent of all marketed biopesticides. Bt produces spores and endotoxins that target specific pests, a major one being lepidopteran larvae, or caterpillars (Nicholson, 2002). Besides Bt, many different species and strains of Bacillus successfully inhibit the growth of specific fungi such as B. cinerea.

One example is commercial product Serenade ${ }^{\circledR}$, consisting of Bacillus subtilis QST 713 and used on a variety of food crops to control various types of fungi and bacteria that cause diseases such as powdery mildew, sour rot, early blight, and late blight (Burr, 1985). The product is a powder mixed with water and sprayed on foliage. In addition, it poses no harmful health effects to humans and no adverse effects to non-target organisms (EPA Fact Sheet, 2000).

Another example is the use of EcoGuard ${ }^{\circledR}$ (Bacillus licheniformis), rotated with chlorothalonil, a synthetic fungicide, to control Dollar Spot (Sclerotinia homoeocarpa), a serious disease of turfgrass worldwide. This effective IPM practice, to rotate a biological component with a chemical component, outperformed a standard conventional fungicide program on Bermuda grass. In fact, EcoGuard ${ }^{\circledR}$ exhibited 95 percent control alone against Dollar Spot (Brennan, 2011). 
In a case of Bacillus controlling the growth of a type of Botrytis, Bacillus amyloliquefaciens B190 has successfully been used to control mold on lily pads, or Botrytis elliptica. In fact, B. amyloliquefaciens B190 mixed with $0.025 \%$ calcium hydroxide and $0.05 \%$ sodium carbonate was able to completely inhibit B. elliptica germination and decreased lily pad disease severity (Chiou, 2003).

My thesis research consists of the investigation of $\mathrm{BiOWiSH}^{\mathrm{TM}}$-Aqua, which contains $B$. subtilis, as a biopesticide to inhibit $B$. cinerea growth (Figure 3-4). BiOWiSH ${ }^{\mathrm{TM}}$-Aqua is primarily used as a formulation used for wastewater treatment plants to biologically remove nutrients from wastewater. Some of the benefits include odor removal, reduction of sludge, and removal of ammonia and nitrates (BiOWiSH ${ }^{\mathrm{TM}}$-Technologies, 2012). However, BiOWiSH ${ }^{\mathrm{TM}}$-Aqua is also suitable for my research since it contains B. subtilis. A unique strain of B. subtilis was isolated from $\mathrm{BiOWiSH}^{\mathrm{TM}}$-Aqua and identified by NBCI BLAST as a very close relative to both B. subtilis and B. amyloliquefaciens, (Zhang, 2000). This isolate (named B. subtilis strain KLB) was used as the basis of my thesis to inhibit Botrytis growth. 


\section{CHAPTER 3: MATERIALS AND METHODS}

\subsection{Source and Culturing of Pathogen and Biopesticide}

The pathogen was the gray mold Botrytis sp. (M. A. Yoshimura, personal communication, January 12, 2011) cultured from strawberries that came from Y Hayashi \& Sons Farms based in Arroyo Grande, CA. The strawberries were placed in a beaker, covered with Parafilm ${ }^{\circledR}$ to prevent drying, and left at room temperature for five days in the lab at Building 13 Room 112 (13-112) in Cal Poly San Luis Obispo. After the five days the strawberry body, or the fruit tissue, contained the gray mold Botrytis, which had the appearance of a gray-brown and fluffy mass as shown in Figure 3-1. On a microscopic level under 1000x magnification, conidia were seen as shown in Figure 3-2. Botrytis conidia were collected using a sterile inoculum loop and inoculated into a test tube containing $10 \mathrm{~mL}$ of sterile deionized (DI) water. The test tube was vortexed and then $10 \mu \mathrm{L}$ of suspended conidia was inoculated in the middle of a Potato Dextrose Agar (PDA) plate as shown in Figure 3-3. The plate was placed in an incubator at $30^{\circ} \mathrm{C}$ for 48 hours, and then used as the source for Botrytis inoculum. 


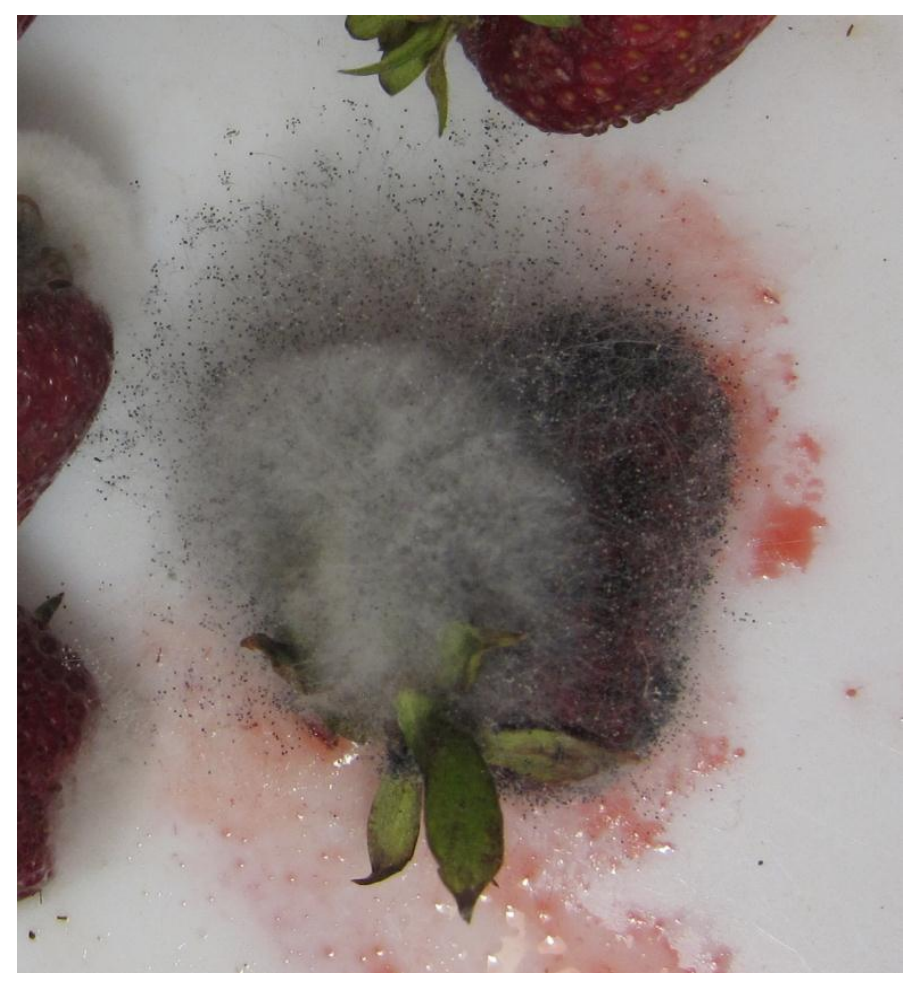

Figure 3-1. Botrytis growth on strawberry after five days.

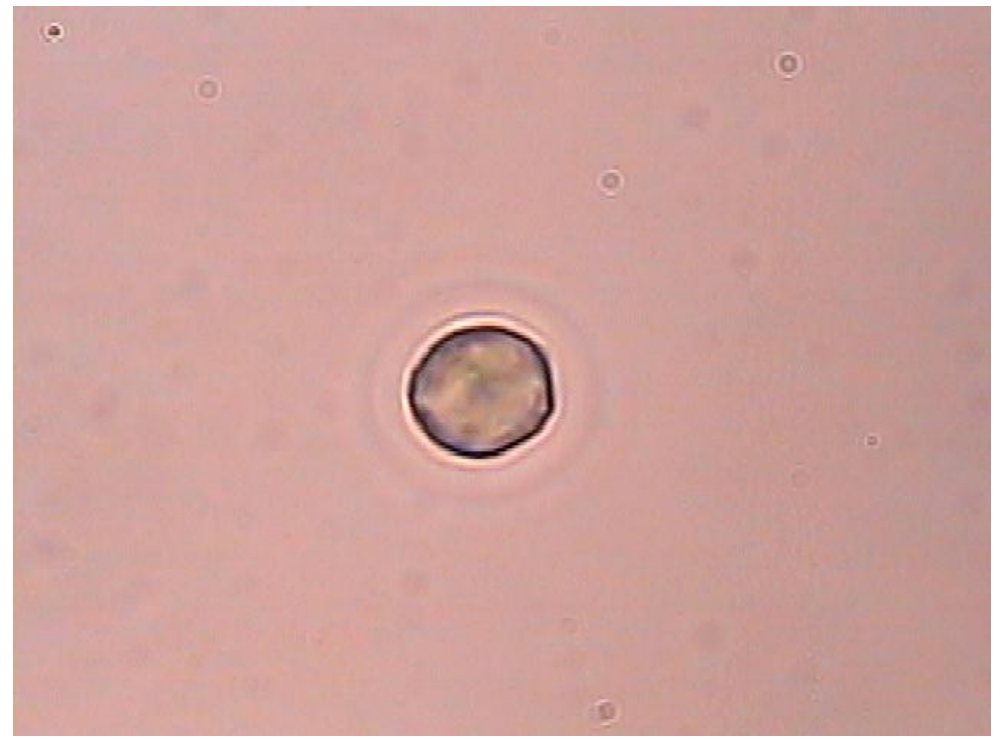

Figure 3-2. A single Botrytis conidium at 1000x magnification. 


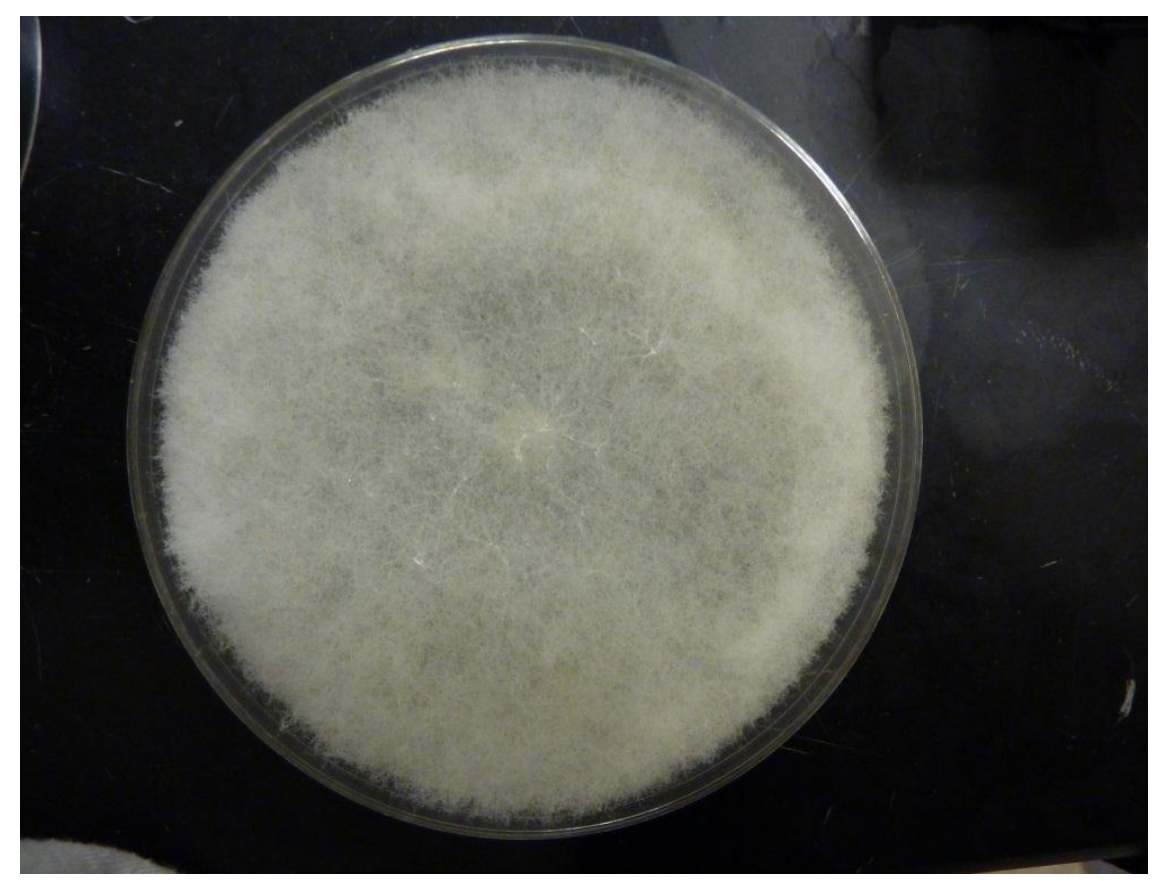

Figure 3-3. Botrytis cultured on a PDA plate.

For in vitro testing of inhibition against Botrytis, a commercial product named $\mathrm{BiOWiSH}^{\mathrm{TM}}$-Aqua, shown in Figure 3-4, was used as a biopesticide. $\mathrm{BiOWiSH}^{\mathrm{TM}}$-Aqua is a dry solid formulation that contains a consortium of bacteria and yeast and is used for multiple applications including wastewater treatment, plant growth enhancement, pathogen inhibition, etc. BiOWiSH ${ }^{\mathrm{TM}}$-Aqua consists of at least five known organisms, including Pediococcus pentosaceus Mees, Bacillus subtilis, Pediococcus acidilactici, Dekkera anomala and Pichia farinosa. Of particular interest is Bacillus spp., many of which produce antifungal peptide antibiotics (Rao, 2007).

In the initial testing, two controls were used. The first control was B. subtilis strain QST 713. The source was the commercial pesticide spray called Serenade ${ }^{\circledR}$ Garden Disease 
Control Spray, consisting of concentrated spores in suspension, and used as a fungicide and bacteriocide. However, the B. subtilis QST 713 formulation is concentrated so much that cell concentration far exceeded any cell concentration in a normal liquid fermentation. The negative control consisted of sterile DI water.

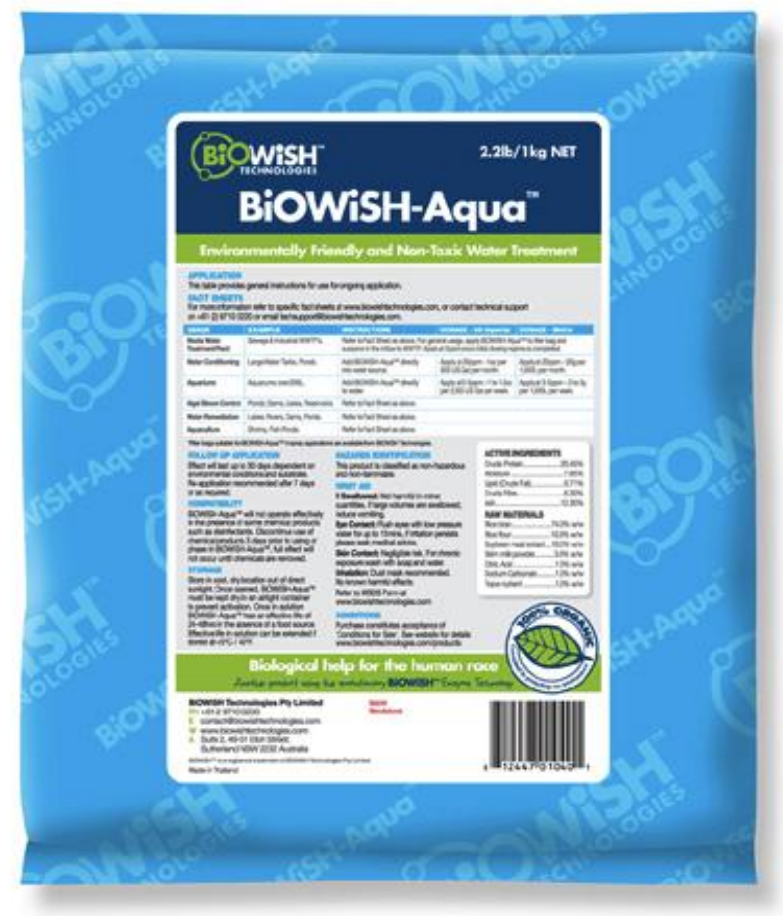

Figure 3-4. BiOWiSH ${ }^{\mathrm{TM}}$-Aqua packaging.

\subsection{In Vitro Experiments on PDA Plates}

To determine which agar to use for plating, $\mathrm{BiOWiSH}^{\mathrm{TM}}$-Aqua and Botrytis were screened on different types of agar including Luria Broth (LB) agar, Plate Count Agar (PCA), and Potato Dextrose Agar (PDA). Although BiOWiSH ${ }^{\mathrm{TM}}$-Aqua grew on all types of agar, Botrytis was only able to grow on PDA. 


\subsubsection{BiOWiSH ${ }^{\mathrm{TM}}$-Aqua Activation}

Activation consisted of inoculating $10 \mathrm{~g}$ of $\mathrm{BiOWiSH}^{\mathrm{TM}}$-Aqua into $1 \mathrm{~L}$ of tap water, equivalent to 10,000 parts per million (ppm). Prior to activation, a $1 \mathrm{~L}$ beaker was wiped with $70 \%$ ethanol and dried before addition of tap water. After inoculation, the top of the beaker was covered with Parafilm ${ }^{\circledR}$ to prevent contamination during incubation.

Incubation took place in a New Brunswick Series 25 Incubator Shaker at $60 \mathrm{rpm}$ and $30^{\circ} \mathrm{C}$ for the three activation times in hours $\left(\mathrm{T}_{\text {app }}\right)$. After time $\mathrm{T}_{\text {app }}$ had elapsed, three different concentrations in ppm of $\mathrm{BiOWiSH}^{\mathrm{TM}}$-Aqua $\left(\mathrm{C}_{\mathrm{bw}}\right)$ were made in sterilized test tubes: 10,000 ppm (original concentration), 1,000 ppm, and $100 \mathrm{ppm}$. For the original concentration, the beaker was mixed well with a clean glass rod, and then the solids were allowed to settle before pipetting $10 \mathrm{~mL}$ of the $\mathrm{BiOWiSH}^{\mathrm{TM}}$-Aqua suspension into the first test tube. The second and third test tubes were filled with 1,000 ppm and $100 \mathrm{ppm}$ $\mathrm{BiOWiSH}^{\mathrm{TM}}$-Aqua, respectively, by serially diluting $1 \mathrm{~mL}$ of $\mathrm{BiOWiSH}^{\mathrm{TM}}$-Aqua from the previous test tube with $9 \mathrm{~mL}$ of tap water.

\subsubsection{Microscope Enumeration of Botrytis conidia}

A Olympus BX50 Microscope was used for both identifying cells and determining Botrytis conidia concentration (Figure 3). In order to determine conidia concentration, the area of the field of vision, the area of a cover slip, and the amount of inoculum were calculated using the steps below:

1. Adjusted microscope to 100x objective lens. The ocular lens was 10x. The total zoom of 1000x is the multiplication of the two lenses. 
2. Calculated field of vision area by measuring radius with a calibration slide.

3. Calculated equivalent number of fields of vision in a cover slip area of $25 \mathrm{~mm} \mathrm{x}$ $25 \mathrm{~mm}$ by using the formula: Area of cover slip $\left(\mathrm{mm}^{2}\right) /$ area of field of vision $\left(\mathrm{mm}^{2}\right)=$ Total \# fields of vision / cover slip.

The following is the calculation of fields of vision / $\mathrm{mL}$ :

Radius $=0.12 \mathrm{~mm}$

Field of vision area $=\pi \mathrm{r}^{2}=\pi(0.12)^{2}=0.0452 \mathrm{~mm}^{2}$

Number of fields of vision / cover slip $=$

$\left(25 \mathrm{~mm}^{2} * 25 \mathrm{~mm}^{2}\right) /$ cover slip $*$ field of vision $/ 0.0452 \mathrm{~mm}^{2}=$

$1.383 \times 10^{4}$ fields of vision / cover slip

Each cover slip completely contains $10 \mu \mathrm{L}$ Botrytis inoculum, so:

1 cover slip $=$

$10 \mu \mathrm{L} 1.383 \times 10^{4}$ fields of vision / cover slip * 1 cover slip / $10 \mu \mathrm{L}$

$1000 \mu \mathrm{L} / 1 \mathrm{~mL}=$

$1.383 \times 10^{6}$ fields of vision $/ \mathrm{mL}$

The factor of $1.383 \times 10^{6}$ fields of vision / mL was used to calculate the concentration in the Botrytis inoculum. Botrytis conidia were suspended in DI water at a concentration of 1,000 conidia/mL. This suspension was prepared fresh on the days of inoculation. Inoculating $10 \mu \mathrm{L}$ provided an average of ten conidia on each PDA plate, more than 
enough for strong radial growth of Botrytis mycelia. The following procedure was used to prepare the conidia suspension:

1. Flamed metal tweezers were used to take a pinch of Botrytis from the inoculum plate and suspended in a test tube with $10 \mathrm{~mL}$ DI water.

2. Pipetted $10 \mu \mathrm{L}$ of Botrytis suspension onto microscope slide. Placed a cover slip over the Botrytis solution.

3. Placed immersion oil on top of the cover slip, and used the coarse and fine adjustments to focus the field.

4. Twenty random fields were selected and the total number of conidia (Figure 3-2) were tallied. In order to avoid counting a field twice and to get a sample representation of the whole cover slip, the first field started at the top-left corner and the last field ended at the bottom-right corner of the cover slip.

5. The following calculations were performed to determine the amount of Botrytis solution and DI water to make a $10 \mathrm{~mL}$ Botrytis inoculum of 1,000 conidia/mL.

a. Counted number of Botrytis conidia / 20 fields of vision * fields of vision / one cover slip = Number of Botrytis conidia $/$ one cover slip $=$ Number of Botrytis conidia / $10 \mu \mathrm{L}$.

A sample calculation to dilute Botrytis solution to $\mathrm{C}_{\mathrm{bot}}=1,000$ conidia/mL if 13 conidia are counted in 20 fields of vision: 13 conidia $/ 20$ fields $\times 1.383 \times 10^{6}$ fields $/ \mathrm{mL}=8.99 \times 10^{5}$ conidia / $\mathrm{mL}$ 
b. Dilute $11.1 \mu \mathrm{L}$ Botrytis inoculum into $10 \mathrm{~mL}-0.0111 \mathrm{~mL}=9.989 \mathrm{~mL}$ DI water to obtain $\mathrm{C}_{\mathrm{bot}}=1,000$ conidia $/ \mathrm{mL}$

6. The calculated amounts were pipetted into a sterile test tube and ready for use.

\subsection{In Vitro Experiments of Biopesticide vs. Pathogen}

A method was developed for screening BiOWiSH ${ }^{\mathrm{TM}}$-Aqua (and later Bacillus subtilis KLB) against strawberry mold Botrytis cinerea. This in vitro method involved plating both BiOWiSH ${ }^{\mathrm{TM}}$-Aqua and Botrytis on a PDA plate. To understand the interaction between the two, the experimental design was based on three important concerns. The first concern was BiOWiSH ${ }^{\mathrm{TM}}$-Aqua's mode of action against Botrytis, that is, whether its organisms attack or inhibit Botrytis mycelial growth. The second was to determine which of the BiOWiSH ${ }^{\mathrm{TM}}$-Aqua organism(s) would be effective against Botrytis. The last was to find the concentration $\left(\mathrm{C}_{\mathrm{bw}}\right)$ of $\mathrm{BiOWiSH}^{\mathrm{TM}}$-Aqua needed to be effective against $10 \mu \mathrm{L}$ of $\mathrm{C}_{\mathrm{bot}}=1,000 \mathrm{CFU} / \mathrm{mL}$ of Botrytis. In order to address these concerns, three different variables in the experiment were defined, listed in section 3.3.1.

\subsubsection{Experiment Variables}

The following variables were tested to determine which parameter(s) had a significant effect on the inhibition of Botrytis: 


\subsubsection{Effect of Botrytis Incubation Period}

$\mathrm{T}_{\text {app }}$ denotes time of BiOWiSH ${ }^{\mathrm{TM}}$-Aqua incubation on agar plates before Botrytis inoculation $-0,24$, and 48 hours. For $\mathrm{T}_{\text {app }}=0$ hours, Botrytis is point-inoculated right after $\mathrm{BiOWiSH}^{\mathrm{TM}}$-Aqua was streaked onto the plate. The reasoning behind this variable is to determine whether $\mathrm{BiOWiSH}^{\mathrm{TM}}$-Aqua organisms can control or prevent Botrytis growth by inhibition. In this scenario, Botrytis would establish colonies around or overlapping the Botrytis in order to inhibit its growth.

\subsubsection{Determination of Optimal BiOWiSH ${ }^{\mathrm{TM}}$-Aqua Activation Time} $\mathrm{T}_{\text {act }}$ denotes time of BiOWiSH ${ }^{\mathrm{TM}}$-Aqua activation $-48,72$, and 96 hours. Since $\mathrm{BiOWiSH}^{\mathrm{TM}}$-Aqua contains organisms from the original inoculum (with the five types of organisms) as well as suspected unknown organisms from the raw material, the effectiveness of BiOWiSH ${ }^{\mathrm{TM}}$-Aqua for Botrytis inhibition is dependent on which organisms are present. Different organisms may be predominant at different times of the activation, which may or may not affect Botrytis inhibition.

\subsubsection{Determination of Optimal BiOWiSH ${ }^{\mathrm{TM}}$-Aqua Concentration}

$\mathrm{C}_{\mathrm{bw}}$ denotes concentration of $\mathrm{BiOWiSH}^{\mathrm{TM}}$-Aqua in $\mathrm{ppm}-100,1,000$, and 10,000 ppm. Concentration is a critical variable to determine the amount of $\mathrm{BiOWiSH}^{\mathrm{TM}}$-Aqua to use in Botrytis inhibition. A concentration too low may not inhibit Botrytis growth, but a concentration too high would by wasteful and more costly. 


\subsubsection{Fixed Experiment Parameters}

To limit the number of variables, fixed variables were defined prior to the experiments. The following constants involved the concentration of Botrytis conidia onto each plate, temperatures for $\mathrm{BiOWiSH}^{\mathrm{TM}}$-Aqua activation and incubation, shaking speed, and the agar plate medium used. In addition, tap water was used for all activation of BiOWiSH $^{\mathrm{TM}}$-Aqua.

$\mathrm{C}_{\mathrm{bot}}=$ concentration of Botrytis, 1000 conidia $/ \mathrm{mL}$. Since $10 \mu \mathrm{L}$ was point-inoculated, this provided an average of 10 Botrytis conidia, enough for Botrytis to grow radially and to measure area of Petri dish occupied.

Temperature of activation $=30^{\circ} \mathrm{C}$. This temperature was referenced from Rao, 2007, which was used to build up B. amyloliquefaciens $\mathrm{B} 128$ inoculum. At $30^{\circ} \mathrm{C}$ and a $\mathrm{T}_{\text {act }}$ of at least 48 hours, $\mathrm{BiOWiSH}^{\mathrm{TM}}$-Aqua contained sufficient growth by observation of turbidity.

Temperature of incubation $=30^{\circ} \mathrm{C}$. Plates were incubated at $30^{\circ} \mathrm{C}$ to keep the temperature consistent from activation to incubation. At this temperature, colonies grew to sufficient size for counting within 48 hours after plating. 
$\mathrm{RPM}=$ activation of $\mathrm{BiOWiSH}^{\mathrm{TM}}$-Aqua, $60 \mathrm{rpm}$. Agitation at $60 \mathrm{rpm}$ stirred $\mathrm{BiOWiSH}^{\mathrm{TM}}$-Aqua material sufficiently to prevent settling/precipitation and to provide aeration without the liquid sloshing.

Agar plate medium $=$ potato dextrose agar. Both $\mathrm{BiOWiSH}^{\mathrm{TM}}$-Aqua as well as Botrytis grew well on this medium as described in section 3.2.

\subsubsection{Initial Inhibition Experiments Using BiOWiSH ${ }^{\mathrm{TM}}$-Aqua}

A total of 27 combinations, every combination of the three variables, were plated in triplicate. The following conditions were tested, totaling 27 combinations:

$\mathrm{T}_{\mathrm{app}}=0,24$, and 48 hours

$\mathrm{T}_{\mathrm{act}}=48,72$, and 96 hours

$\mathrm{C}_{\mathrm{bw}}=100,1,000$, and $10,000 \mathrm{ppm}$

Plates were inoculated with $100 \mathrm{~L}_{\text {of }} \mathrm{BiOWiSH}^{\mathrm{TM}}$-Aqua at its specified concentrations and spread by using sterilized glass hockey sticks. $\mathrm{T}_{\mathrm{app}}=0$ hour plates were inoculated with Botrytis immediately. $\mathrm{T}_{\mathrm{app}}=24$ hours and $\mathrm{T}_{\mathrm{app}}=48$ hour plates were inoculated with Botrytis 24 and 48 hours after $\mathrm{BiOWiSH}^{\mathrm{TM}}$-Aqua was spread plated, respectively. All plates were incubated at $30^{\circ} \mathrm{C}$ for 48 hours.

Since not all Botrytis growth was radial, one of the following methods was used to determine the percentage of the plate overtaken by Botrytis:

1) Measured diameter of Botrytis to calculate area (Figure 3-5), then divided by total agar plate area to determine percentage:

Percentage Botrytis growth $=\left(\begin{array}{lll}\pi \mathrm{r}_{\text {bot }}^{2} / \pi & \mathrm{r}_{\text {plate }}{ }^{2}\end{array}\right) * 100$ 
2) If Botrytis growth did not resemble a circle, growth was visually inspected and estimated.

Measured diameters were converted into a percentage of the total surface area of a Petri dish $($ diameter $=8.65 \mathrm{~cm})$. Since agar was filled halfway to the top of the Petri dish, the area of was calculated based on the average of the bottom and top inner diameters, $8.5 \mathrm{~cm}$ and $8.8 \mathrm{~cm}$, respectively.

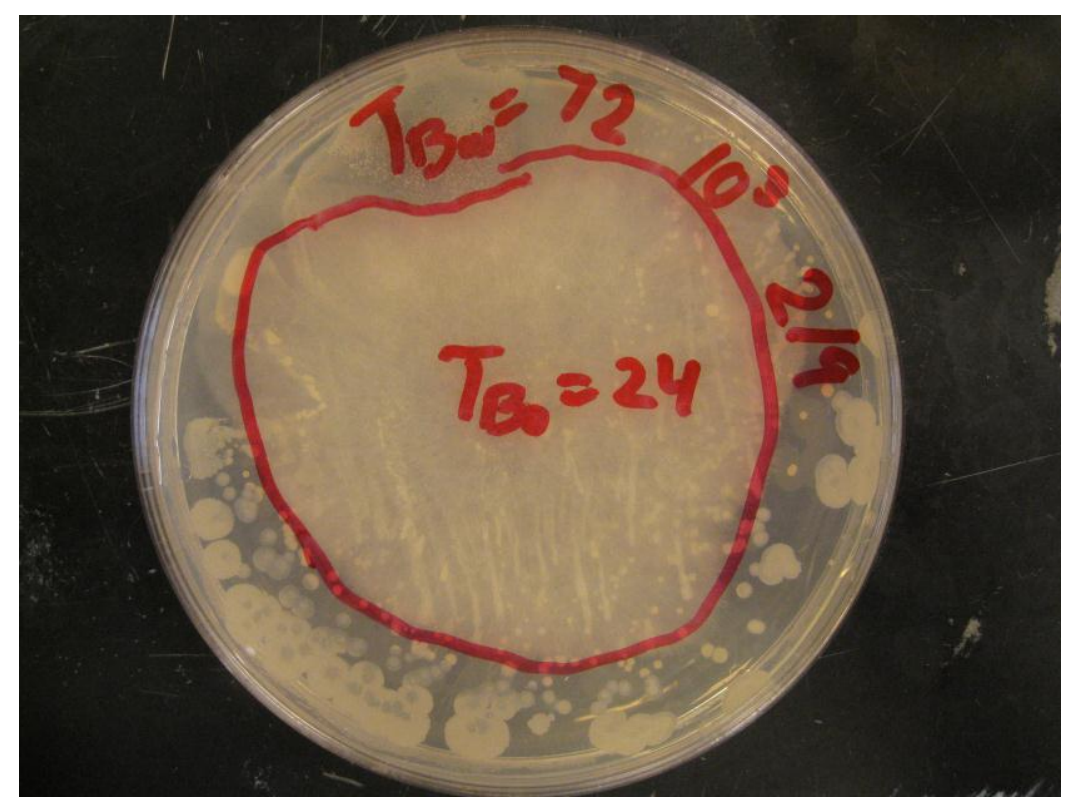

Figure 3-5. Sample plate with Botrytis growth circled in red. 


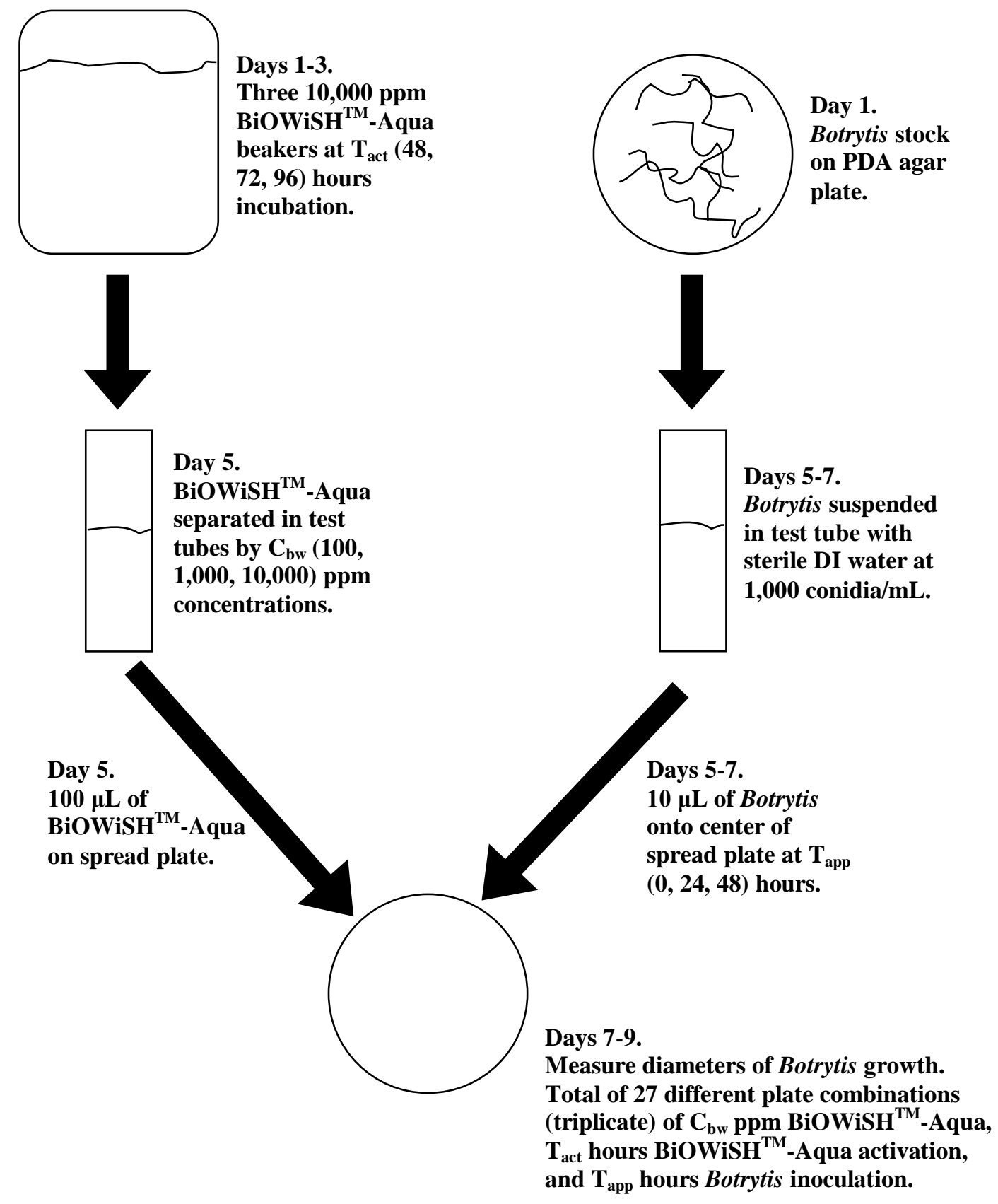

Figure 3-6. Process of plate inoculation. 
The experiment schedule was as follows:

Day 1 - Activated 10,000 ppm BiOWiSH ${ }^{\mathrm{TM}}$-Aqua for $\mathrm{T}_{\text {act }}=96$ hours plates (step 1 in Figure 3-6).

Day 2 - Activated 10,000 ppm BiOWiSH ${ }^{\mathrm{TM}}$-Aqua for $\mathrm{T}_{\text {act }}=72$ hours plates (step 1 in Figure 3-6).

Day 3 - Activated 10,000 ppm BiOWiSH ${ }^{\mathrm{TM}}$-Aqua for $\mathrm{T}_{\text {act }}=48$ hours plates (step 1 in Figure 3-6).

Day 5 - Prepared 81 spread plates with $\mathrm{BiOWiSH}^{\mathrm{TM}}$-Aqua (27 combinations in triplicate) as well as three concentrations of B. subtilis strain QST713 as control in triplicate (steps 2-3 in Figure 3-6). Also, point inoculated $\mathrm{T}_{\text {app }}=0$ hours plates with Botrytis (steps 4-6 Figure 3-6).

Day 6 - Point inoculated $\mathrm{T}_{\mathrm{app}}=24$ hours plates with Botrytis (steps 4-6 in Figure 3-6). Day 7 - Point inoculated $\mathrm{T}_{\mathrm{app}}=48$ hours plates with Botrytis. Measured diameter of Botrytis growth of $\mathrm{T}_{\mathrm{app}}=0$ hours plates (steps 4-6 in Figure 3-6).

Day 8 - Measured diameter of Botrytis growth of $\mathrm{T}_{\mathrm{app}}=24$ hours plates. Day 9 - Measured diameter of Botrytis growth of $\mathrm{T}_{\mathrm{app}}=48$ hours plates.

Botrytis application $\left(\mathrm{T}_{\mathrm{app}}\right)$ and $\mathrm{BiOWiSH}^{\mathrm{TM}}$-Aqua activation $\left(\mathrm{T}_{\mathrm{act}}\right)$ times were adjusted as needed for every subsequent experiment based on results and observations of the previous experiment. For example, if most or all spread plates at application time of 0 hours contained a high percentage of Botrytis growth, the next experiment focused on application times of 24 and 48 hours. If activation time of 72 hours showed greater 
inhibition against Botrytis compared to the other times, the three activation times tested were lessened to 12 -hour intervals, with the middle at 72 hours.

\subsubsection{B. subtilis KLB Isolation}

B. subtilis $\mathrm{KLB}$ was isolated from a BiOWiSH ${ }^{\mathrm{TM}}$-Aqua plate. To confirm the identity of the isolate taxonomically, its $16 \mathrm{~S}$ rRNA sequence was determined (courtesy of Alice Hamrick and Dr. Christopher Kitts) and analyzed using NCBI BLAST searching tool (details in Section 4.1.2.1).

Initially, KLB inoculum was grown in a test tube containing Luria Broth (LB), a nutrientrich medium containing $\mathrm{NaCl}$, tryptone, and yeast extract for fast cell growth (Figure 3-7). A colony was isolated using a flamed inoculum loop, placed into the test tube, and incubated at $30^{\circ} \mathrm{C}$ and $120 \mathrm{rpm}$ for 24 hours. However, KLB, an obligate aerobe, congregated at the liquid surface to form a biofilm (Figure 3-7). 


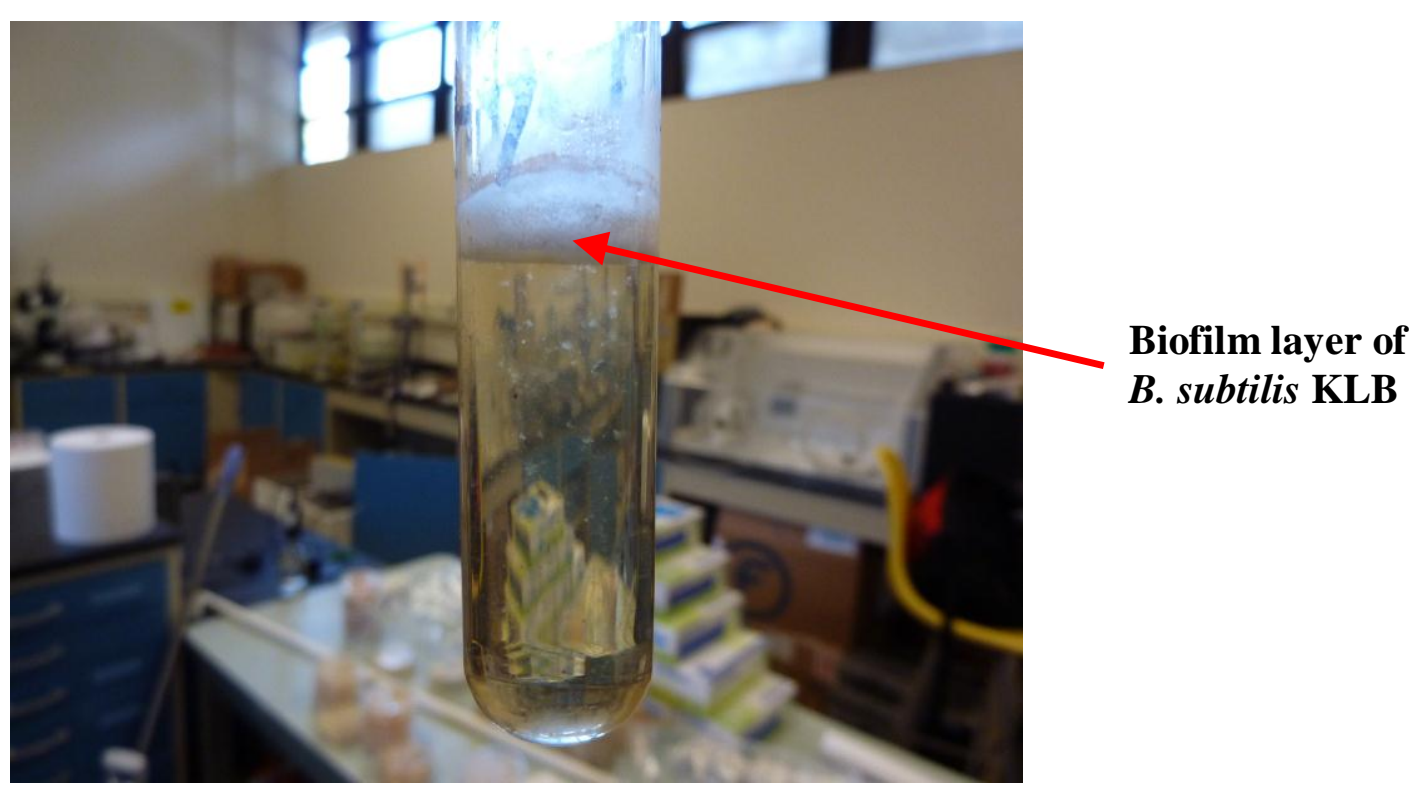

Figure 3-7. B. subtilis KLB biofilm layer in a test tube with LB broth.

KLB inoculum was subsequently grown in a $250 \mathrm{~mL}$ Erlenmeyer flask containing $50 \mathrm{~mL}$ broth at the same conditions as for growth in a test tube. The broth in the Erlenmeyer flask was turbid as opposed to transparent as shown in Figure 9. The shaking speed was increased from $60 \mathrm{rpm}$, the speed used to activate $\mathrm{BiOWiSH}^{\mathrm{TM}}$-Aqua, to $120 \mathrm{rpm}$ because lower speeds resulted in flocculation and biofilm growth. Fresh inoculum approximately 24 hours old was used because the cells in the inoculum were in log phase. A growth curve was constructed correlating optical density at $600 \mathrm{~nm}\left(\mathrm{OD}_{600}\right)$ and cell count. For $\mathrm{OD}_{600}$, cuvettes with KLB and its dilutions of 1:2, 1:4, 1:8, 1:16, 1:32, and 1:64 were placed into a Hitachi U-3010 UV-Visible Spectrophotometer. In order to gather cell count data, a $10^{-6}$ dilution of $\mathrm{KLB}$ (diluted $1: 2, \mathrm{OD}_{600}=0.948$ ) was made and $100 \mu \mathrm{L}$ of the $10^{-6}$ dilution was spread on each agar plate in triplicate. The plates were 
incubated at $30^{\circ} \mathrm{C}$ for 48 hours and colonies were counted. To determine KLB concentration, the following equation was used:

Concentration of $B$. subtilis $\mathrm{KLB}\left(\mathrm{C}_{\mathrm{KLB}}\right)=$ colonies $/($ dilution $* 0.1 \mathrm{~mL})$

Using this formula, cell densities were determined by finding $\mathrm{OD}_{600}$ using the spectrophotometer.

A quick visual screening study was conducted to confirm that KLB specifically inhibited Botrytis growth and to determine the effective concentrations. Two initial plates were sectioned into thirds. KLB was spread plated at the specified concentrations. The two plates were point inoculated (applied) in the center with Botrytis at application times of 0 and 24 hours (Figure 4-14 and Figure 4-15, respectively).

\subsubsection{Inhibition Experiments Using B. subtilis KLB}

In subsequent in vitro inhibition experiments, $\mathrm{BiOWiSH}^{\mathrm{TM}}$-Aqua was replaced by $B$. subtilis KLB. The inoculum was cultured as described in Section 3.3.4. Experiments were conducted in the same manner as the previous experiments with $\mathrm{BiOWiSH}^{\mathrm{TM}}$-Aqua. However, there were a few key differences in the experimental setups between using $\mathrm{BiOWiSH}^{\mathrm{TM}}$-Aqua and KLB. The first difference was that activation time $\left(\mathrm{T}_{\mathrm{act}}\right)$ was not used because KLB inoculum was incubated for 24 hours in every experiment. The second difference was instead of using $\mathrm{C}_{\mathrm{bw}}(\mathrm{ppm}), \mathrm{C}_{\mathrm{KLB}}(\mathrm{CFU} / \mathrm{mL})$ was used in order to determine $\mathrm{CFU} / \mathrm{mL}$ vs. percent growth of Botrytis of the total Petri dish surface area. 
The last difference was that in the $\mathrm{BiOWiSH}^{\mathrm{TM}}$-Aqua inhibition experiments, the concentrations were the same for every experiment at 100, 1,000, and 10,000 ppm. In the KLB inhibition experiments, instead of inoculating a powder, KLB was grown as a liquid inoculum and therefore, initial concentrations varied each experiment or trial. To obtain the desired KLB concentrations for the experiments, KLB inoculum was diluted $\mathrm{n}$ times, where $\mathrm{n}$ was the number of ten-fold dilutions made, and expressed as $10^{-\mathrm{n}}$. For example,

if $n=5$, then the dilution was expressed as $10^{-5}$ of the undiluted concentration. For these experiments, $\mathrm{n}$ ranged from 0 (the concentration of the inoculum) to 7 (diluted ten-fold seven times).

\subsection{Initial Carbon Source Screening Experiments}

The purpose of the carbon source screening experiments was to determine whether $B$. subtilis KLB was able to grow on food-grade carbon sources such as table sugar since LB broth is not viable economically as a growth medium on a commercial scale. In order to minimize growth medium costs while keeping cell counts high, two food-grade carbon sources bought in the supermarket, liquid molasses and cooked tapioca, were tested as variables. The liquid molasses, Grandma's ${ }^{\circledR}$ Unsulphured Liquid Molasses, was weighed and diluted in DI water for ease of pipetting. Precooked tapioca balls, Kraft Minute ${ }^{\circledR}$ Tapioca, were ground up into a fine starch by a Krups coffee blender. Amounts of trace minerals, peptone $(8.0 \mathrm{~g} / \mathrm{L})$, and ammonium sulfate $(1.8 \mathrm{~g} / \mathrm{L})$ were kept constant at levels based on a spore production optimization study of B. amyloliquefaciens B128, an 
organism that is very similar to B. subtilis (Rao, 2007). As in the Rao, 2007 study, each carbon source was tested at three different concentration levels in triplicate to determine the optimal concentration for viable cell density $(\mathrm{CFU} / \mathrm{mL})$. In addition to the trace minerals, peptone, ammonium sulfate, and carbon source (liquid molasses or precooked tapioca balls), $0.25 \mathrm{~g} / \mathrm{L}(2 \%$ of $12.5 \mathrm{~g} / \mathrm{L})$ of $\mathrm{LB}$ powder was added to include trace amounts of tryptone and yeast extract, ingredients vital for successful KLB inoculum growth (Section 3.3.4).

Experiment 1 consisted of the initial experiments using 5,15, and $25 \mathrm{~g} / \mathrm{L}$ of carbon source, with the low level (5 g/L) lower than the optimum concentration and the high level (25 g/L) higher than the optimum concentration based on the Rao, 2007 study. Experiment 1 was conducted twice (trials 1 and 2) with identical conditions, but at different times, in order to measure variation of cell counts. The experiments were done in triplicate $250 \mathrm{~mL}$ shake flasks with $50 \mathrm{~mL}$ media in each flask. Each flask was inoculated with $0.5 \mathrm{~g}$ of inoculum from liquid media (one percent by volume). The shake flasks were placed in a shaker at $30^{\circ} \mathrm{C}$ and $120 \mathrm{rpm}$ for 48 hours. After growth, cells were diluted in test tubes containing sterilized DI water. The dilutions were in increments of 1:10 to yield approximately 30-300 CFU/plate. Each triplicate flask, three flasks of each 5,15 , and $25 \mathrm{~g} / \mathrm{L}$ of carbon source, was plated three times, for a total of 27 plates. The diluted cells were spread plated on PDA and incubated at $30^{\circ} \mathrm{C}$. Cells were counted after 48 hours of growth. 
Experiment 2 consisted of three changes: 1) tapioca was the only carbon source,

2) the concentrations of tapioca tested were 5,15 , and $20 \mathrm{~g} / \mathrm{L}$, and 3) four trials instead of two were run in order to determine repeatability of the experiment.

\subsection{Growth Curves of B. subtilis KLB and BiOWiSH ${ }^{\mathrm{TM}}$-Aqua}

A growth curve of $B$. subtilis $\mathrm{KLB}$ and comparative $\mathrm{OD}_{600}$ readings of $\mathrm{BiOWiSH}^{\mathrm{TM}}$ Aqua were determined to evaluate how the growth of a single organism, KLB, compared with the growth of a product containing multiple organisms, $\mathrm{BiOWiSH}^{\mathrm{TM}}$-Aqua. Since $\mathrm{BiOWiSH}^{\mathrm{TM}}$-Aqua contains multiple organisms, inhibition or proliferation of certain organisms may affect the overall growth curve. 


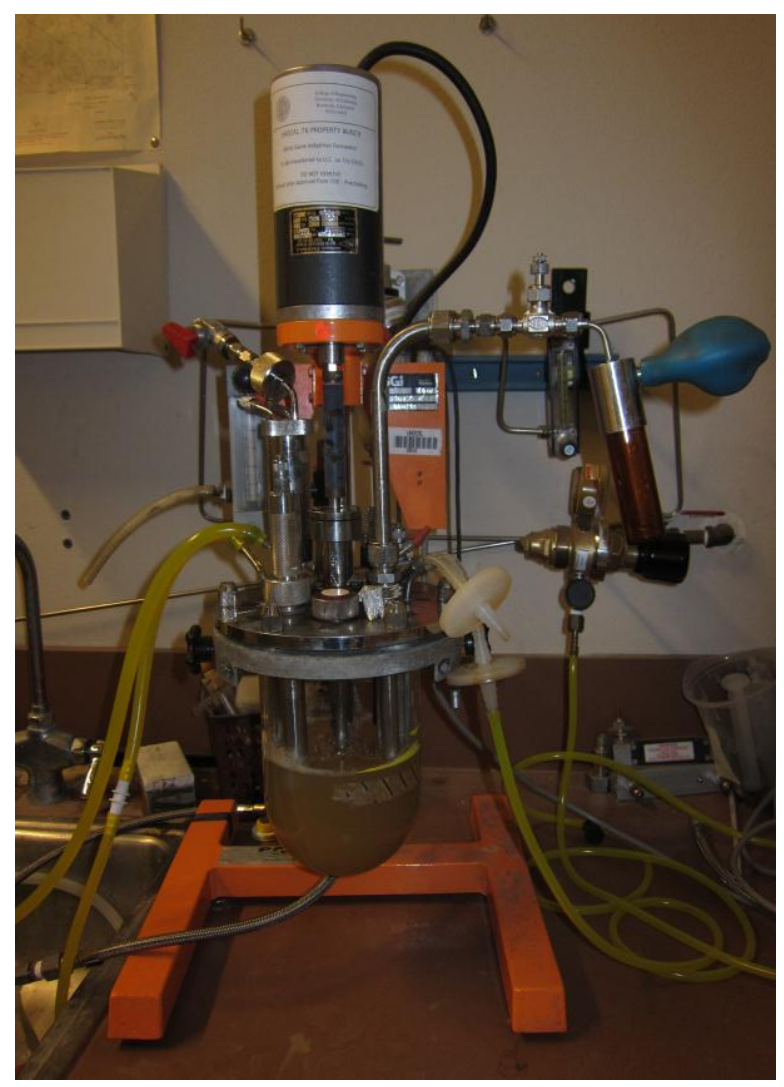

Figure 3-8. Setric Genie 2L laboratory-scale bioreactor.

To determine the growth rates, a 2 L bioreactor shown in Figure 3-8 was used as a laboratory-scale bioreactor to grow KLB and separately $\mathrm{BiOWiSH}^{\mathrm{TM}}$-Aqua to compare growth rates. A laboratory-scale bioreactor such as this one provided more control of growth conditions, such as propeller speed and air sparge rate, as opposed to a laboratoryscale flask. Since the goal was to compare growth rates, LB was used because both KLB and separately BiOWiSH ${ }^{\mathrm{TM}}$-Aqua grew well in it. At the specified LB concentration of $25 \mathrm{~g} / \mathrm{L}$, the $\mathrm{OD}_{600}$ reading was out of range because the concentration of cells was too high. Therefore, 1.25 L of LB at a concentration of $12.5 \mathrm{~g} / \mathrm{L}$ ( $50 \%$ of the specified 25 
$\mathrm{g} / \mathrm{L}$ ) was used. The LB broth was poured into the bioreactor and autoclaved at $121^{\circ} \mathrm{C}$ at 15 psi for 20 minutes. After the bioreactor reached room temperature, $12.5 \mathrm{~mL}$ of inoculum ( $1 \%$ of total media volume) was pipetted into the bioreactor. Agitation was set at $180 \mathrm{rpm}$ (close to the $200 \mathrm{rpm}$ in an orbital shaker by Rao, 2007) and temperature at $30^{\circ} \mathrm{C}$. To determine the initial $\mathrm{OD}_{600}, 1 \mathrm{~mL}$ of cells were sampled from the bioreactor immediately after inoculation. $\mathrm{OD}_{600}$ readings were subsequently taken every 8-12 hours, more often during the initial lag and growth phases, and converted to $\mathrm{CFU} / \mathrm{mL}$ using a calibration curve (Figure 4-13).

\subsection{Effect of B. subtilis KLB in vivo on Strawberry Fruit Bodies}

The purpose of this experiment was to determine whether mold growth on post-harvest strawberry fruit bodies could be slowed with B. subtilis KLB as a biopesticide. The controls for this experiment were B. subtilis strain QST713 and no biopesticide (just water). Just as for the culturing of Botrytis, the strawberries for the in vivo experiments were obtained from Y Hayashi \& Sons Farms based in Arroyo Grande, CA. The strawberries were placed in a chamber as shown in Figure 3-9. Tap water was filled in five beakers and placed into the chamber in order to increase humidity to prevent the strawberries from drying. The strawberries were sprayed with the following biopesticides: 
Undiluted KLB (approximately $5.0 \times 10^{8} \mathrm{CFU} / \mathrm{mL}$ )

1:10 concentration KLB

1:100 concentration KLB

Undiluted B. subtilis QST 713 (from Serenade ${ }^{\circledR}$ )

No biopesticide (just water)

\subsubsection{Initial Experimental Setup}

Strawberries from each biopesticide treatment were placed together as shown in Figure 3-10. Six strawberries were used for each treatment in Trials 1-3 and nine were used in Trial 4. Approximately $2.5 \mathrm{~mL}$ of the biopesticide was sprayed on each group of strawberries outside the chamber. The biopesticide was rubbed on the whole surface of each strawberry and placed into the chamber. Then, $1 \mathrm{~mL}$ of $100 \mathrm{CFU} / \mathrm{mL}$ Botrytis was sprayed onto each group of strawberries. The strawberries were observed daily for eight days for any Botrytis growth. Humidity and temperature were recorded at the same time as observation. Pictures were taken daily as well to visually document the extent of molding over time. A strawberry was tallied as infected with Botrytis if any sign of Botrytis was seen on the fruit body. 


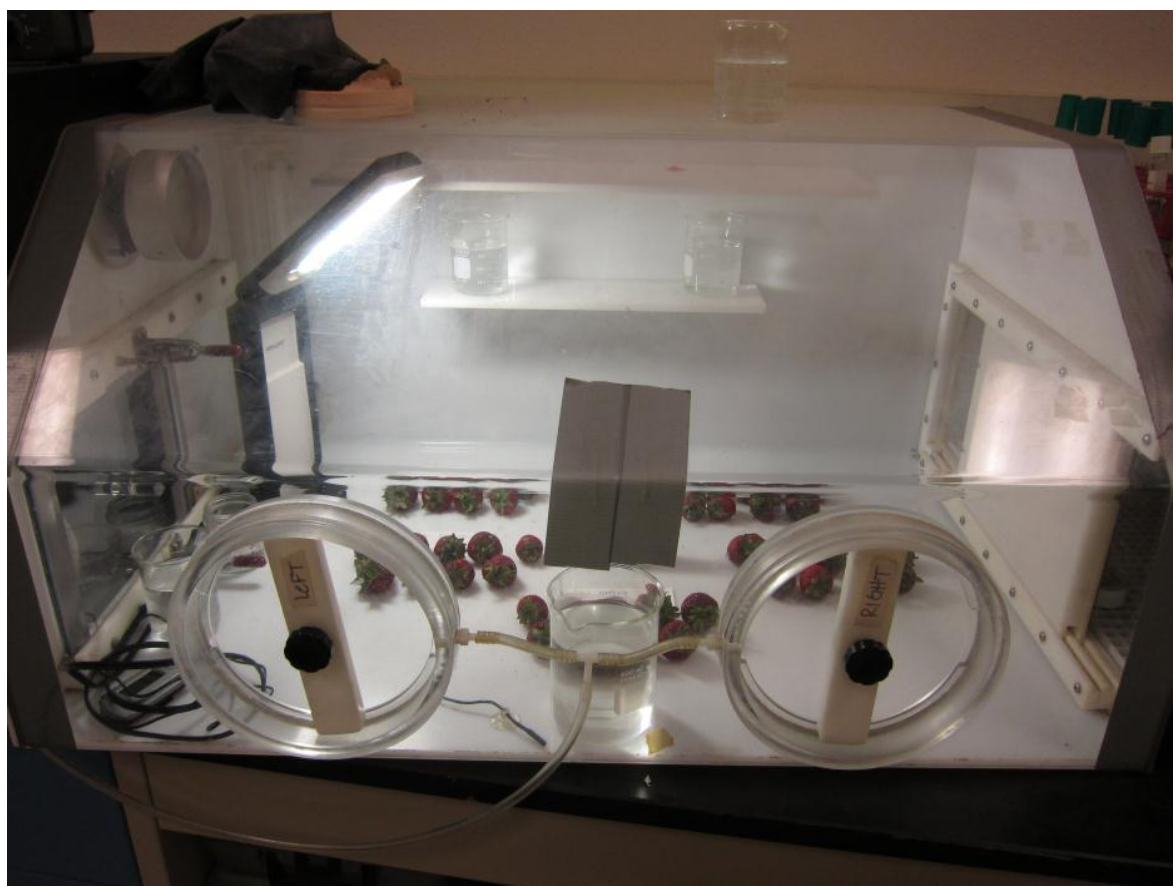

Figure 3-9. Chamber for in vivo experiments using strawberry fruit bodies.

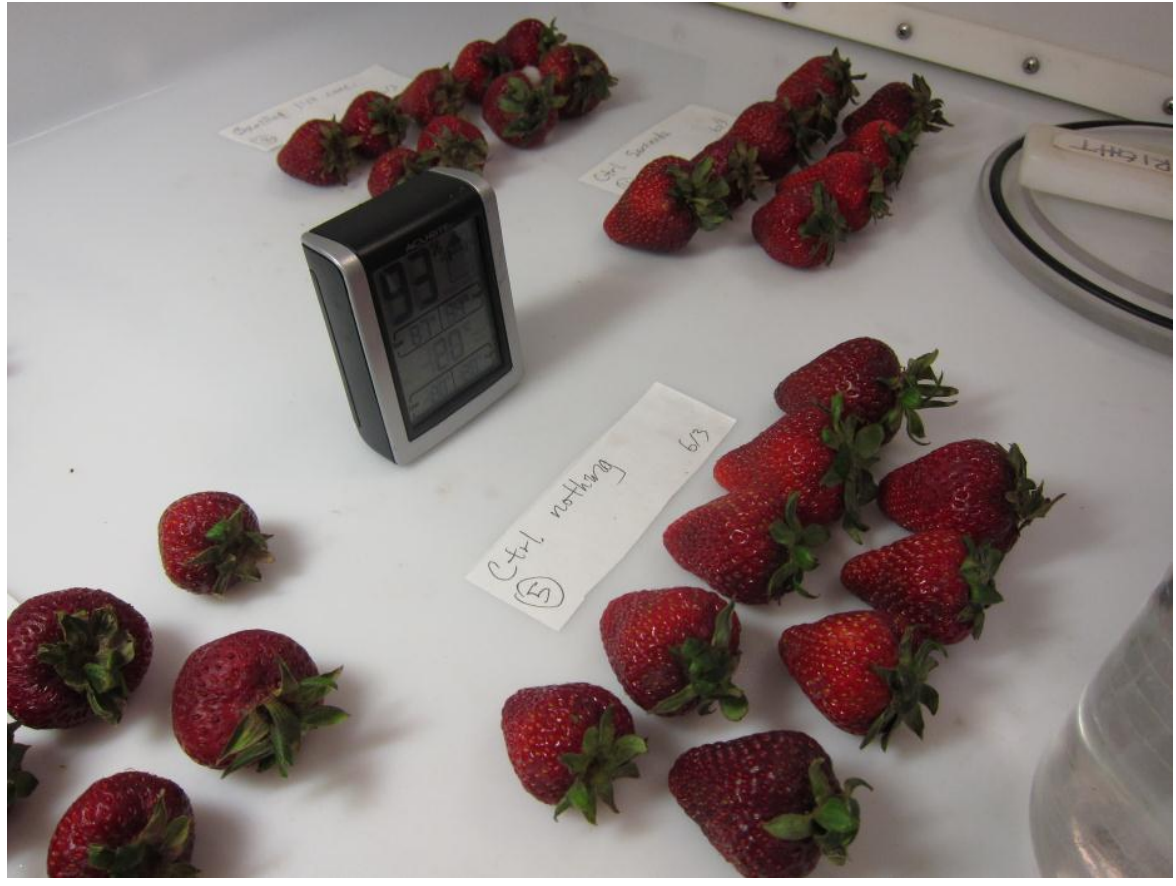

Figure 3-10. Initial strawberry placement in chamber. 


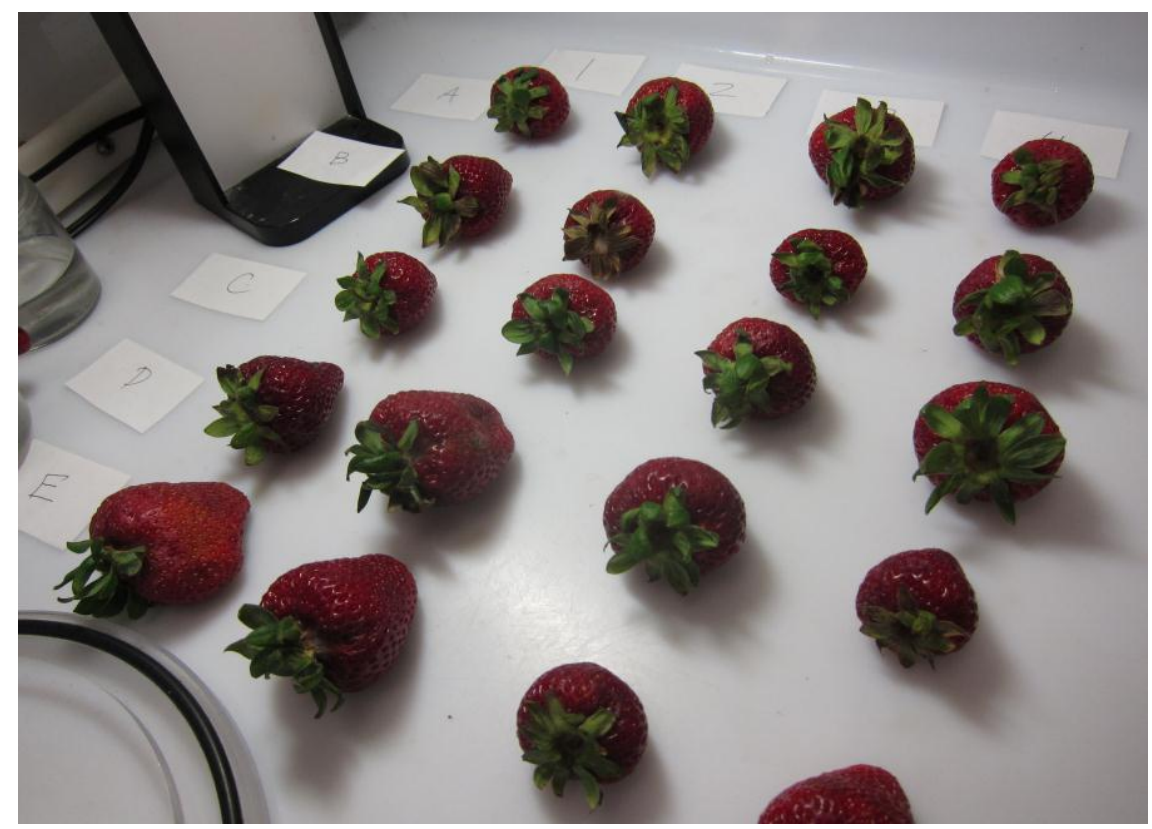

Figure 3-11. Modified strawberry placement in chamber.

\subsubsection{Modification to Initial Experimental Setup}

The experiment was later modified based on possible cross-contamination and positioning bias in the experiment. Strawberries in certain areas within the chamber might have been more or less susceptible to Botrytis growth, so strawberry placement was randomized in a grid structure in the chamber as shown in the figure below. Rows were labeled A through $\mathrm{E}$ and columns were numbered 1 through 8 as shown in Figure 3-11. Using the same biopesticide groups and the same inoculating procedures as in the Initial Experiment Setup, eight strawberries were used for each of the five groups. Each strawberry was randomly placed in the chamber and its position was recorded. The strawberries were observed daily for eight days and those infected with mold were marked. 


\section{CHAPTER 4: RESULTS}

\subsection{Inhibition Experiments}

This section presents results for initial Botrytis inhibition experiments with $\mathrm{BiOWiSH}^{\mathrm{TM}}$ Aqua, followed by inhibition experiments with the B. subtilis KLB isolate.

\subsubsection{Botrytis Inhibition Results Using BiOWiSH ${ }^{\mathrm{TM}}$-Aqua}

The initial goal was to determine how concentration of $\mathrm{BiOWiSH}^{\mathrm{TM}}$-Aqua, time of $\mathrm{BiOWiSH}^{\mathrm{TM}}$-Aqua activation, and time of $\mathrm{BiOWiSH}^{\mathrm{TM}}$-Aqua growth prior to Botrytis inoculation affected percent growth of Botrytis on a Petri dish. Four trials were conducted using BiOWiSH ${ }^{\mathrm{TM}}$-Aqua as the biopesticide. Data for the four trials begin at Table 4-1 and Figure 4-3. Some plates contained radial Botrytis growth (Figure 4-1) while other plates contained more random Botrytis growth patterns (Figure 4-2). The variations in Botrytis growth patterns were due to the different compositions of organisms in each plate, even within the triplicates. 


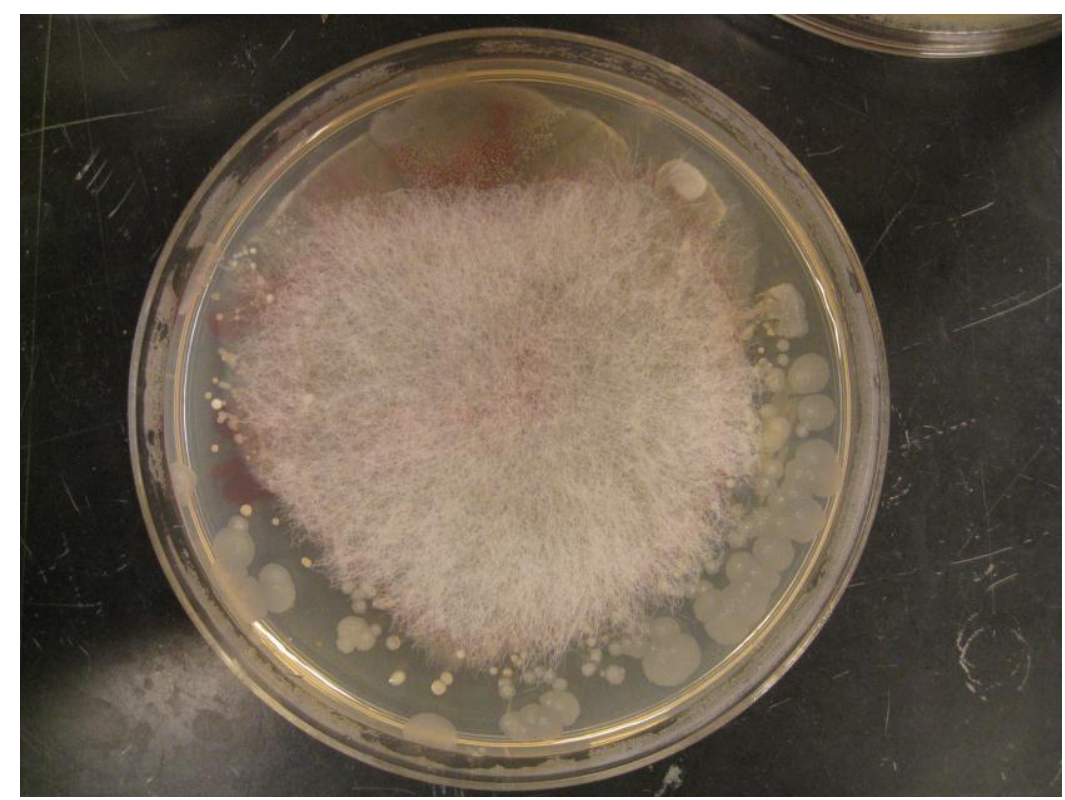

Figure 4-1. Sample plate with typical radial Botrytis growth 48 hours after inoculation.

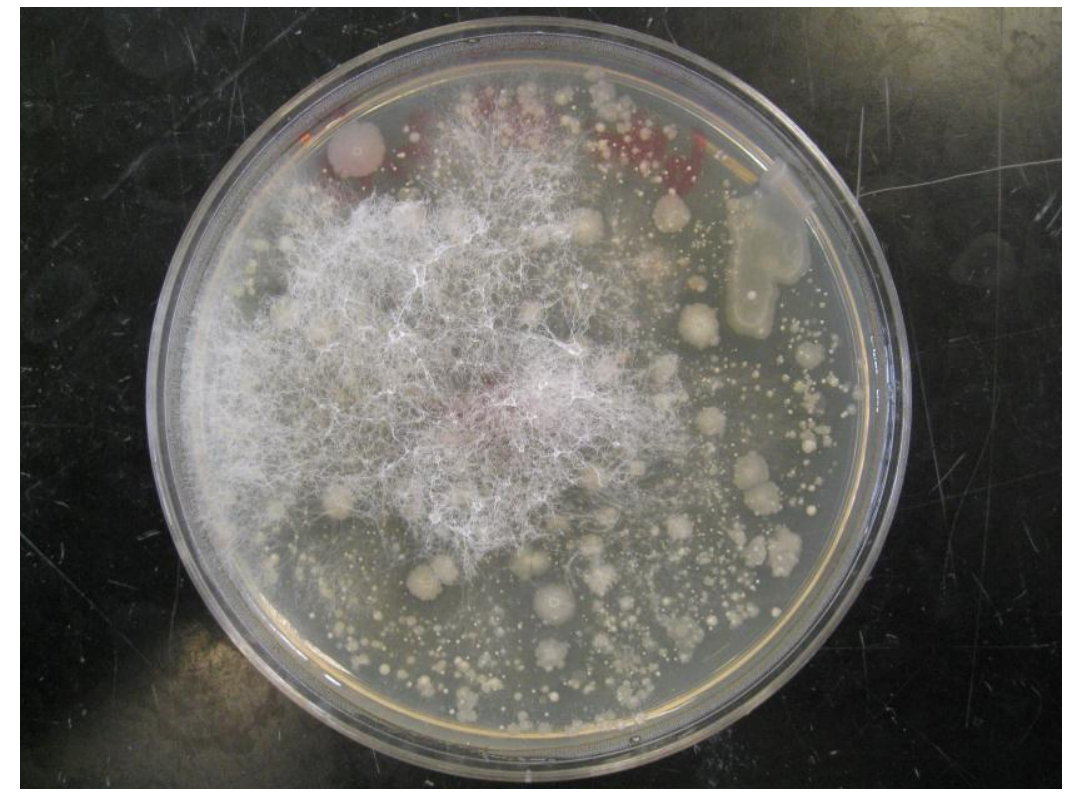

Figure 4-2. Sample plate with Botrytis inhibition seen around various areas of the plate. 
Table 4-1. Trial 1 data with Botrytis application right after BiOWiSH $^{\mathrm{TM}}$-Aqua spread plated $\left(\mathbf{T}_{\mathrm{app}}=\mathbf{0}\right.$ hours $)$.

\begin{tabular}{|c|c|c|c|}
\hline \multicolumn{4}{|c|}{ Percent growth of Botrytis on plate } \\
\hline \multirow{2}{*}{$\begin{array}{l}\text { BiOWiSH }^{\mathrm{TM}}- \\
\text { Aqua conc. } \\
\text { (ppm) }\end{array}$} & \multicolumn{3}{|c|}{ BiOWiSH $^{\mathrm{TM}}$-Aqua activation time $\left(\mathrm{T}_{\text {act }}\right)$} \\
\hline & $48 \mathrm{hr}$ & $72 \mathrm{hr}$ & $96 \mathrm{hr}$ \\
\hline \multirow{3}{*}{$10^{2}$} & 51.4 & 61.8 & 100 \\
\hline & 41.9 & 81.3 & 100 \\
\hline & 48.1 & 69.3 & 100 \\
\hline Avg & 47.1 & 70.8 & 100.0 \\
\hline \multirow{3}{*}{$10^{3}$} & 41.9 & 51.4 & 100.0 \\
\hline & 65.5 & 48.1 & 100.0 \\
\hline & 51.4 & 41.9 & 100.0 \\
\hline Avg & 52.9 & 47.1 & 100.0 \\
\hline \multirow{3}{*}{$10^{4}$} & 54.7 & $\mathrm{n} / \mathrm{a}$ & 100.0 \\
\hline & 54.7 & 58.2 & 100.0 \\
\hline & 51.4 & 54.7 & 100.0 \\
\hline Avg & 53.6 & 56.5 & 100.0 \\
\hline
\end{tabular}

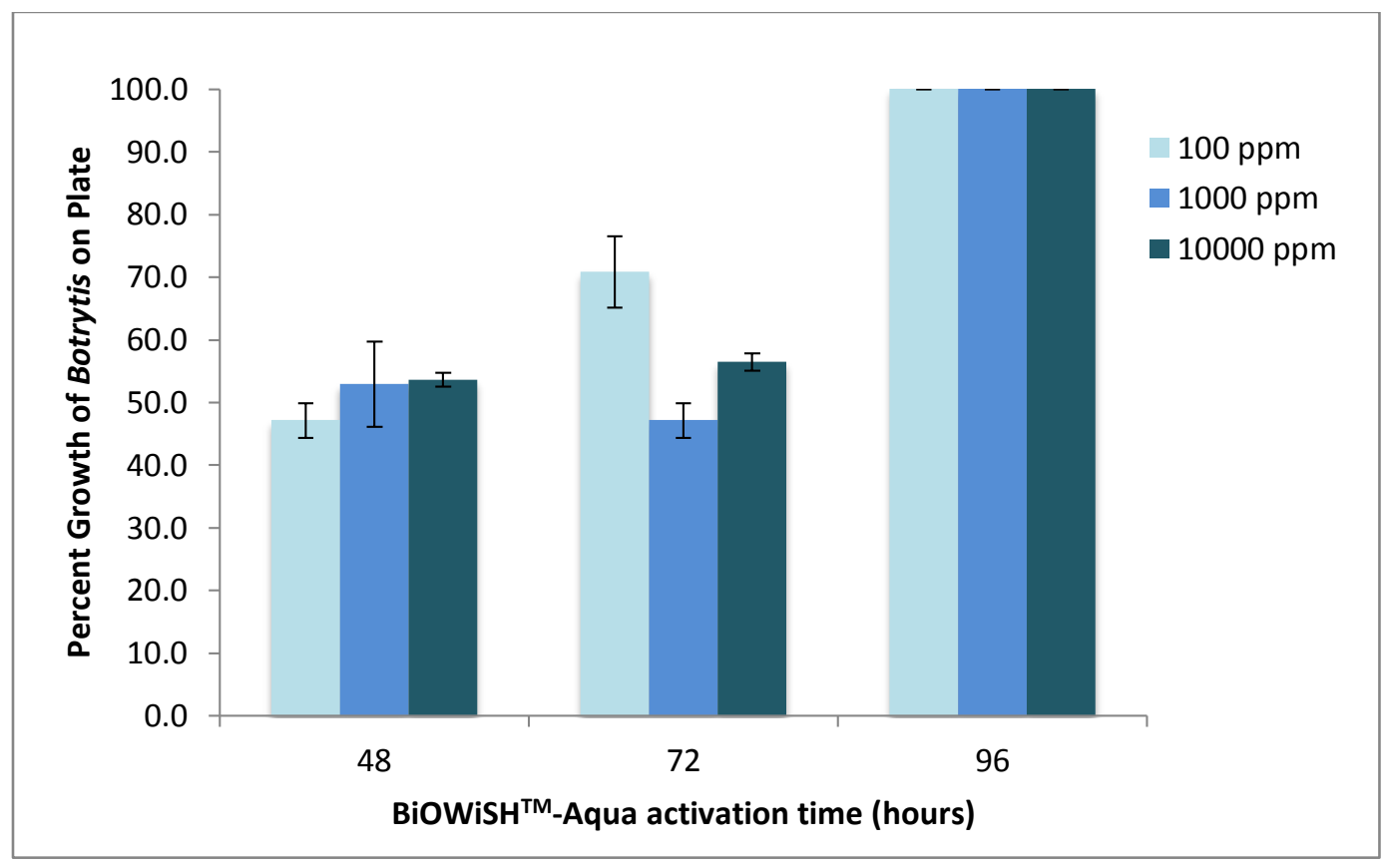

Figure 4-3. Effect of $\mathrm{BiOWiSH}^{\mathrm{TM}}$-Aqua activation time on Botrytis grow th at 0 hours application time in Trial 1 (Table 4-1). 
Botrytis application time was 0 hours relative to $\mathrm{BiOWiSH}^{\mathrm{TM}}$-Aqua, shown in Figure 4-3 and Table 4-1. Lower average Botrytis growth (more inhibition) was seen in plates of $\mathrm{BiOWiSH}^{\mathrm{TM}}$-Aqua activation times of 48 and 72 hours compared to activation time of 96 hours. Growth was defined as percentage of the plate overtaken by Botrytis, measured either by diameter or by estimation.

At activation time of 48 hours, average Botrytis growth was nearly identical, from 47 to 54 percent for all $\mathrm{BiOWiSH}^{\mathrm{TM}}$-Aqua concentrations. At activation time of 72 hours, average growth ranged from 47 to 71 percent at 1,000 ppm and $100 \mathrm{ppm}$, respectively. At activation time of 96 hours, 100 percent growth (Petri dish full of Botrytis) was observed for all samples.

Table 4-2. BiOWiSH ${ }^{\mathrm{TM}}$-Aqua Trial 1 control data of the negative control (no biopesticide) and B. subtilis QST 713.

\begin{tabular}{c|ccc}
\hline \multicolumn{4}{|c}{ Percent growth of Botrytis on plate } \\
\hline & \multicolumn{3}{|c}{ Application time of Botrytis $\left(\mathrm{T}_{\text {app }}\right)$} \\
\hline & $\mathbf{0}$ & $\mathbf{2 4}$ & $\mathbf{4 8}$ \\
\hline B. subtilis & 10.5 & 0.0 & 0.0 \\
QST 713 & 17.3 & 23.6 & 23.6 \\
(undiluted) & 15.4 & 12.0 & 12.0 \\
\hline Avg & 14.4 & $\mathbf{1 1 . 9}$ & $\mathbf{7 . 1}$ \\
\hline No & & & \\
biopesticide & 100.0 & 100.0 & 100.0 \\
\hline Avg & $\mathbf{1 0 0 . 0}$ & $\mathbf{1 0 0 . 0}$ & $\mathbf{1 0 0 . 0}$ \\
\hline
\end{tabular}




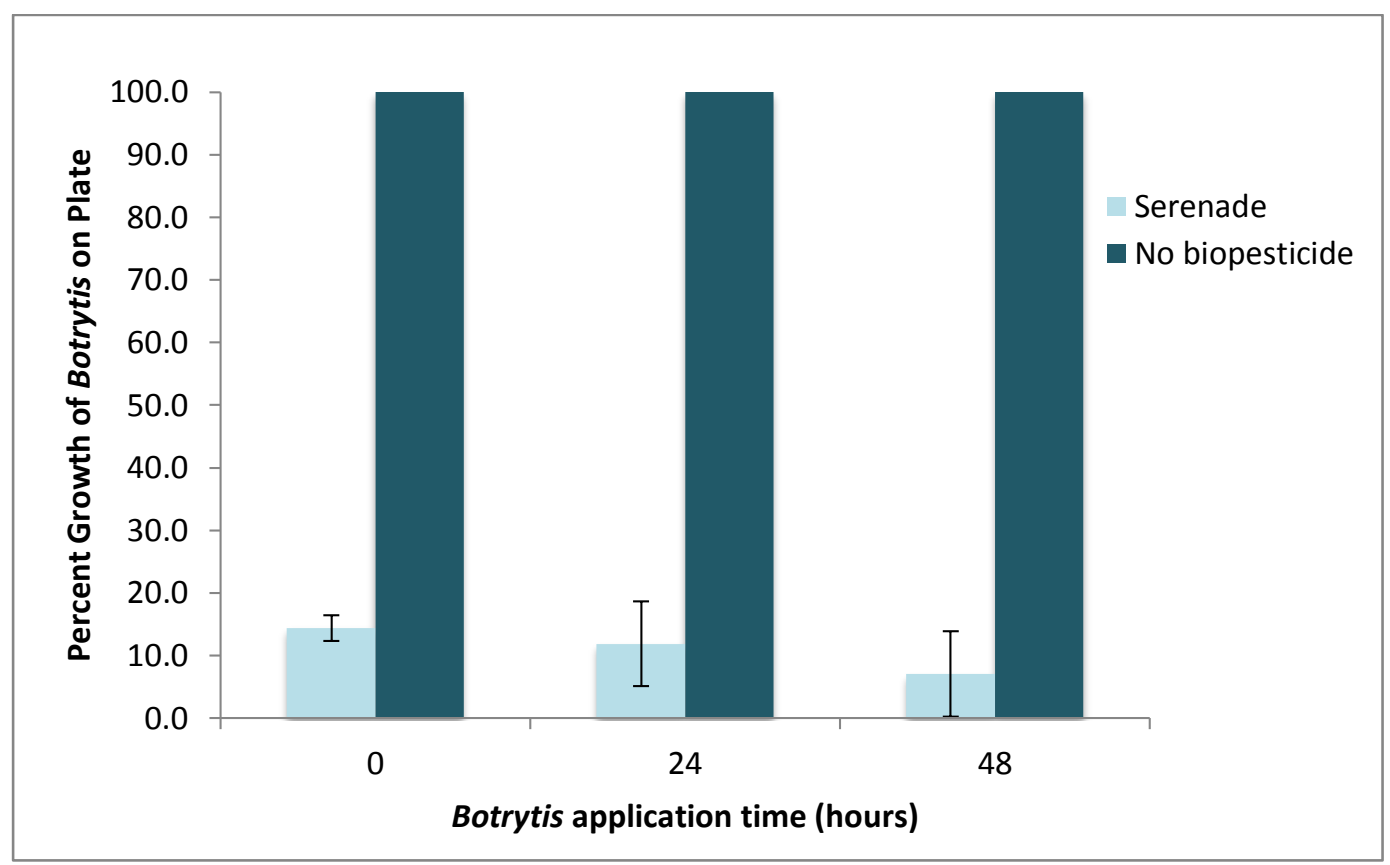

Figure 4-4. Control data of Serenade (B. subtilis QST 713) at three Botrytis application times and no biopesticide.

As expected, all plates with no biopesticide contained 100 percent growth of Botrytis, comparable to the plate in Figure 3-3. Application times did not apply to the "no biopesticide" negative control since Botrytis was inoculated on empty PDA plates. Regardless of Botrytis application time, B. subtilis QST 713 kept average Botrytis growth to a minimum, from 7 percent at 48 hours to 14 percent at 0 hours (Table 4-2 and Figure 4-4). These two controls showed extremes of Botrytis growth since one is a commercial biopesticide, which greatly inhibited growth, and the other did not contain any biopesticide, which allowed Botrytis to grow undisturbed. 
Table 4-3. Trial 1 data with Botrytis application 24 hours after BiOWiSH ${ }^{\mathrm{TM}}$-Aqua spread-plated.

\begin{tabular}{|c|c|c|c|}
\hline \multicolumn{4}{|c|}{ Percent growth of Botrytis on plate } \\
\hline \multirow{2}{*}{$\begin{array}{l}\text { BiOWiSH }^{\mathrm{TM}}- \\
\text { Aqua conc. } \\
\text { (ppm) }\end{array}$} & \multicolumn{3}{|c|}{ BiOWiSH $^{\mathrm{TM}}$-Aqua activation time $\left(\mathrm{T}_{\text {act }}\right)$} \\
\hline & $48 \mathrm{hr}$ & $72 \mathrm{hr}$ & $96 \mathrm{hr}$ \\
\hline \multirow{3}{*}{$10^{2}$} & 36.1 & 0.0 & 0.0 \\
\hline & 65.5 & 0.0 & 0.0 \\
\hline & 41.9 & 23.6 & 65.5 \\
\hline Avg & 47.8 & 7.9 & 21.8 \\
\hline \multirow{3}{*}{$10^{3}$} & 54.7 & 33.4 & 100.0 \\
\hline & 58.2 & 73.2 & 100.0 \\
\hline & 73.2 & 69.3 & 100.0 \\
\hline Avg & 62.0 & 58.6 & 100.0 \\
\hline \multirow{3}{*}{$10^{4}$} & 73.2 & 0.0 & 100.0 \\
\hline & 65.5 & 0.0 & 48.1 \\
\hline & 98.8 & 0.0 & 85.5 \\
\hline Avg & 79.2 & 0.0 & 77.9 \\
\hline
\end{tabular}

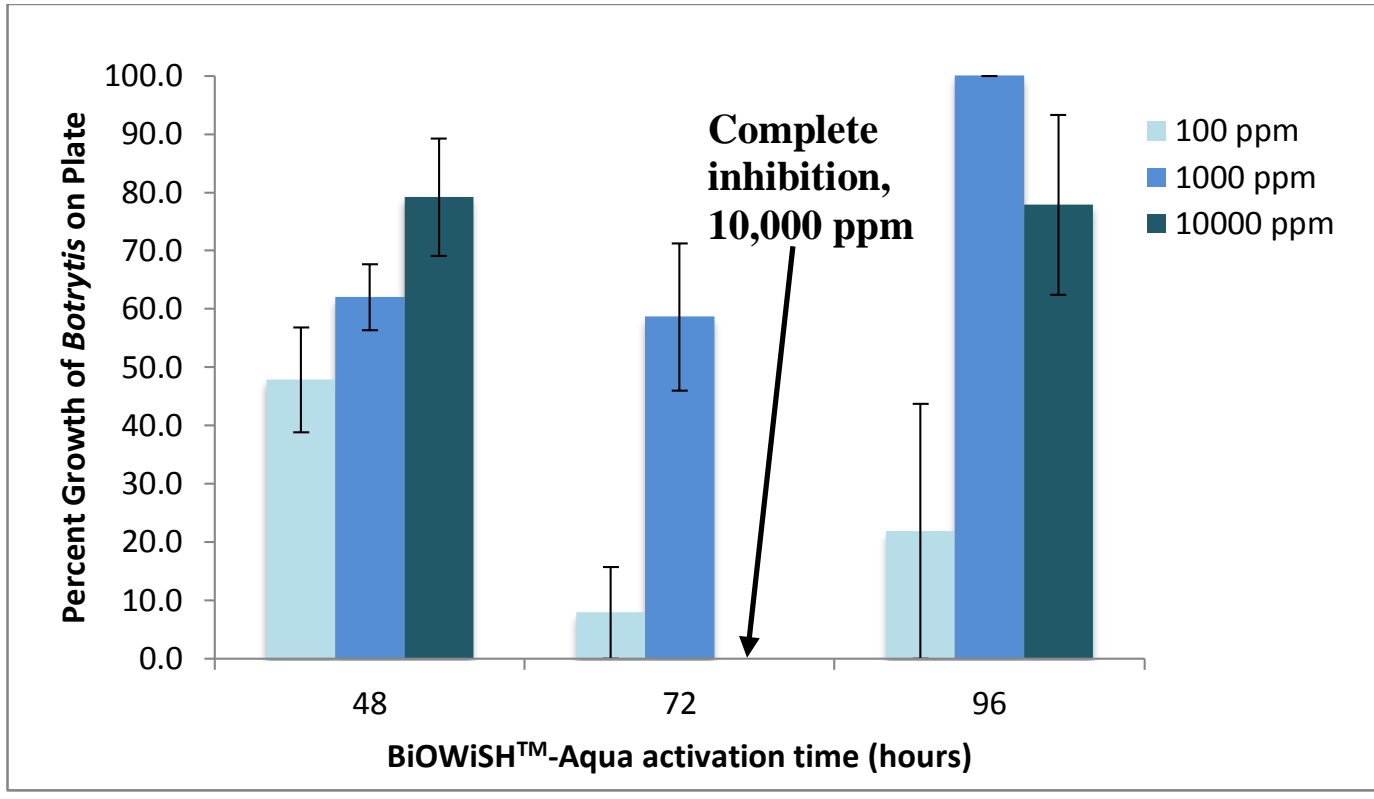

Figure 4-5. Effect of BiOWiSH ${ }^{\mathrm{TM}}$-Aqua activation time on Botrytis growth at 24 hours application time in Trial 1 (Table 4-3). 
Botrytis application time was 24 hours relative to $\mathrm{BiOWiSH}^{\mathrm{TM}}$-Aqua, shown in Figure 4-5 and Table 4-3. Percent growth of Botrytis varied widely from plate to plate. The least average Botrytis growth was seen at activation time of 72 hours. In fact, complete inhibition of Botrytis was seen on all of the triplicate plates with 10,000 ppm of $\mathrm{BiOWiSH}^{\mathrm{TM}}$-Aqua and on two of the plates with $100 \mathrm{ppm}$. In contrast, average Botrytis growth was close to 60 percent at $1,000 \mathrm{ppm}$.

At activation time of 48 hours, average Botrytis growth ranged from 48 to 79 percent, increasing from 100 to $10,000 \mathrm{ppm}$. At activation time of 96 hours, average growth ranged from 22 percent at $100 \mathrm{ppm}$ to full growth at $1,000 \mathrm{ppm}$. Plates at $100 \mathrm{ppm}$ contained fewer and larger $\mathrm{BiOWiSH}^{\mathrm{TM}}$-Aqua colonies. Select colonies formed inhibition zones to limit the growth of Botrytis. 
Table 4-4. Trial 1 data with Botrytis application 48 hours after BiOWiSH ${ }^{\mathrm{TM}}$-Aqua spread-plated.

\begin{tabular}{c|ccc}
\hline \multicolumn{4}{c}{ Percent growth of Botrytis on plate } \\
\hline & BiOWiSH ${ }^{\mathrm{TM}}$-Aqua activation time $\left(\mathrm{T}_{\text {act }}\right)$ \\
\hline $\begin{array}{c}\text { BiOWiSH } \\
\text { Aqua conc. } \\
\text { (ppm) }\end{array}$ & 48 hours & 72 hours & 96 hours \\
\hline \multirow{2}{*}{$10^{2}$} & 69.3 & 39.0 & 21.4 \\
& 69.3 & 30.8 & 36.1 \\
Avg & 51.4 & 45.0 & 41.9 \\
\hline & $\mathbf{6 3 . 3}$ & $\mathbf{3 8 . 2}$ & $\mathbf{3 3 . 1}$ \\
$10^{3}$ & 28.3 & 41.9 & 33.4 \\
& 21.4 & 36.1 & 30.8 \\
\hline Avg & 23.6 & 36.1 & 28.3 \\
\hline \multirow{2}{*}{$10^{4}$} & $\mathbf{2 4 . 4}$ & $\mathbf{3 8 . 1}$ & $\mathbf{3 0 . 8}$ \\
\hline Avg & 0.0 & 65.5 & 39.0 \\
& 45.0 & 41.9 & 36.1 \\
\hline
\end{tabular}

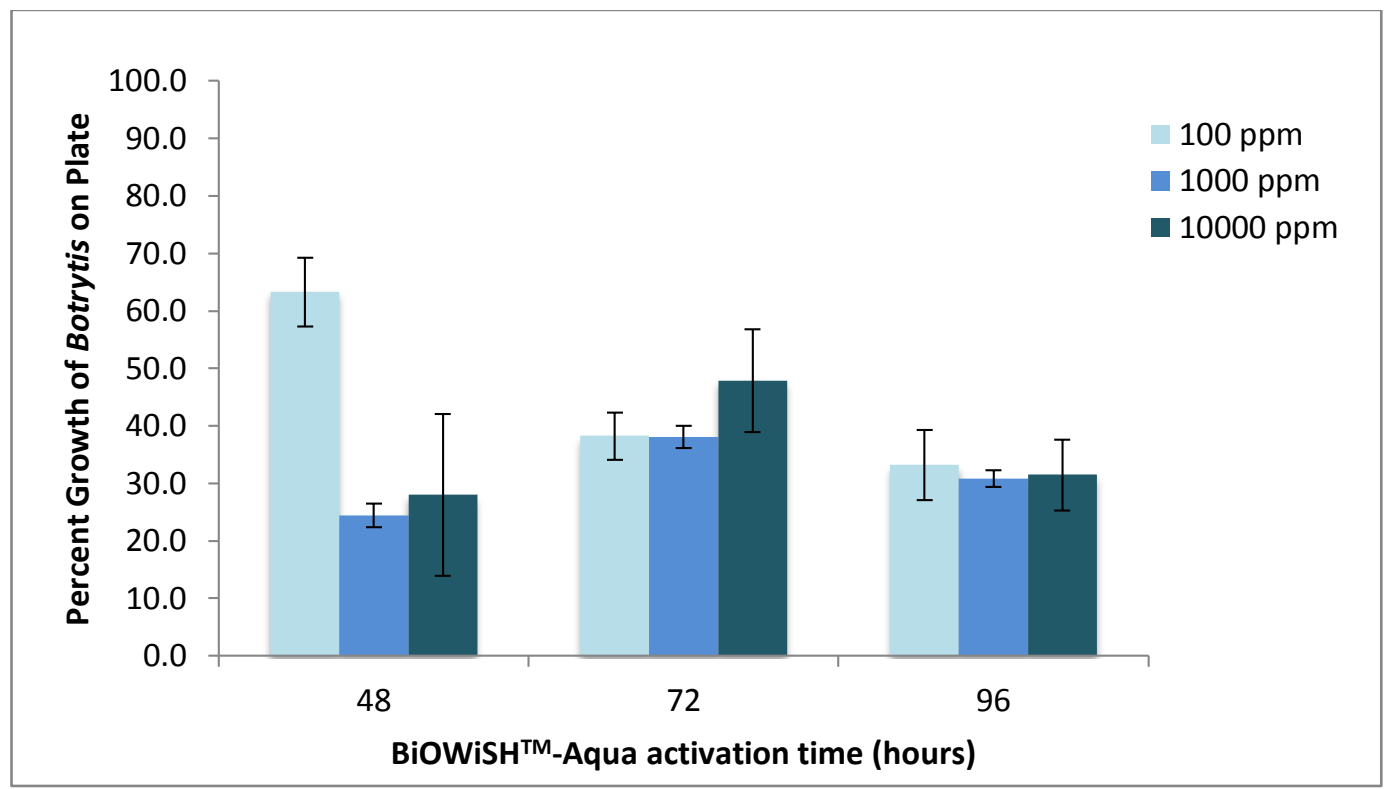

Figure 4-6. Effect of BiOWiSH ${ }^{\mathrm{TM}}$-Aqua activation time on Botrytis growth at 48 hours application time in Trial 1 (Table 4-4). 
Botrytis application time was 48 hours relative to $\mathrm{BiOWiSH}^{\mathrm{TM}}$-Aqua, shown in Figure 4-6 and Table 4-4. Botrytis growth was relatively similar throughout all $\mathrm{BiOWiSH}^{\mathrm{TM}}$ Aqua activation times compared to growth at Botrytis application times of 0 and 24 hours.

At application time of 48 hours, 24 to 63 percent average Botrytis growth was observed. At application time of 72 hours, average growth was consistent at 38 to 48 percent. At application time of 96 hours, average growth was almost identical at 31 to 33 percent.

Table 4-5. Trial 2 data with Botrytis application right after BiOWiSH $^{\mathrm{TM}}$-Aqua spread plated.

\begin{tabular}{c|ccc}
\hline \multicolumn{4}{c}{ Percent growth of Botrytis on plate } \\
\hline & \multicolumn{3}{c}{ BiOWiSH $^{\mathrm{TM}}$-Aqua activation time $\left(\mathbf{T}_{\text {act }}\right)$} \\
\hline $\begin{array}{c}\text { BiOWiSH } \\
\text { Aqua conc. } \\
\text { (ppm) }\end{array}$ & 60 hours & 73 hours & $\mathbf{8 5}$ hours \\
\hline & 100.0 & 100.0 & 80.3 \\
$10^{2}$ & 100.0 & 100.0 & 80.3 \\
& 85.5 & 100.0 & 81.3 \\
\hline Avg & $\mathbf{9 5 . 2}$ & $\mathbf{1 0 0 . 0}$ & $\mathbf{8 0 . 6}$ \\
\hline & 91.0 & 80.3 & 85.5 \\
$10^{3}$ & 85.5 & 100.0 & 100.0 \\
& 85.5 & 100.0 & 85.5 \\
\hline Avg & $\mathbf{8 7 . 3}$ & $\mathbf{9 3 . 4}$ & $\mathbf{9 0 . 4}$ \\
\hline \multirow{2}{*}{$10^{4}$} & 85.5 & 71.2 & 85.5 \\
& 100.0 & 48.1 & 85.5 \\
\hline Avg & 81.3 & 48.1 & 51.4 \\
\hline
\end{tabular}




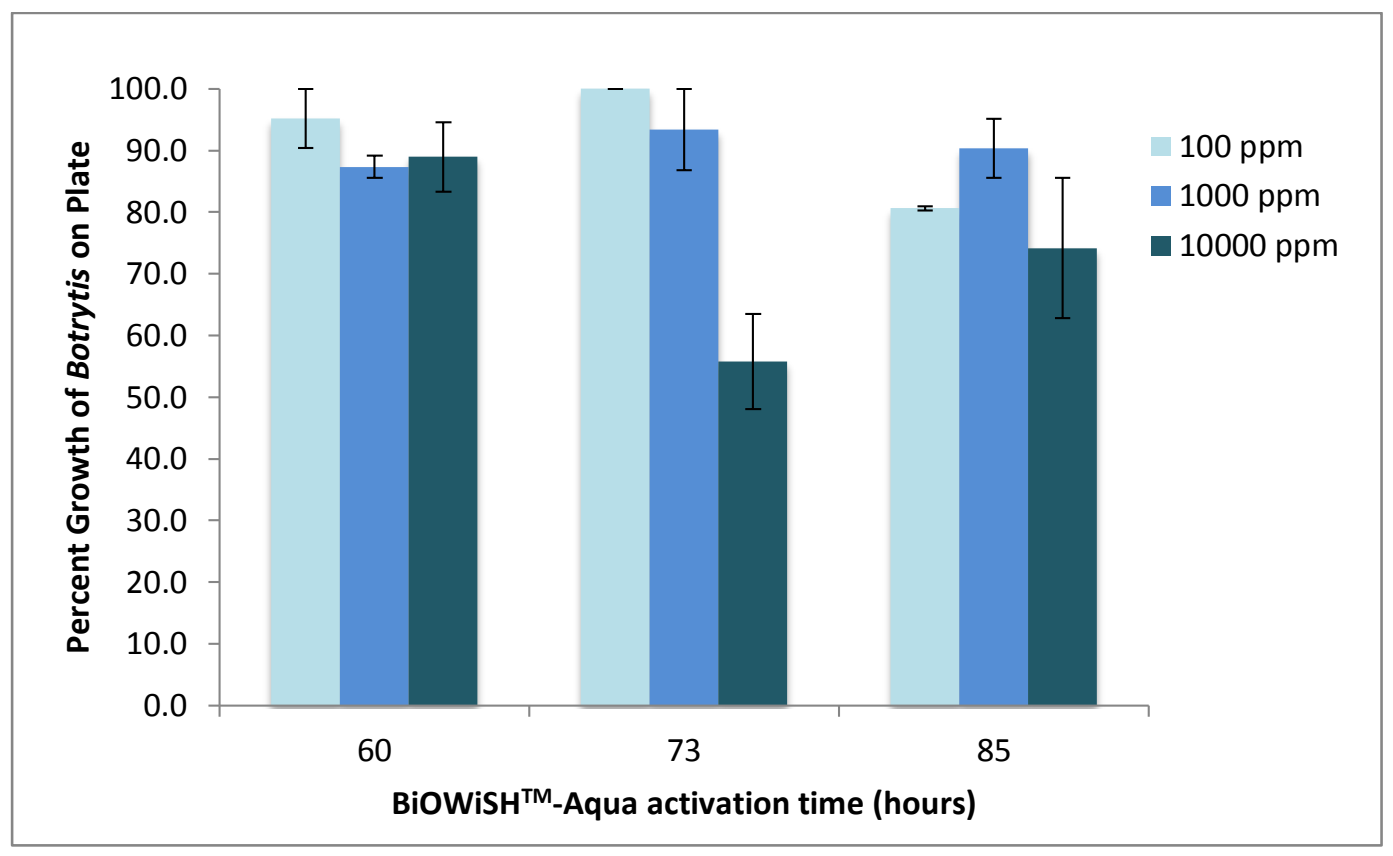

Figure 4-7. Effect of $\mathrm{BiOWiSH}^{\mathrm{TM}}$-Aqua activation time on Botrytis growth at 0 hours application time in Trial 2 (Table 4-5).

In Trial 2, Botrytis application times were at 0 and 24 hours and $\mathrm{BiOWiSH}^{\mathrm{TM}}$-Aqua activation times focused around 72 hours, at 60, 73 and 85 hours.

Botrytis application time was 0 hours relative to $\mathrm{BiOWiSH}^{\mathrm{TM}}$-Aqua, shown in Figure 4-7 and Table 4-5. Botrytis growth was particularly high for all plates regardless of $\mathrm{BiOWiSH}^{\mathrm{TM}}$-Aqua activation time or concentration. One explanation of greater Botrytis growth is that the batch of $\mathrm{BiOWiSH}^{\mathrm{TM}}$-Aqua used in Trial 1 was different than the batch used in Trial 2. Another possibility is that since application time was 0 hours, $\mathrm{BiOWiSH}^{\mathrm{TM}}$-Aqua did not have time to grow on the Petri dish before application of Botrytis. 
The least average Botrytis growth was observed (56 percent) at activation time of 73 hours with $10,000 \mathrm{ppm}$ of $\mathrm{BiOWiSH}^{\mathrm{TM}}$-Aqua. The second least (74 percent) was at activation time of 85 hours with 10,000 ppm. All other plates contained average growth of at least 87 percent and most were at greater than 90 percent.

Table 4-6. Trial 2 data with Botrytis application 24 hours after BiOWiSH $^{\mathrm{TM}}$-Aqua spread-plated.

\begin{tabular}{c|ccc}
\hline \multicolumn{4}{c}{ Percent growth of Botrytis on plate } \\
\hline & BiOWiSH ${ }^{\mathrm{TM}}$-Aqua activation time $\left(\mathbf{T}_{\text {act }}\right)$ \\
\hline $\begin{array}{c}\text { BiOWiSH } \\
\text { Aqua conc. } \\
\text { (ppm) }\end{array}$ & 60 hours & 73 hours & $\mathbf{8 5}$ hours \\
\hline \multirow{2}{*}{$10^{2}$} & 100.0 & 48.1 & 0.0 \\
& 100.0 & 18.8 & 0.0 \\
\hline Avg & 100.0 & 65.5 & 12.0 \\
\hline \multirow{2}{*}{$10^{3}$} & $\mathbf{1 0 0 . 0}$ & $\mathbf{4 4 . 1}$ & $\mathbf{4 . 0}$ \\
\hline Avg & 0.0 & 0.0 & 1.3 \\
& 18.8 & 56.5 & 0.0 \\
$10^{4}$ & 1.3 & 40.4 & 1.3 \\
\hline Avg & $\mathbf{6 . 7}$ & $\mathbf{3 2 . 3}$ & $\mathbf{0 . 9}$ \\
\hline & 85.5 & 0.0 & 3.0 \\
& 48.1 & 12.0 & 21.4 \\
& 33.4 & 0.0 & 56.5 \\
\hline
\end{tabular}




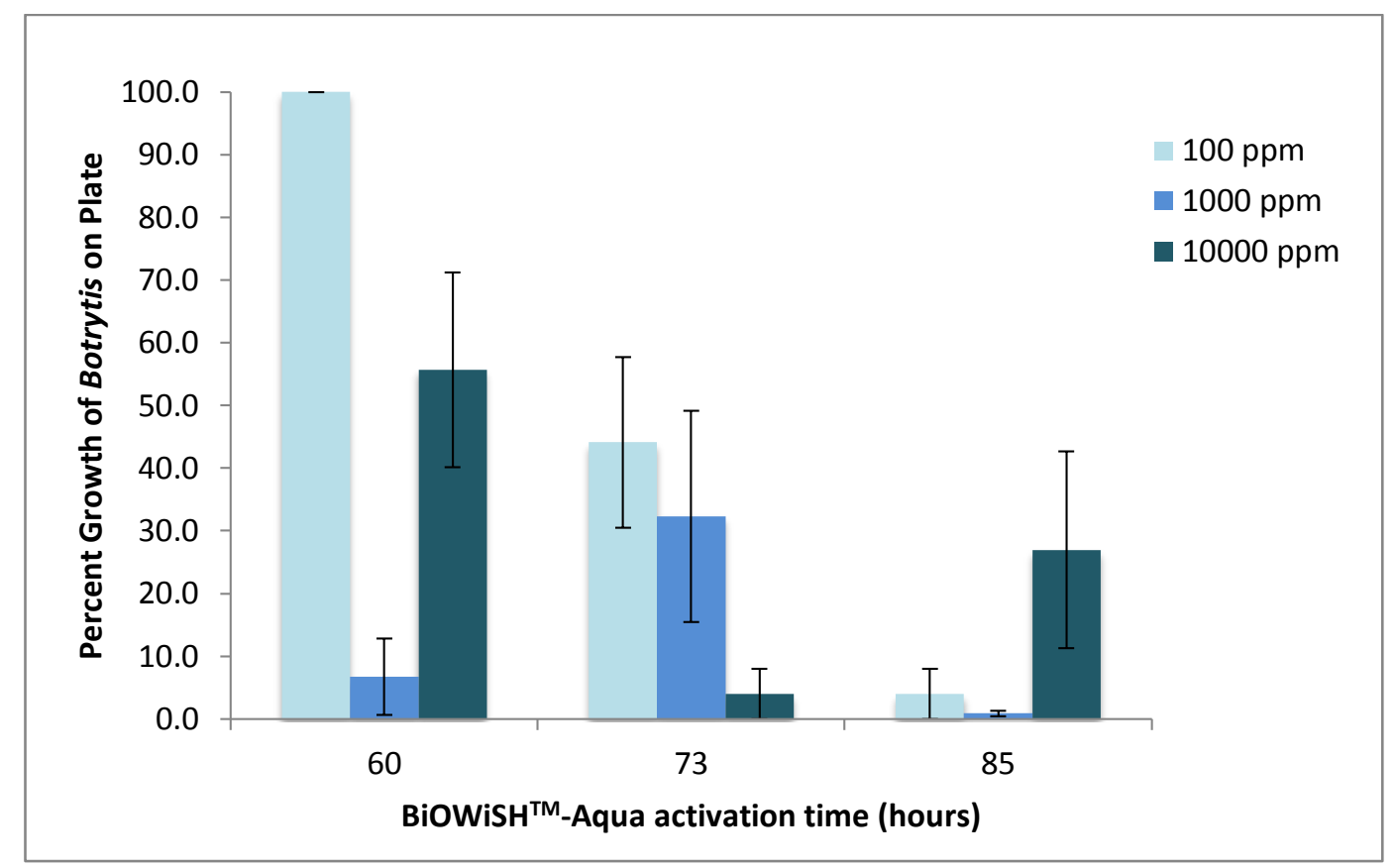

Figure 4-8. Effect of BiOWiSH ${ }^{\mathrm{TM}}$-Aqua activation time on Botrytis growth at 24 hours application time in Trial 2 (Table 4-6).

Botrytis application time was 24 hours relative to $\mathrm{BiOWiSH}^{\mathrm{TM}}$-Aqua, shown in Figure 4-8 and Table 4-6. Botrytis growth was considerably lower compared to application time of 0 hours. One of the possible reasons is that $\mathrm{BiOWiSH}^{\mathrm{TM}}$-Aqua colonies were already established on plates before Botrytis application at 24 hours.

No patterns of Botrytis growth were seen regardless of $\mathrm{BiOWiSH}^{\mathrm{TM}}$-Aqua concentration and activation time. At $100 \mathrm{ppm}$ and activation time of 60 hours, all of the plates contained 100 percent growth. In contrast, at 1,000 ppm, a ten-fold increase, average growth was almost non-existent at 7 percent. At 10,000 ppm, plates yielded considerably more growth at an average of 56 percent. 
At activation time of 73 hours, there was considerable growth variability from plate to plate, shown by relatively large standard error bars. For example, although the average was 44 percent at activation time of $100 \mathrm{ppm}$, the triplicate plates varied from 19 to 66 percent. For $1,000 \mathrm{ppm}$, one plate did not contain any growth while the average was 32 percent. Average growth at 10,000 ppm (4 percent) was almost non-existent. At activation time of 85 hours, minimal average growth was observed at 100 and 1,000 ppm at 4.0 and 0.9 percent, respectively. At $10,000 \mathrm{ppm}$, average growth was 27 percent.

Table 4-7. Trial 3 data with Botrytis application 24 hours after BiOWiSH ${ }^{\mathrm{TM}}$-Aqua spread-plated.

\begin{tabular}{|c|c|c|c|}
\hline \multicolumn{4}{|c|}{ Percent growth of Botrytis on plate } \\
\hline \multirow[b]{2}{*}{$\begin{array}{l}\text { BiOWiSH }^{\mathrm{TM}}- \\
\text { Aqua conc. } \\
\text { (ppm) }\end{array}$} & \multicolumn{3}{|c|}{ BiOWiSH $^{\mathrm{TM}}$-Aqua activation time $\left(\mathrm{T}_{\text {act }}\right)$} \\
\hline & 59 hours & 71 hours & 80 hours \\
\hline \multirow{3}{*}{$10^{2}$} & 65.5 & 56.5 & 60.9 \\
\hline & 65.5 & 65.5 & 60.9 \\
\hline & 65.5 & 56.5 & 65.5 \\
\hline Avg & 65.5 & 59.5 & 62.4 \\
\hline \multirow{3}{*}{$10^{3}$} & 56.5 & 65.5 & 70.2 \\
\hline & 65.5 & 60.9 & 80.3 \\
\hline & 56.5 & 60.9 & 65.5 \\
\hline Avg & 59.5 & 62.4 & 72.0 \\
\hline \multirow{3}{*}{$10^{4}$} & 56.5 & 56.5 & 60.9 \\
\hline & 56.5 & 56.5 & 65.5 \\
\hline & 48.1 & 60.9 & 60.9 \\
\hline Avg & 53.7 & 57.9 & 62.4 \\
\hline
\end{tabular}




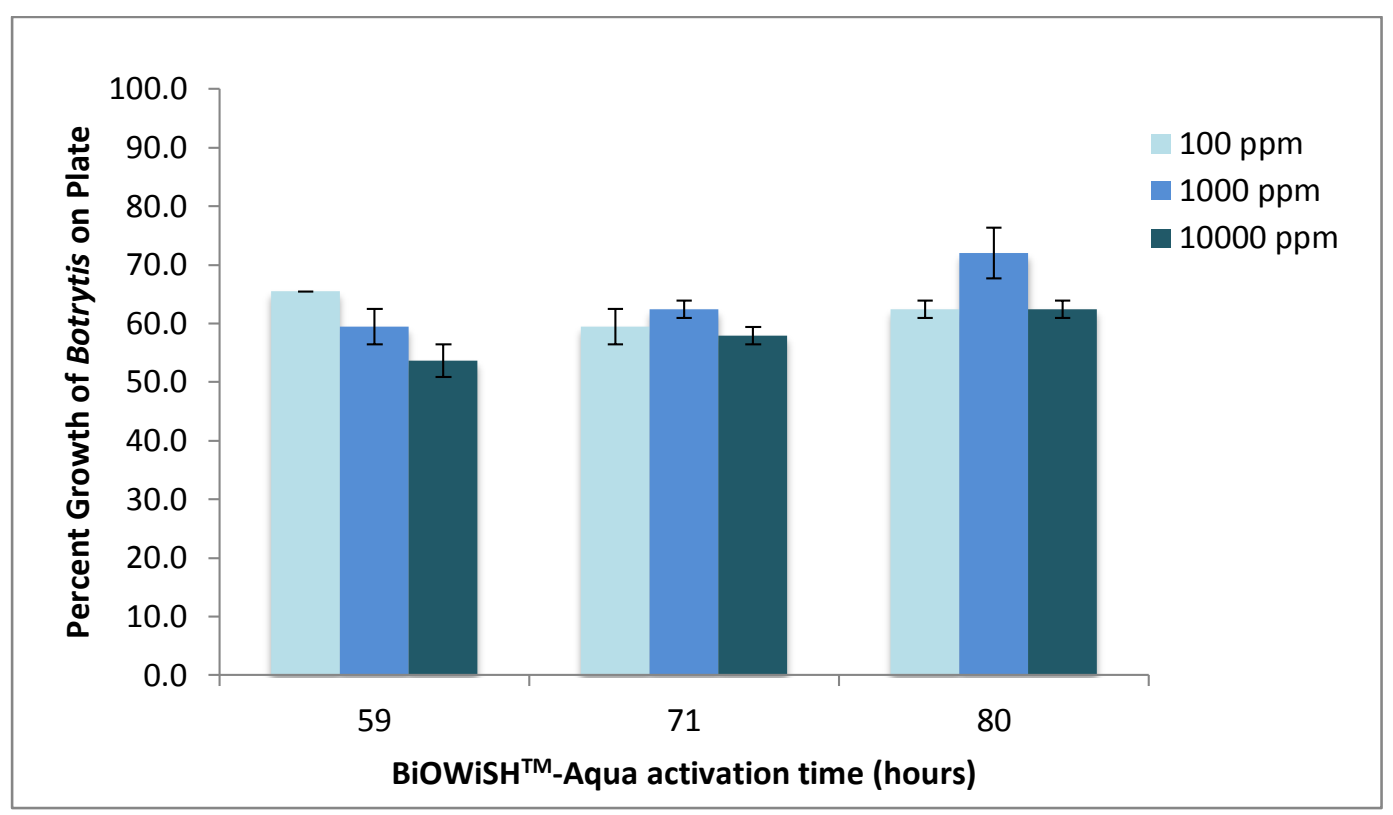

Figure 4-9. Effect of BiOWiSH ${ }^{\mathrm{TM}}$-Aqua activation time on Botrytis growth at 24 hours application time in Trial 3 (Table 4-7).

Table 4-8. Trial 4 data with Botrytis application 23 hours after BiOWiSH ${ }^{\mathrm{TM}}$-Aqua spread-plated.

\begin{tabular}{|c|c|c|c|}
\hline \multicolumn{4}{|c|}{ Percent growth of Botrytis on plate } \\
\hline \multirow{2}{*}{$\begin{array}{l}\text { BiOWiSH }^{\mathrm{TM}}- \\
\text { Aqua conc. } \\
\text { (ppm) }\end{array}$} & \multicolumn{3}{|c|}{ BiOWiSH $^{\mathrm{TM}}$-Aqua activation time $\left(\mathrm{T}_{\text {act }}\right)$} \\
\hline & 65 hours & 77 hours & 89 hours \\
\hline \multirow{3}{*}{$10^{2}$} & 56.5 & 44.2 & 48.1 \\
\hline & 48.1 & 33.4 & 40.4 \\
\hline & 48.1 & 40.4 & 44.2 \\
\hline Avg & 50.9 & 39.3 & 44.2 \\
\hline \multirow{3}{*}{$10^{3}$} & 48.1 & 27.1 & 40.4 \\
\hline & 44.2 & 24.1 & 44.2 \\
\hline & 48.1 & 24.1 & 44.2 \\
\hline Avg & 46.8 & 25.1 & 42.9 \\
\hline \multirow{3}{*}{$10^{4}$} & 36.8 & 40.4 & 40.4 \\
\hline & 48.1 & 44.2 & 48.1 \\
\hline & 48.1 & 48.1 & 40.4 \\
\hline Avg & 44.4 & 44.2 & 43.0 \\
\hline
\end{tabular}




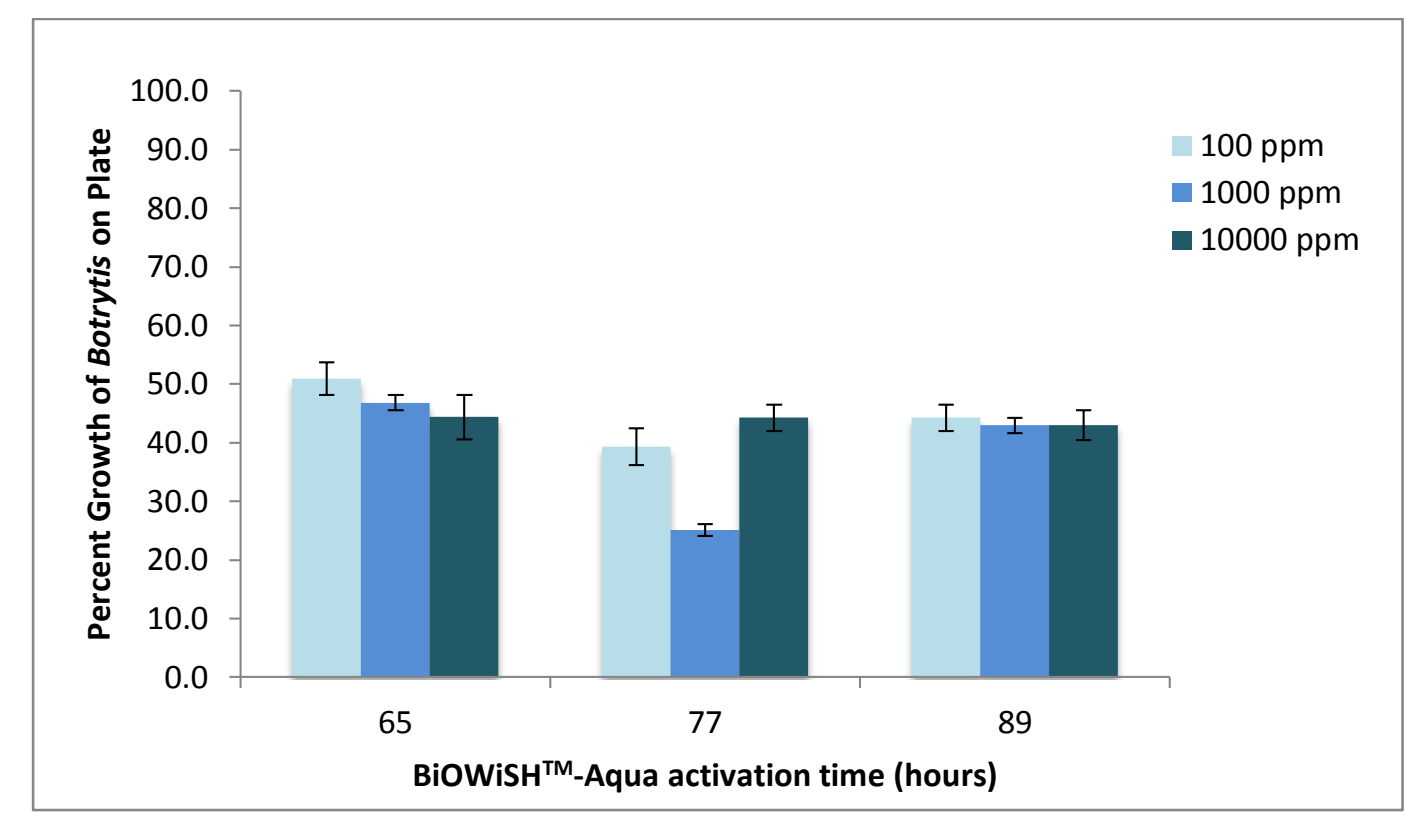

Figure 4-10. Effect of $\mathrm{BiOWiSH}^{\mathrm{TM}}$-Aqua activation time on Botrytis growth at 23 hours application time in Trial 4 (Table 4-8).

Trials 3 and 4 (Figure 4-9 and Figure 4-10) were repetitions of Trial 2 based on relatively low Botrytis growth at application time of 24 hours. However, average Botrytis growth in Trial 3 was greater at nearly all $\mathrm{BiOWiSH}^{\mathrm{TM}}$-Aqua concentrations and activation times, from 54 percent to 72 percent (Figure 4-9 and Table 4-7). Trial 4 contained lower average Botrytis growth, from 25 percent to 51 percent (Figure 4-10 and Table 4-8).

Repeatability of Trial 2 was unsuccessful in Trials 3 and 4 possibly due to the variability of $\mathrm{BiOWiSH}^{\mathrm{TM}}$-Aqua organisms. 
Overall, BiOWiSH ${ }^{\mathrm{TM}}$-Aqua had no observable effect on Botrytis growth. Botrytis growth in these plates ranged from perfectly circular growth to completely random growth, as shown in Figure 4-1 and Figure 4-2.

Figure 4-2 shows inhibition zones around certain colonies that inhibited Botrytis growth while others did not. This suggested that only one or some of the organisms in $\mathrm{BiOWiSH}^{\mathrm{TM}}$-Aqua inhibited Botrytis growth, although that/those organisms were not present in the same proportions on every plate. One organism responsible for Botrytis inhibition was later isolated and identified as B. subtilis KLB (more in Section 4.1.2.1).

\subsubsection{B. subtilis KLB Isolate}

\subsubsection{Isolation and Characterization of B. subtilis KLB}

The spread plates of the $\mathrm{BiOWiSH}^{\mathrm{TM}}$-Aqua inhibition experiments yielded some plates with colonies of various species (Figure 4-2) as well as some plates with colonies of what appeared to be of a singles species (Figure 4-11). The colonies on plates similar to Figure 7 inhibited Botrytis growth. The surrounding area of the colony was clear of any Botrytis growth, indicating that B. subtilis inhibited Botrytis growth in an in vitro environment. The Botrytis, inoculated in the middle of the plate, was never able to form a fuzzy conidial mass in contrast to the control with no biopesticide (Figure 4-11). A colony close to the Botrytis point of inoculation shown in Figure 4-11 was isolated using 
a flamed inoculum loop and smeared onto a microscope glass slide. The cells were then Gram-stained as shown in Figure 4-12. They were identified as Bacillus because they were rod-shaped and gram positive. In addition, its $16 \mathrm{~S}$ rRNA sequence was analyzed using NCBI BLAST searching tool, which closely matched (> 99\% homology) various strains of both B. subtilis and B. amyloliquefaciens (Zhang, 2000). The closest sequence match was to B. subtilis BSn5 (100\% Max ident), an endophytic bacterium with antimicrobial activity against the plant pathogen Erwinia carotovora, with GenBank number CP002468.1.

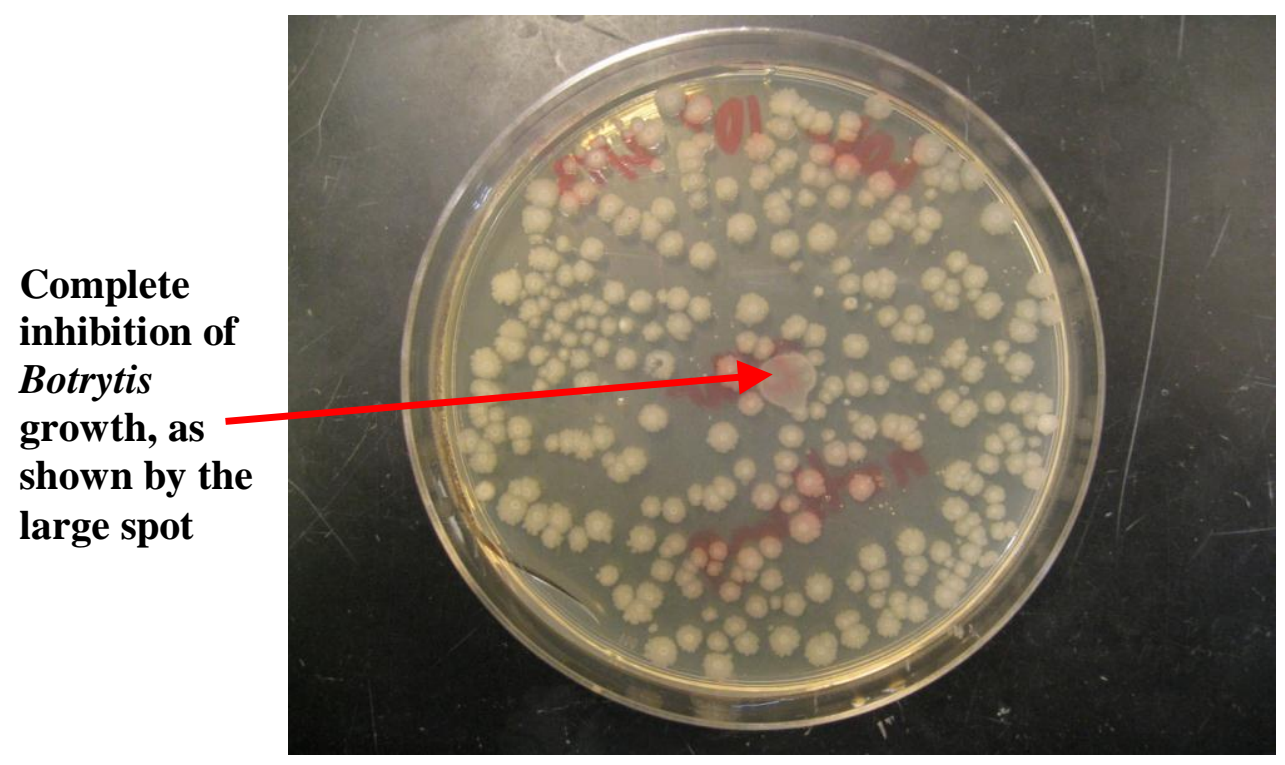

Figure 4-11. PDA plate where $B$. subtilis KLB completely inhibited Botrytis (the large spot shown by the arrow). 


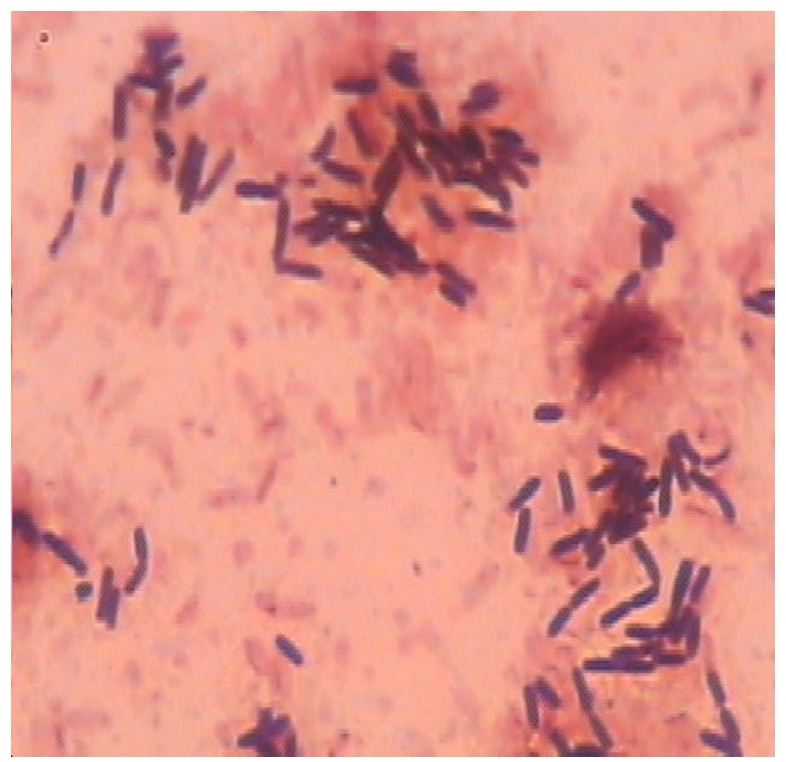

Figure 4-12. 1000x magnification of a Gram-stained slide with B. subtilis KLB.

Concentration of KLB inoculum with $\mathrm{OD}_{600}$ of 0.948 was plated at $10^{-6}$ dilution. The numbers of cells counted on the three plates were 63,51 , and 72 , an average of 62 . The concentration of KLB was used to construct a calibration curve, which was calculated as: $62 \mathrm{CFU} /\left(10^{-6} * 0.1 \mathrm{~mL}\right)=6.2 \times 10^{8} \mathrm{CFU} / \mathrm{mL}$ 


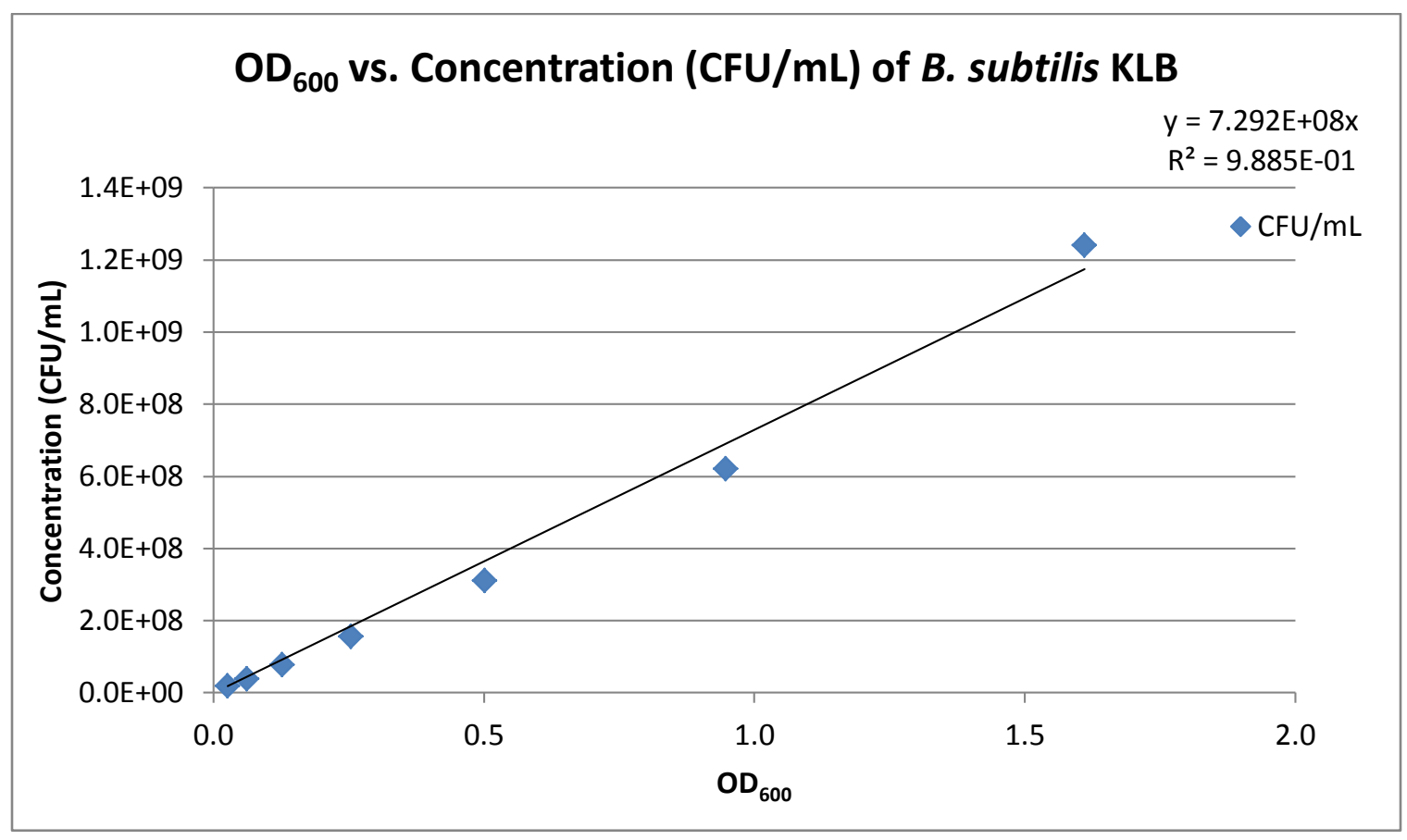

Figure 4-13. Growth curve of B. subtilis KLB.

The following formula on Figure 4-13 was interpreted as follows:

$y=7.292 \times 10^{8} x$, where

$y=$ cell density in CFU $/ \mathrm{mL}$

$x=$ optical density at $600 \mathrm{~nm}\left(\mathrm{OD}_{600}\right)$

Using this formula, cell densities were determined by finding $\mathrm{OD}_{600}$ using the spectrophotometer.

To confirm that B. subtilis KLB specifically inhibited Botrytis growth and to determine the effective concentrations, a quick visual screening study was conducted. Regardless of an application time of 0 or 24 hours, Botrytis growth was completely inhibited in the 4.84 
x $10^{6} \mathrm{CFU} / \mathrm{mL}$ section (Figure 4-14 and Figure 4-15). Botrytis grew well on the $4.84 \mathrm{x}$ $10^{6} \mathrm{CFU} / \mathrm{mL}$ and control sections at an application time of 0 hours (Figure 4-14). Botrytis growth was mostly inhibited at an application time of 24 hours except for minimal growth, shown by the white fuzz, on the control section (Figure 4-15).

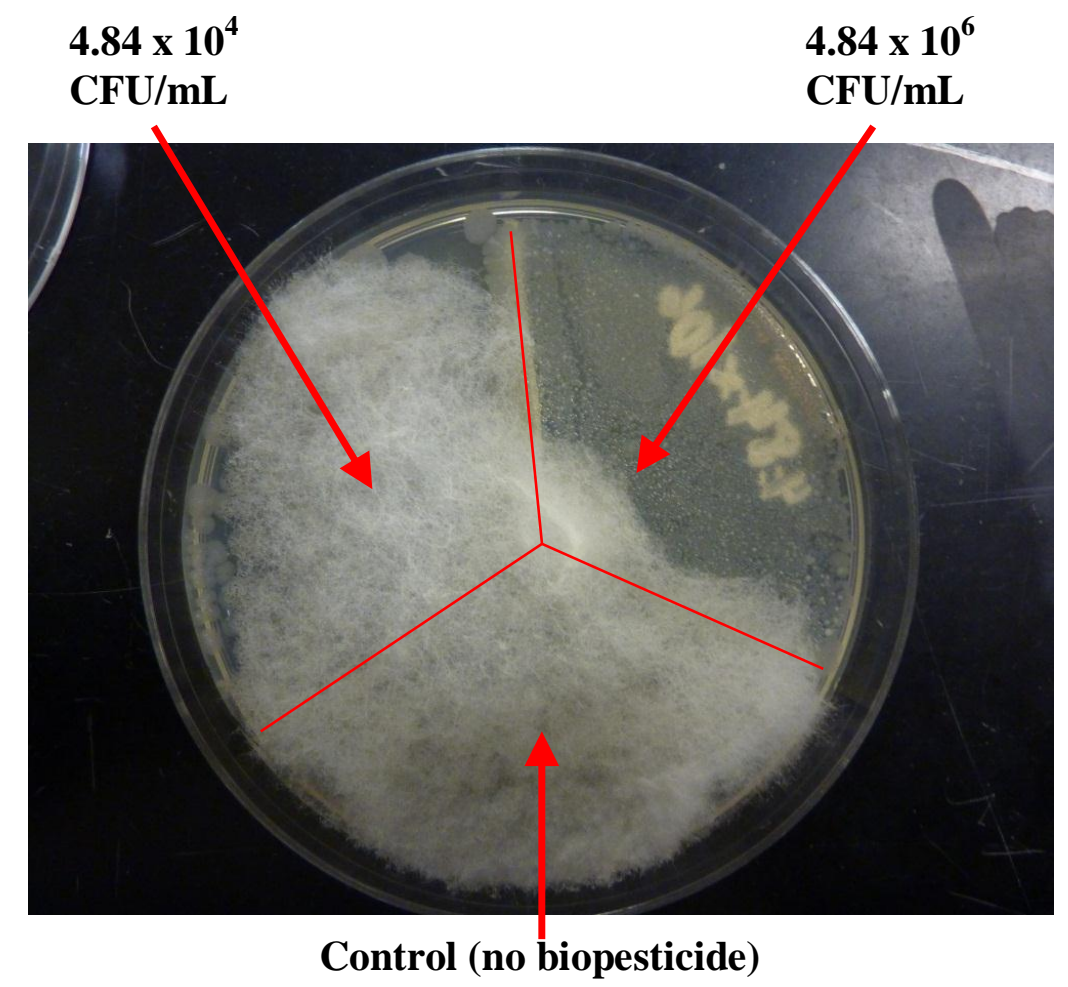

Figure 4-14. Different $B$. subtilis KLB concentrations at application time of 0 hours. 


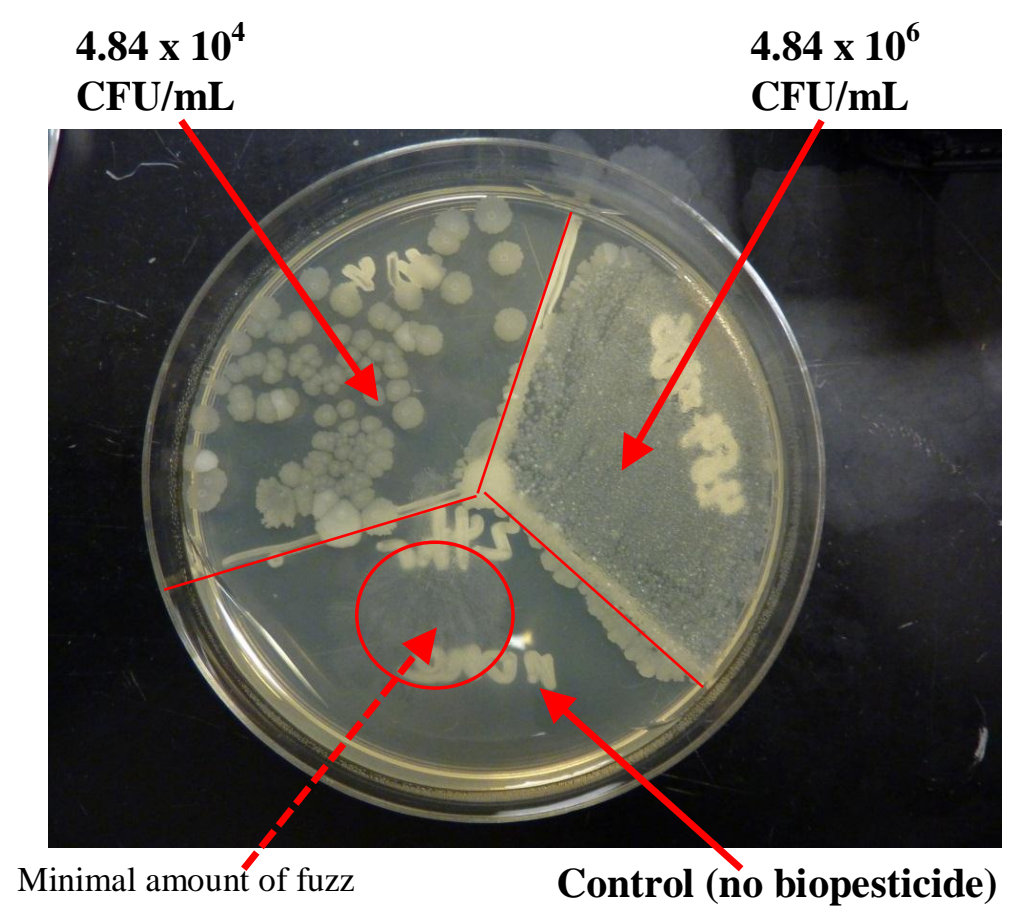

Figure 4-15. Different B. subtilis KLB concentrations at application time of 24 hours.

\subsubsection{Botrytis Inhibition Results Using B. subtilis KLB}

B. subtilis $\mathrm{KLB}$ replaced $\mathrm{BiOWiSH}^{\mathrm{TM}}$-Aqua as the biopesticide in further Botrytis inhibition experiments. The variables evaluated were concentration of $\mathrm{KLB}\left(\mathrm{C}_{\mathrm{KLB}}\right)$ and time of KLB growth on a plate prior to Botrytis application $\left(\mathrm{T}_{\mathrm{app}}\right)$. Nine trials were conducted in all. The conditions of each trial were based on evaluation of results from the previous trial. Afterward, all of the trial data were statistically evaluated using Minitab to determine 1) KLB concentration $\left(\mathrm{C}_{\mathrm{KLB}}\right)$ threshold for complete inhibition of Botrytis at each application time ( $\left.\mathrm{T}_{\mathrm{app}}\right)$ of 0,24, and 48 hours, and 2) relationship between percent growth of Botrytis on plate and KLB concentration at each application time. 
Table 4-9. Trial 1 data with Botrytis application 24 hours after B. subtilis KLB spread-plated $\left(\mathrm{T}_{\mathrm{app}}=24\right.$ hours).

\begin{tabular}{ccc}
\hline $\begin{array}{c}\text { B. subtilis KLB, } \\
\text { dilution }\end{array}$ & $\begin{array}{c}\text { B. subtilis KLB, } \\
\text { CFU/mL }\end{array}$ & $\begin{array}{c}\text { Percent growth of } \\
\text { Botrytis on plate } \\
\left(\mathbf{T}_{\text {app }}=\mathbf{2 4} \text { hrs }\right)\end{array}$ \\
\hline \multirow{2}{*}{$10^{-2}$} & $2.5 \times 10^{5}$ & 4.8 \\
& & 7.1 \\
Avg & & 0.0 \\
\hline \multirow{2}{*}{$10^{-3}$} & $2.5 \times 10^{4}$ & 4.0 \\
\hline \multirow{2}{*}{ Avg } & & 0.0 \\
\multirow{2}{*}{$10^{-4}$} & & 16.4 \\
& & 56.5 \\
\hline Avg & $2.5 \times 10^{3}$ & 24.3 \\
\hline
\end{tabular}

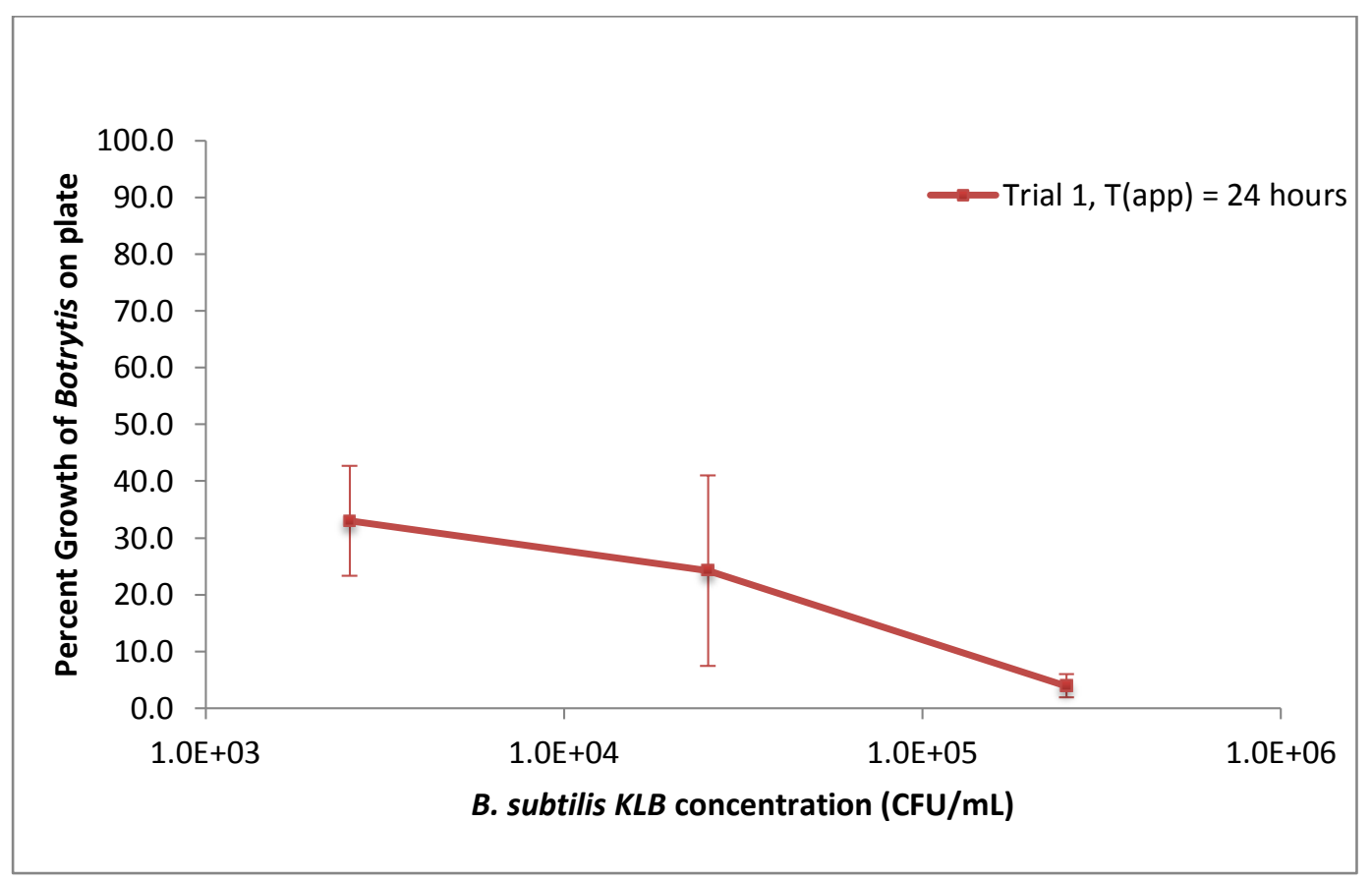

Figure 4-16. B. subtilis KLB Trial 1 data from Table 4-9. 
At application time of 24 hours in Trial 1, the data (Figure 4-16 and Table 4-9) show that as KLB concentration (x-axis) increased, percent growth of Botrytis on plate (y-axis) decreased. At the highest KLB concentration of $2.5 \times 10^{5} \mathrm{CFU} / \mathrm{mL}$, almost complete inhibition of Botrytis was seen with average Botrytis growth of 4 percent. At a concentration of ten times less, $2.5 \times 10^{4} \mathrm{CFU} / \mathrm{mL}$, average Botrytis growth was much greater at 57 percent, with a range from 0 to 57 percent. At a concentration of two logs lower compared to the original, $2.5 \times 10^{3} \mathrm{CFU} / \mathrm{mL}$, average Botrytis growth was 33 percent, with a range from 14 to 43 percent. The results were expected since a higher concentration of KLB should have a stronger effect against Botrytis growth. 
Table 4-10. Trial 2 data with Botrytis application 24 and 48 hours after B. subtilis KLB spread-plated.

\begin{tabular}{|c|c|c|c|}
\hline $\begin{array}{l}\text { B. subtilis KLB, } \\
\text { dilution }\end{array}$ & $\begin{array}{l}\text { B. subtilis KLB, } \\
\text { CFU } / \mathrm{mL}\end{array}$ & $\begin{array}{l}\text { Percent growth of } \\
\text { Botrytis on plate } \\
\left(\mathrm{T}_{\mathrm{app}}=\mathbf{2 4} \mathrm{hrs}\right)\end{array}$ & $\begin{array}{c}\text { Percent growth of } \\
\text { Botrytis on plate } \\
\left(\mathrm{T}_{\mathrm{app}}=48 \mathrm{hrs}\right)\end{array}$ \\
\hline \multirow{3}{*}{$10^{-2}$} & & 25.9 & 33.4 \\
\hline & $8.6 \times 10^{4}$ & 21.4 & 27.1 \\
\hline & & 33.4 & 24.1 \\
\hline Avg & & 26.9 & 28.2 \\
\hline \multirow{3}{*}{$10^{-3}$} & & 33.4 & 30.2 \\
\hline & $8.6 \times 10^{3}$ & 22.5 & 27.1 \\
\hline & & 40.4 & 30.2 \\
\hline Avg & & 32.1 & 29.1 \\
\hline \multirow{3}{*}{$10^{-4}$} & & 0.0 & 48.1 \\
\hline & $8.6 \times 10^{2}$ & 48.1 & 44.2 \\
\hline & & 46.5 & 44.2 \\
\hline Avg & & 31.5 & 45.5 \\
\hline \multirow{3}{*}{$10^{-5}$} & & 43.4 & 33.4 \\
\hline & $8.6 \times 10^{1}$ & 46.5 & 36.8 \\
\hline & & 43.4 & 30.2 \\
\hline Avg & & 44.5 & 33.5 \\
\hline \multirow{3}{*}{$10^{-6}$} & & $\mathrm{n} / \mathrm{a}$ & 100.0 \\
\hline & $8.6 \times 10^{0}$ & $\mathrm{n} / \mathrm{a}$ & 50.0 \\
\hline & & $\mathrm{n} / \mathrm{a}$ & 20.0 \\
\hline Avg & & $\mathrm{n} / \mathrm{a}$ & 56.7 \\
\hline
\end{tabular}




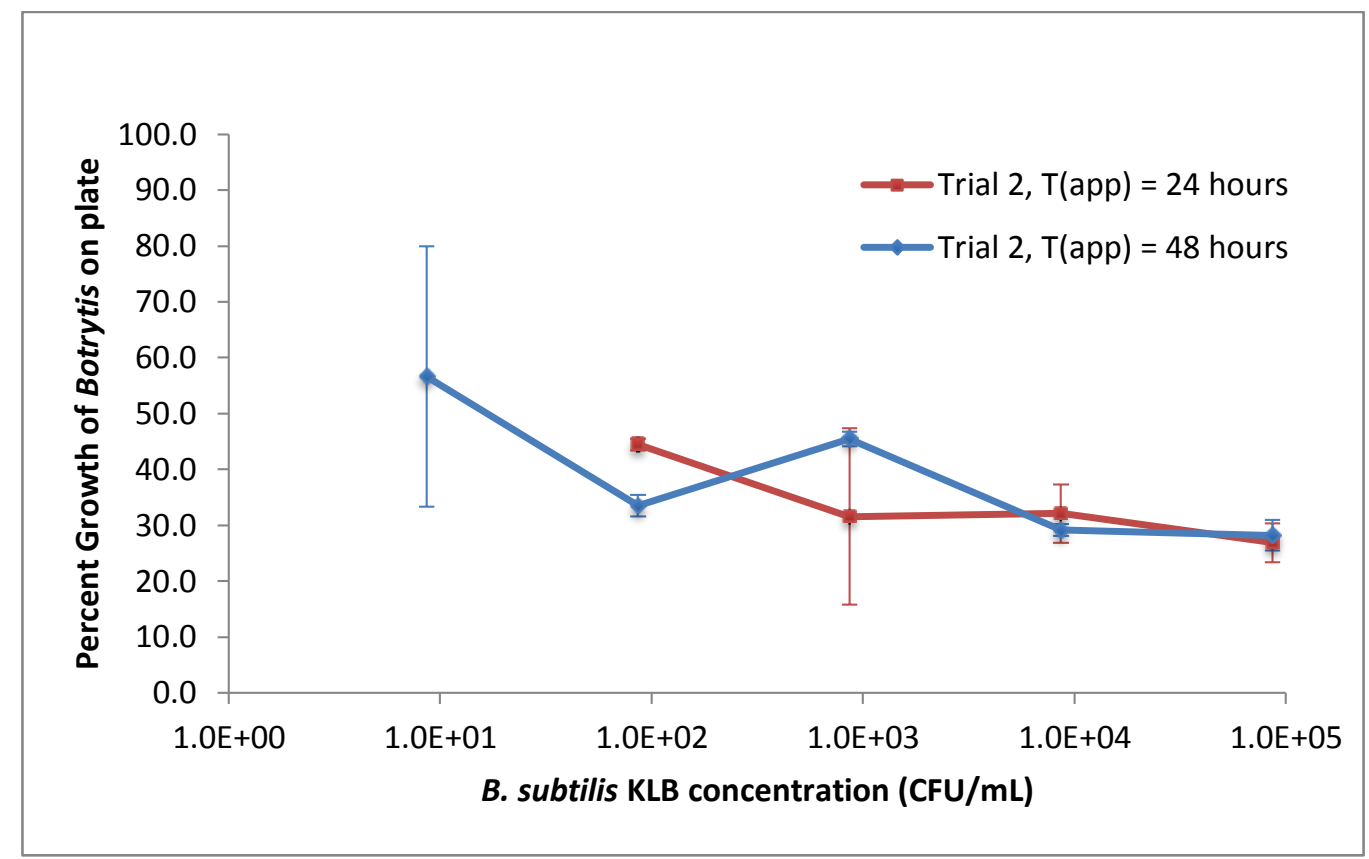

Figure 4-17. B. subtilis KLB Trial 2 data from Table 4-10.

At application times of 24 and 48 hours in Trial 2, the data (Figure 4-17 and Table 4-10) also show that as KLB concentration increased, percent growth of Botrytis on plate decreased as in Trial 1. KLB concentrations were lowered to observe a larger spectrum of concentrations against percent growth of Botrytis. Average Botrytis growth ranged from 27 to 45 percent at application time of 24 hours. Average growth ranged from 28 to 57 percent, at application time of 48 hours. No significant differences were seen between the two application times. One observation was at very low KLB concentrations, Botrytis growth was not radial and varied greatly. An example is the inhibition of Botrytis growth on plates with just $8.6 \mathrm{CFU} / \mathrm{mL}$ of KLB with application time of 48 hours. These plates contained only one or a few colonies, but they grew much larger in size compared to those on more concentrated plates and greatly inhibited Botrytis growth. As shown in 
Figure 4-17, the standard error at the lowest concentration was large, where Botrytis growth was 0,20 , and 100 percent in the triplicate plates.

Table 4-11. Trial 3 data with Botrytis application 0 and 24 hours after B. subtilis KLB spread-plated.

\begin{tabular}{cccc}
\hline $\begin{array}{c}\text { B. subtilis KLB, } \\
\text { dilution }\end{array}$ & $\begin{array}{c}\text { B. subtilis KLB, } \\
\text { CFU/mL }\end{array}$ & $\begin{array}{c}\text { Percent growth of } \\
\text { Botrytis on plate } \\
\left(\mathbf{T}_{\text {app }}=\mathbf{0} \text { hrs }\right)\end{array}$ & $\begin{array}{c}\text { Percent growth of } \\
\text { Botrytis on plate } \\
\left(\mathbf{T}_{\text {app }}=\mathbf{2 4} \text { hrs }\right)\end{array}$ \\
\hline \multirow{2}{*}{$10^{0}$} & \multirow{2}{*}{$6.6 \times 10^{6}$} & 0.0 & 0.0 \\
& & 0.0 & 0.0 \\
Avg & 0.0 & 0.0 \\
\hline \multirow{2}{*}{$10^{-1}$} & \multirow{2}{*}{$6.6 \times 10^{5}$} & 0.0 & 0.0 \\
\hline \multirow{2}{*}{ Avg } & 2.6 & 0.0 \\
& & 0.7 & 0.0 \\
\hline
\end{tabular}

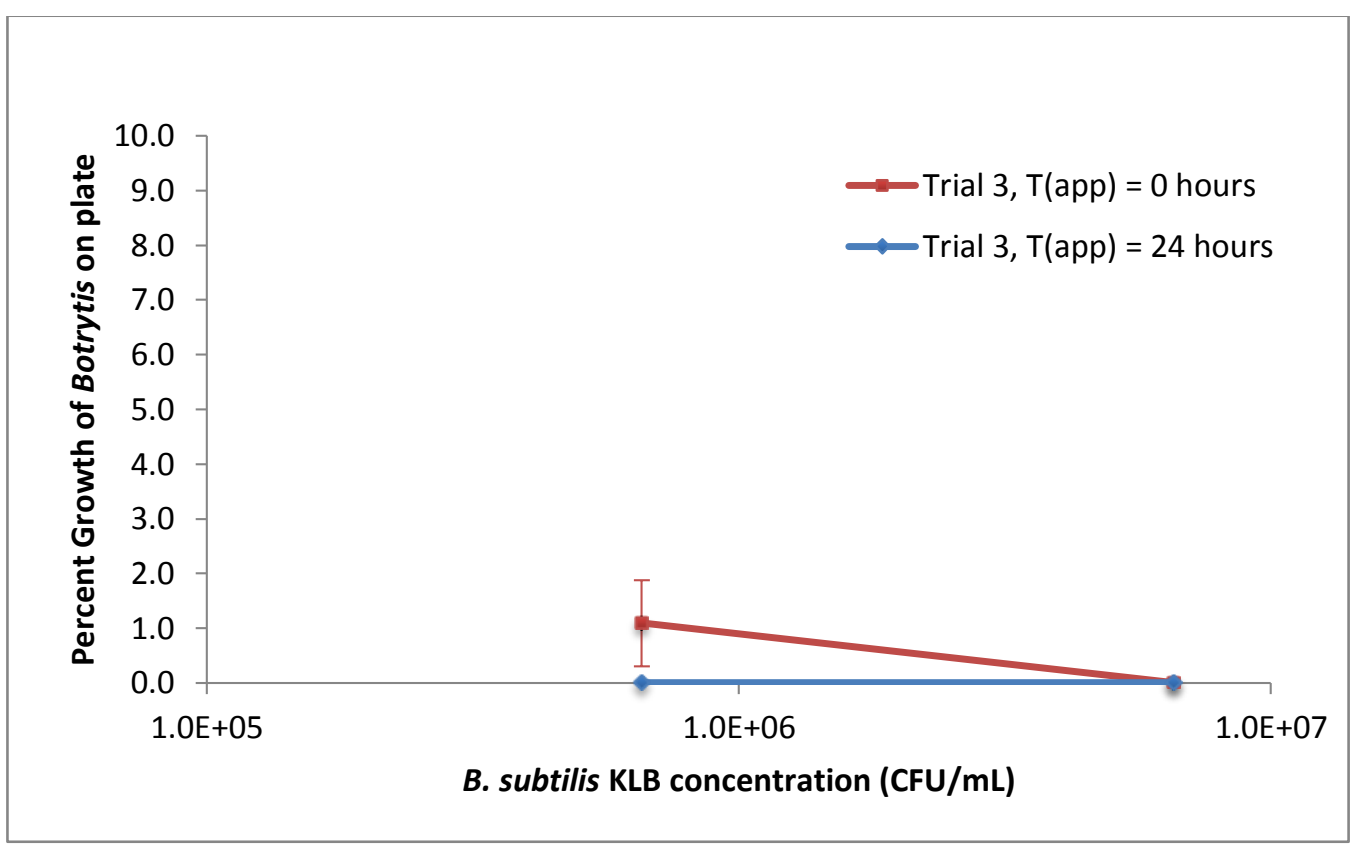

Figure 4-18. B. subtilis KLB Trial 3 data from Table 4-11. 


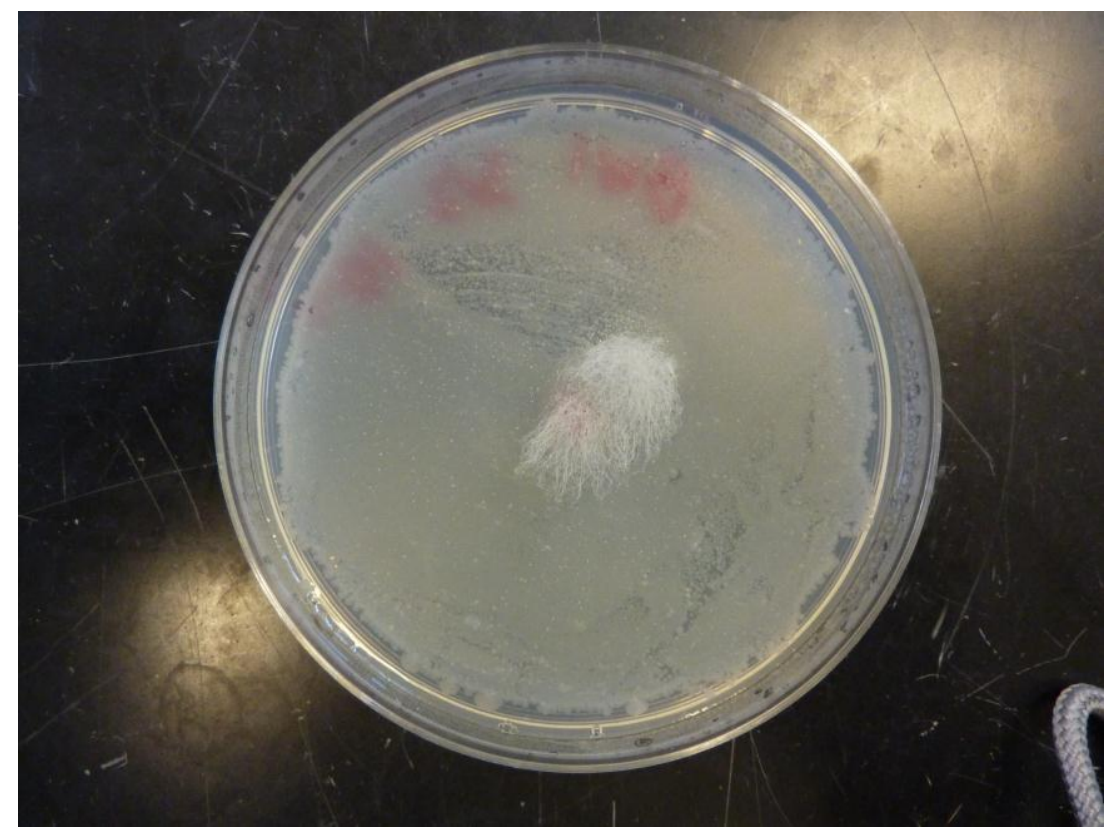

Figure 4-19. Minimal Botrytis growth (2.6 percent) at $6.6 \times 10^{5} \mathrm{CFU} / \mathrm{mL}$ of $B$. subtilis KLB in Trial 3.

At application times of 0 and 24 hours in Trial 3, the data (Figure 4-18 and Table 4-11) show nearly complete inhibition of Botrytis growth. Application time of 0 hours was tested in this trial since minimal differences were seen between application times of 24 and 48 hours in Trial 2. Another change was increasing KLB concentrations by 10 and 100 times compared to Trial 2, since the KLB concentration threshold to completely inhibit Botrytis growth was not reached in the previous trial.. Average Botrytis growth ranged from 0 to 1 percent at application time of 0 hours. Complete inhibition of Botrytis growth was seen at all KLB concentrations with application time of 24 hours. Figure 4-19 shows minimal Botrytis growth seen on plates with application time of 0 hours and $6.5 \times 10^{5} \mathrm{CFU} / \mathrm{mL}$ of KLB. The results were expected because this trial contained very large concentrations of KLB. 
Table 4-12. Trial 4 data with Botrytis application right after $B$. subtilis KLB spreadplated.

\begin{tabular}{ccc}
\hline $\begin{array}{c}\text { B. subtilis KLB, } \\
\text { dilution }\end{array}$ & $\begin{array}{c}\text { B. subtilis KLB, } \\
\text { CFU/mL }\end{array}$ & $\begin{array}{c}\text { Percent growth of } \\
\text { Botrytis on plate } \\
\left(\mathbf{T}_{\text {app }}=\mathbf{0} \text { hrs }\right)\end{array}$ \\
\hline \multirow{2}{*}{$10^{-2}$} & $4.3 \times 10^{5}$ & 22.5 \\
& & 27.1 \\
Avg & 23.6 \\
\hline \multirow{2}{*}{$10^{-3}$} & $4.3 \times 10^{4}$ & 24.4 \\
\hline Avg & & 70.0 \\
\multirow{2}{*}{$10^{-4}$} & & 60.0 \\
& \multirow{3}{*}{$4.3 \times 10^{3}$} & 80.0 \\
\hline Avg & & 70.0 \\
\hline \multirow{2}{*}{$10^{-5}$} & & 100.0 \\
& $4.3 \times 10^{2}$ & 100.0 \\
Avg & 100.0 \\
\hline
\end{tabular}




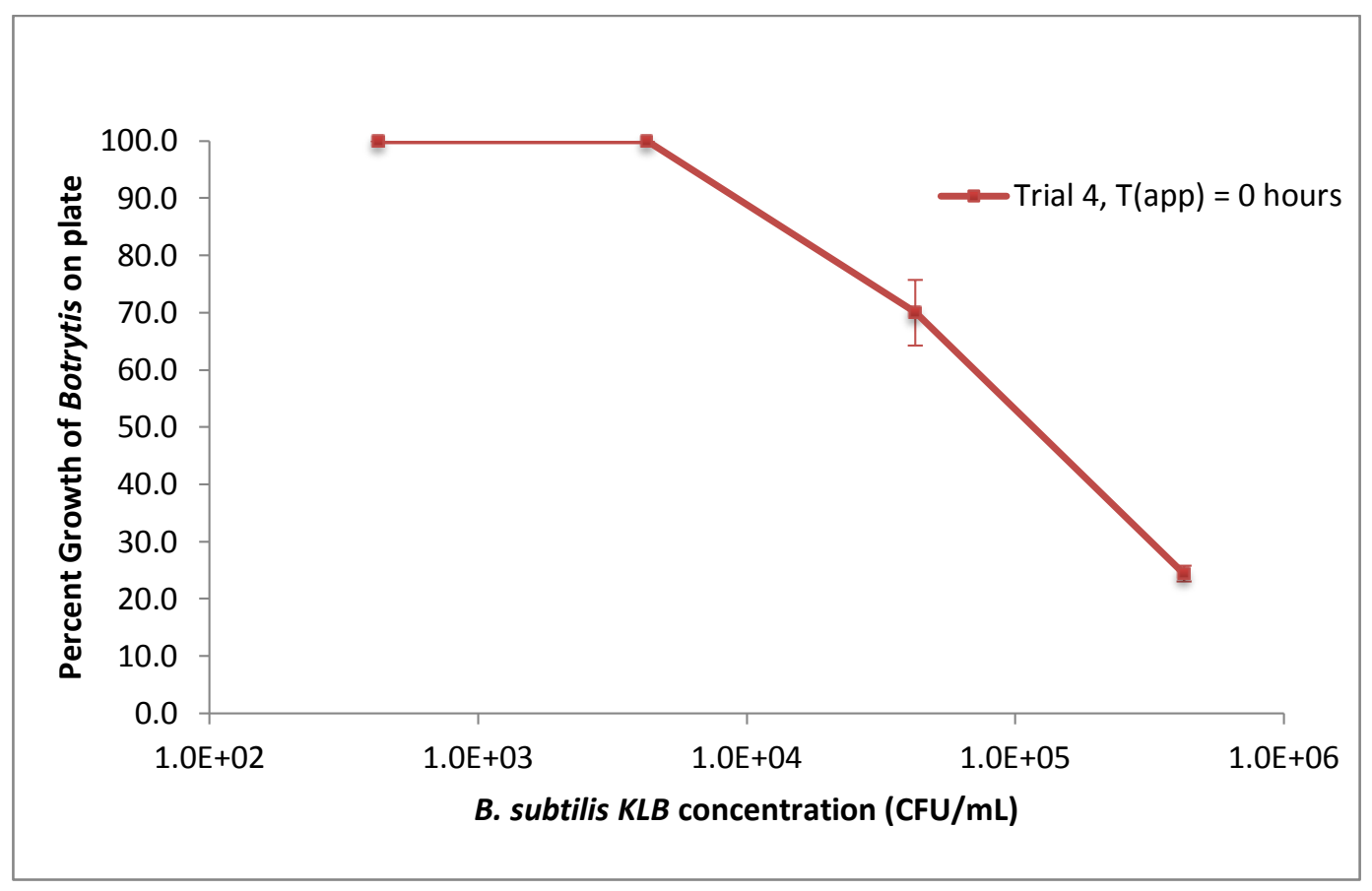

Figure 4-20. B. subtilis KLB Trial 4 data from Table 4-12.

At application time of 0 hours in Trial 4, the data (Figure 4-20 and Table 4-12) show a very strong relationship between the increase in KLB concentration and the decrease in percent growth of Botrytis on plate. In Trial 4, the goal was to determine the KLB concentration threshold to completely inhibit Botrytis growth at application time of 0 hours. At $4.3 \times 10^{2}$ and $4.3 \times 10^{3} \mathrm{CFU} / \mathrm{mL}$, all triplicate plates were completely filled with Botrytis (100 percent growth). Average Botrytis growth was 70 percent at $4.3 \times 10^{4}$ $\mathrm{CFU} / \mathrm{mL}$ and 24 percent at $4.3 \times 10^{5} \mathrm{CFU} / \mathrm{mL}$. By following the trend of the graph, complete inhibition of Botrytis growth would be predicted if KLB concentration was increased ten-fold to $4.3 \times 10^{6} \mathrm{CFU} / \mathrm{mL}$. 
Table 4-13. Trial 5 data with Botrytis application right after B. subtilis KLB spreadplated.

\begin{tabular}{ccc}
$\begin{array}{c}\text { B. subtilis KLB, } \\
\text { dilution }\end{array}$ & $\begin{array}{c}\text { B. subtilis KLB, } \\
\text { CFU/mL }\end{array}$ & $\begin{array}{c}\text { Percent growth of } \\
\text { Botrytis on plate } \\
\left(\mathbf{T}_{\text {app }}=\mathbf{0} \text { hrs }\right)\end{array}$ \\
\hline \multirow{2}{*}{$10^{\circ}$} & $5.6 \times 10^{6}$ & 7.1 \\
& & 10.5 \\
Avg & & 7.7 \\
\hline \multirow{2}{*}{$10^{-1}$} & \multirow{2}{*}{$5.6 \times 10^{5}$} & 8.4 \\
\hline \multirow{2}{*}{ Avg } & & 11.2 \\
\multirow{2}{*}{$10^{-2}$} & & 21.4 \\
& & 15.4 \\
\hline Avg & $5.6 \times 10^{4}$ & 16.0 \\
\hline
\end{tabular}

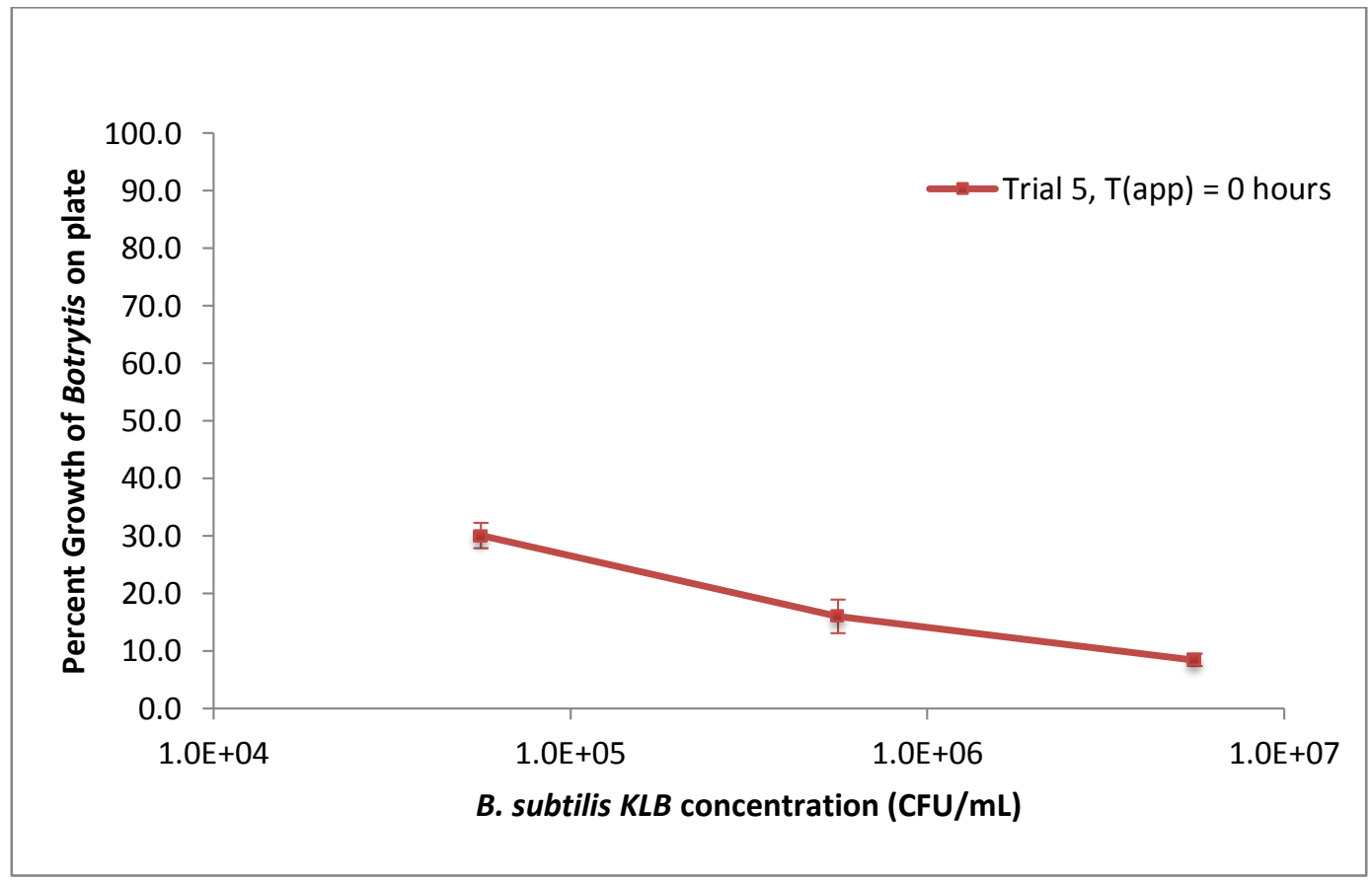

Figure 4-21. B. subtilis KLB Trial 5 data from Table 4-13. 
At application time of 0 hours in Trial 5 (Figure 4-21 and Table 4-13), the highest KLB concentration was approximately 10 times higher, at $5.6 \times 10^{6} \mathrm{CFU} / \mathrm{mL}$, compared to in Trial $4\left(4.3 \times 10^{5} \mathrm{CFU} / \mathrm{mL}\right)$. Average Botrytis growth was 16 percent at $5.6 \times 10^{5}$ $\mathrm{CFU} / \mathrm{mL}$ of KLB and 8 percent at $5.6 \times 10^{6} \mathrm{CFU} / \mathrm{mL}$. As a comparison, average growth was 24 percent at $4.3 \times 10^{5} \mathrm{CFU} / \mathrm{mL}$ in Trial 4. Although complete Botrytis inhibition did not occur at $5.6 \times 10^{6} \mathrm{CFU} / \mathrm{mL}$ of $\mathrm{KLB}$, average growth was limited to 8 percent.

Table 4-14. Trial 6 data with Botrytis application 24 and 48 hours after $B$. subtilis KLB spread-plated.

\begin{tabular}{cccc}
\hline $\begin{array}{c}\text { B. subtilis KLB, } \\
\text { dilution }\end{array}$ & $\begin{array}{c}\text { B. subtilis KLB, } \\
\text { CFU/mL }\end{array}$ & $\begin{array}{c}\text { Percent growth of } \\
\text { Botrytis on plate } \\
\left(\mathbf{T}_{\text {app }}=\mathbf{2 4} \text { hrs }\right)\end{array}$ & $\begin{array}{c}\text { Percent growth of } \\
\text { Botrytis on plate } \\
\left(\mathbf{T}_{\text {app }}=\mathbf{4 8} \text { hrs }\right)\end{array}$ \\
\hline \multirow{2}{*}{$10^{-3}$} & $5.3 \times 10^{4}$ & 0.0 & 0.0 \\
& & 0.0 & 0.0 \\
Avg & 0.0 & 0.0 \\
\hline \multirow{2}{*}{$10^{-4}$} & \multirow{2}{*}{$5.3 \times 10^{3}$} & 0.0 & 0.0 \\
\hline Avg & & 0.0 & 0.0 \\
\hline \multirow{2}{*}{$10^{-5}$} & & 0.0 & 0.0 \\
& \multirow{3}{*}{$5.3 \times 10^{2}$} & 25.0 & 0.0 \\
\hline Avg & 8.3 & 0.0 \\
\hline
\end{tabular}




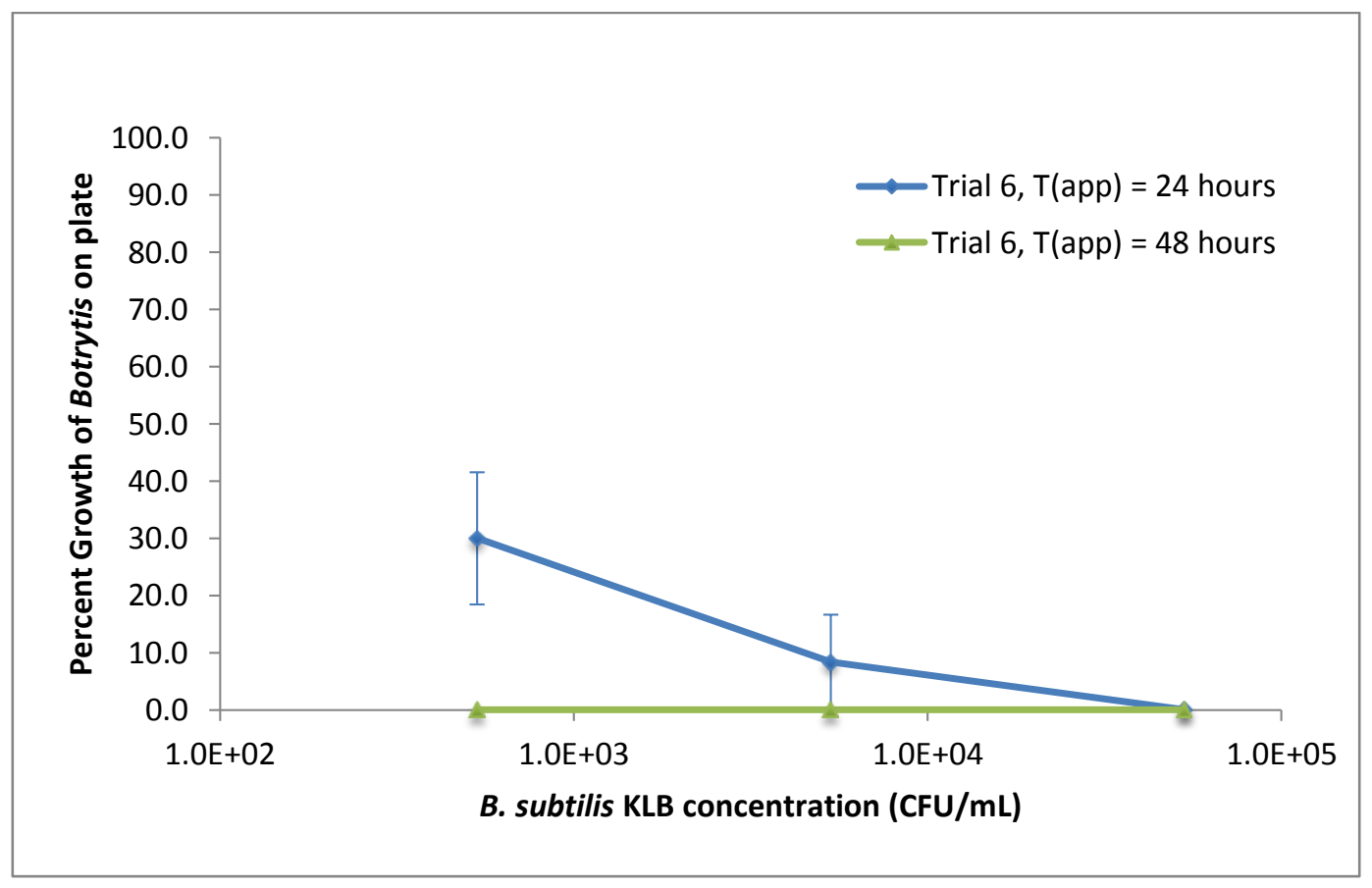

Figure 4-22. B. subtilis KLB Trial 6 data from Table 4-14.

Trial 6 (Figure 4-22 and Table 4-14) was mainly a repeat of Trial 2, with application times of 24 and 48 hours and very similar KLB concentrations used. Trial 2 conditions were revisited because KLB concentration thresholds were determined at application time of 0 hours (Trial 5). Average Botrytis growth ranged from 0 to 30 percent at application time of 24 hours. Complete inhibition of growth was seen at $5.3 \times 10^{4} \mathrm{CFU} / \mathrm{mL}$ of KLB. At application time of 48 hours, complete inhibition of growth was seen at all KLB concentrations. This was in contrast to Trial 2, in which average growth was 27 to 28 percent at $8.6 \times 10^{4} \mathrm{CFU} / \mathrm{mL}$ for both application times of 24 and 48 hours. Although conditions were identical between Trial 2 and Trial 6, the difference may be attributed to different growth phases of certain KLB colonies. For example, select colonies may grow 
larger than others and consume most of the nutrients in the agar, which inhibit the growth of smaller colonies. From observation of the plates, these larger colonies greatly inhibited Botrytis growth.

Table 4-15. Trial 7 data with Botrytis application 24 and 48 hours after B. subtilis KLB spread-plated.

\begin{tabular}{|c|c|c|c|}
\hline $\begin{array}{c}\text { B. subtilis KLB, } \\
\text { dilution }\end{array}$ & $\begin{array}{c}\text { B. subtilis KLB, } \\
\text { CFU/mL }\end{array}$ & $\begin{array}{c}\text { Percent growth of } \\
\text { Botrytis on plate } \\
\left(\mathrm{T}_{\mathrm{app}}=24 \mathrm{hrs}\right)\end{array}$ & $\begin{array}{c}\text { Percent growth of } \\
\text { Botrytis on plate } \\
\left(\mathrm{T}_{\mathrm{app}}=48 \mathrm{hrs}\right)\end{array}$ \\
\hline \multirow{3}{*}{$10^{-3}$} & & 0.0 & 0.0 \\
\hline & $4.3 \times 10^{4}$ & 0.0 & 0.0 \\
\hline & & 0.0 & 2.0 \\
\hline \multirow[t]{2}{*}{ Avg } & & 0.0 & 0.7 \\
\hline & & 0.0 & 1.6 \\
\hline \multirow[t]{2}{*}{$10^{-4}$} & $4.3 \times 10^{3}$ & 3.9 & 0.0 \\
\hline & & 23.6 & 30.0 \\
\hline \multirow[t]{2}{*}{ Avg } & & 9.1 & 10.5 \\
\hline & & 80.0 & 0.0 \\
\hline \multirow[t]{2}{*}{$10^{-5}$} & $4.3 \times 10^{2}$ & 90.0 & 2.3 \\
\hline & & 95.0 & 35.0 \\
\hline \multirow[t]{2}{*}{ Avg } & & 88.3 & 12.4 \\
\hline & & 55.0 & 90.0 \\
\hline \multirow[t]{2}{*}{$10^{-6}$} & $4.3 \times 10^{1}$ & 85.0 & 100.0 \\
\hline & & 65.0 & 85.0 \\
\hline Avg & & 68.3 & 91.7 \\
\hline
\end{tabular}




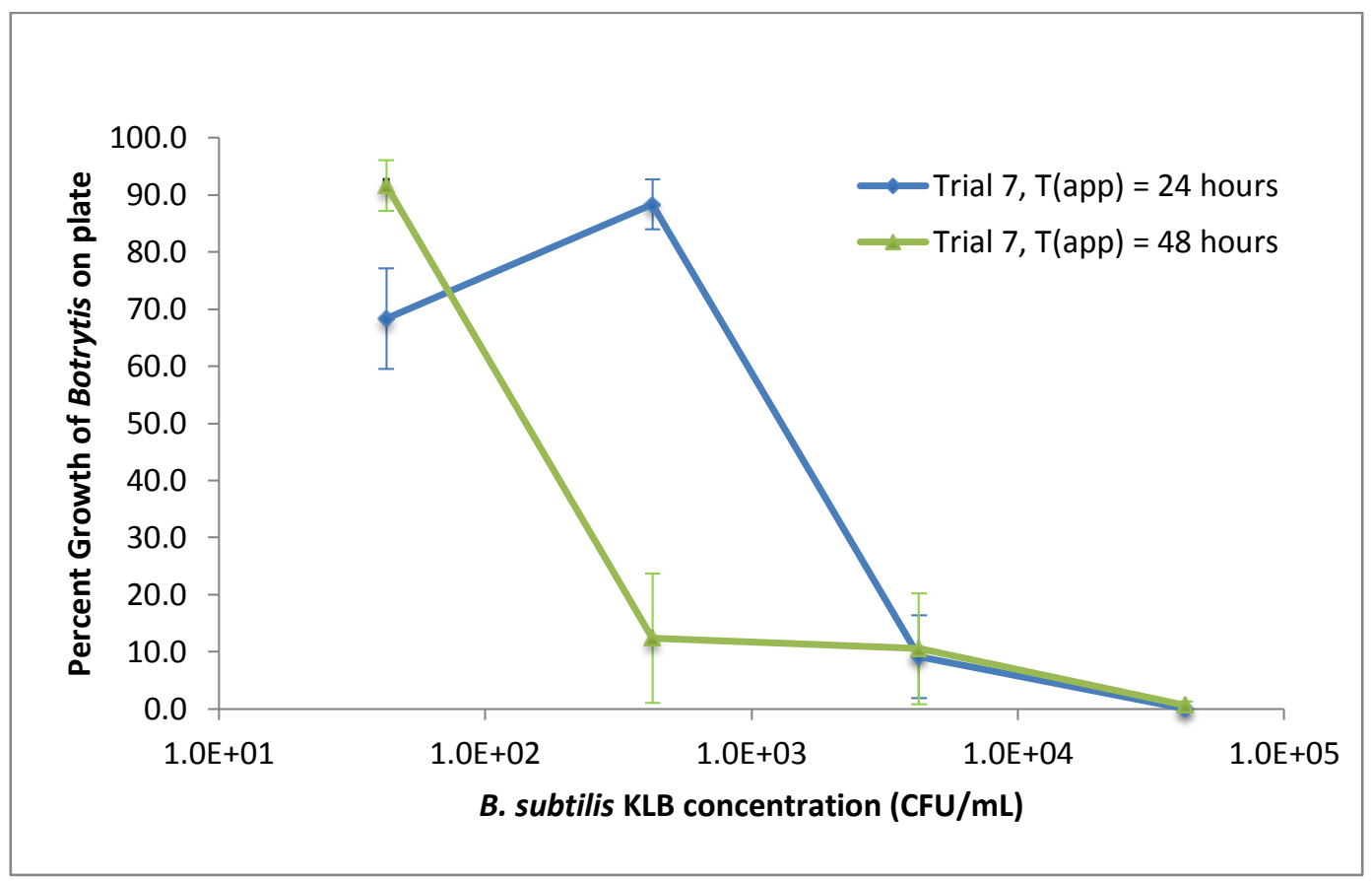

Figure 4-23. B. subtilis KLB Trial 7 data from Table 4-15.

Trial 7 (Figure 4-23 and Table 4-15) was a repeat of Trial 6, with application times of 24 and 48 hours. For both application times, complete inhibition of Botrytis growth was seen at $4.3 \times 10^{4} \mathrm{CFU} / \mathrm{mL}$ of KLB and approximately 10 percent growth at $4.3 \times 10^{3}$ $\mathrm{CFU} / \mathrm{mL}$. For application time of 48 hours, complete inhibition of growth was seen at all KLB concentrations. The KLB concentration threshold to completely inhibit Botrytis growth, at $4.3 \times 10^{3} \mathrm{CFU} / \mathrm{mL}$, was similar to the threshold in Trial 6, at $5.3 \times 10^{3}$ $\mathrm{CFU} / \mathrm{mL}$. 
Table 4-16. Trial 8 data with Botrytis application 24 and 48 hours after $B$. subtilis KLB spread-plated.

\begin{tabular}{|c|c|c|c|}
\hline $\begin{array}{c}\text { B. subtilis KLB, } \\
\text { dilution }\end{array}$ & $\begin{array}{c}\text { B. subtilis KLB, } \\
\text { CFU/mL }\end{array}$ & $\begin{array}{c}\text { Percent growth of } \\
\text { Botrytis on plate } \\
\left(\mathrm{T}_{\mathrm{app}}=\mathbf{2 4 \mathrm { hrs } )}\right. \\
\end{array}$ & $\begin{array}{c}\text { Percent growth of } \\
\text { Botrytis on plate } \\
\left(\mathrm{T}_{\mathrm{app}}=48 \mathrm{hrs}\right) \\
\end{array}$ \\
\hline \multirow{3}{*}{$10^{-3}$} & & 0.0 & 9.0 \\
\hline & $4.0 \times 10^{4}$ & 0.0 & 16.4 \\
\hline & & 0.0 & 12.0 \\
\hline Avg & & 0.0 & 12.5 \\
\hline \multirow{3}{*}{$10^{-4}$} & & 10.0 & 0.0 \\
\hline & $4.0 \times 10^{3}$ & 75.0 & 0.0 \\
\hline & & 50.0 & 15.0 \\
\hline Avg & & 45.0 & 5.0 \\
\hline \multirow{3}{*}{$10^{-5}$} & & 90.0 & 50.0 \\
\hline & $4.0 \times 10^{2}$ & 75.0 & 50.0 \\
\hline & & 75.0 & 65.0 \\
\hline Avg & & 80.0 & 55.0 \\
\hline \multirow{3}{*}{$10^{-6}$} & & 90.0 & 90.0 \\
\hline & $4.0 \times 10^{1}$ & 90.0 & 75.0 \\
\hline & & 85.0 & 15.0 \\
\hline Avg & & 88.3 & 60.0 \\
\hline
\end{tabular}




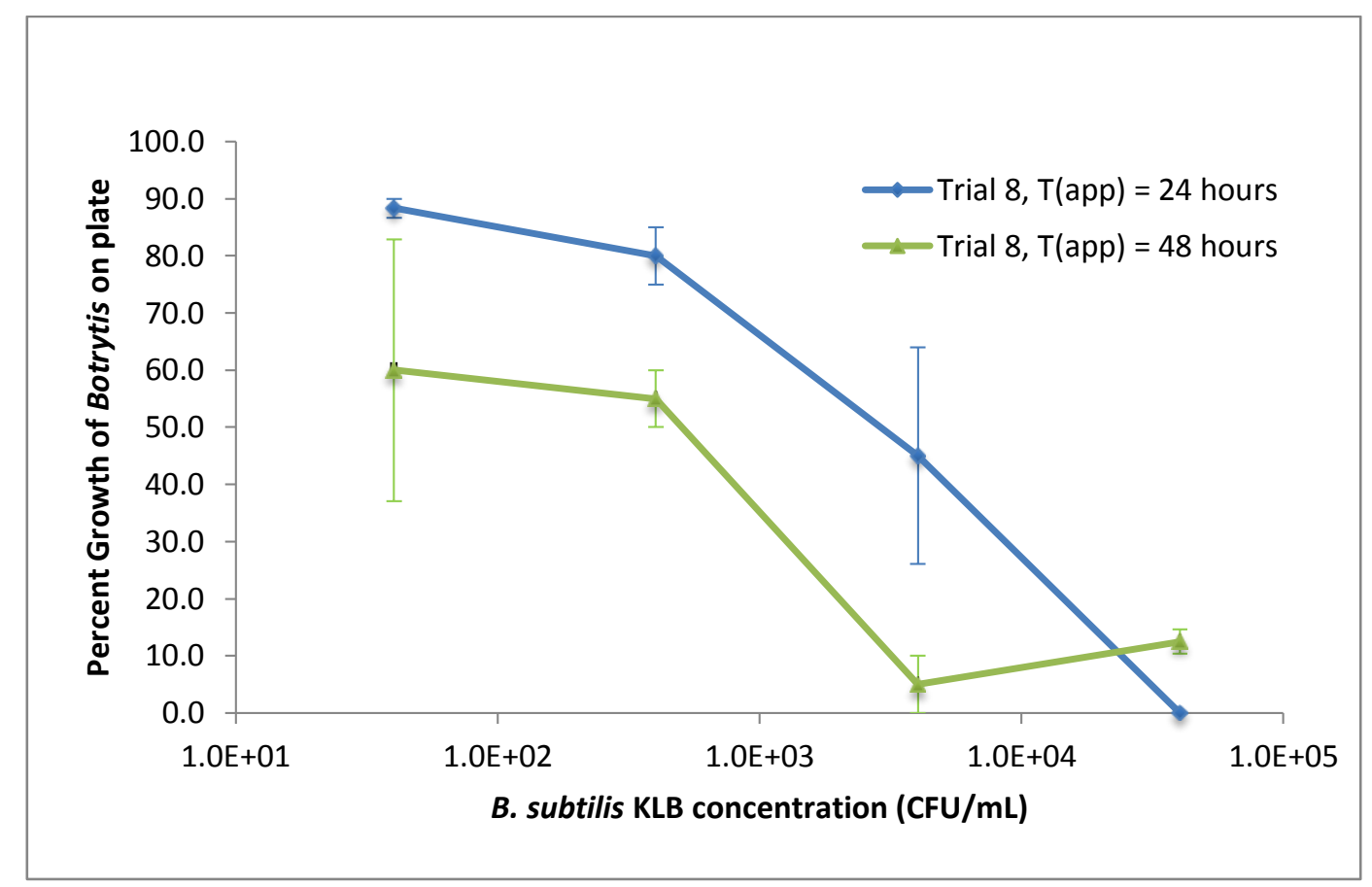

Figure 4-24. B. subtilis KLB Trial 8 data from Table 4-16.

Trial 8 (Figure 4-24 and Table 4-16) was a repeat of Trial 6 and Trial 7, with application times of 24 and 48 hours. At application time of 24 hours, complete inhibition of Botrytis growth was seen at $4.0 \times 10^{4} \mathrm{CFU} / \mathrm{mL}$ of KLB. At application time of 48 hours, average growth was 13 percent at $4.0 \times 10^{4} \mathrm{CFU} / \mathrm{mL}$ and even lower at 5 percent when KLB concentration was reduced ten-fold, at $4.0 \times 10^{4} \mathrm{CFU} / \mathrm{mL}$. Botrytis growth was minimal starting at a KLB concentration of $4.0 \times 10^{3} \mathrm{CFU} / \mathrm{mL}$. 
Table 4-17. Trial 9 data with Botrytis application 0, 24, and 48 hours after B. subtilis KLB spread-plated.

\begin{tabular}{|c|c|c|c|c|}
\hline $\begin{array}{c}\text { B. subtilis } \\
\text { KLB, dilution }\end{array}$ & $\begin{array}{c}\text { B. subtilis } \\
\text { KLB, CFU/mL }\end{array}$ & $\begin{array}{c}\text { Percent growth of } \\
\text { Botrytis on plate } \\
\left(\mathrm{T}_{\mathrm{app}}=0 \mathrm{hrs}\right)\end{array}$ & $\begin{array}{c}\text { Percent growth of } \\
\text { Botrytis on plate } \\
\left(\mathrm{T}_{\text {app }}=\mathbf{2 4} \mathrm{hrs}\right)\end{array}$ & $\begin{array}{c}\text { Percent growth of } \\
\text { Botrytis on plate } \\
\left(\mathrm{T}_{\mathrm{app}}=48 \mathrm{hrs}\right)\end{array}$ \\
\hline \multirow{3}{*}{$10^{-2}$} & & 10.5 & 0.0 & 0.0 \\
\hline & $4.3 \times 10^{5}$ & 12.0 & 0.0 & 0.0 \\
\hline & & 13.7 & 0.0 & 0.0 \\
\hline \multirow[t]{2}{*}{ Avg } & & 12.1 & 0.0 & 0.0 \\
\hline & & 45.0 & 0.0 & 0.0 \\
\hline \multirow[t]{2}{*}{$10^{-3}$} & $4.3 \times 10^{4}$ & 45.0 & 0.0 & 0.0 \\
\hline & & 30.0 & 0.0 & 0.0 \\
\hline \multirow[t]{2}{*}{ Avg } & & 40.0 & 0.0 & 0.0 \\
\hline & & 75.0 & 0.0 & 0.0 \\
\hline \multirow[t]{2}{*}{$10^{-4}$} & $4.3 \times 10^{3}$ & 85.0 & 0.0 & 0.0 \\
\hline & & 70.0 & 2.6 & 0.0 \\
\hline Avg & & 76.7 & 0.9 & 0.0 \\
\hline
\end{tabular}

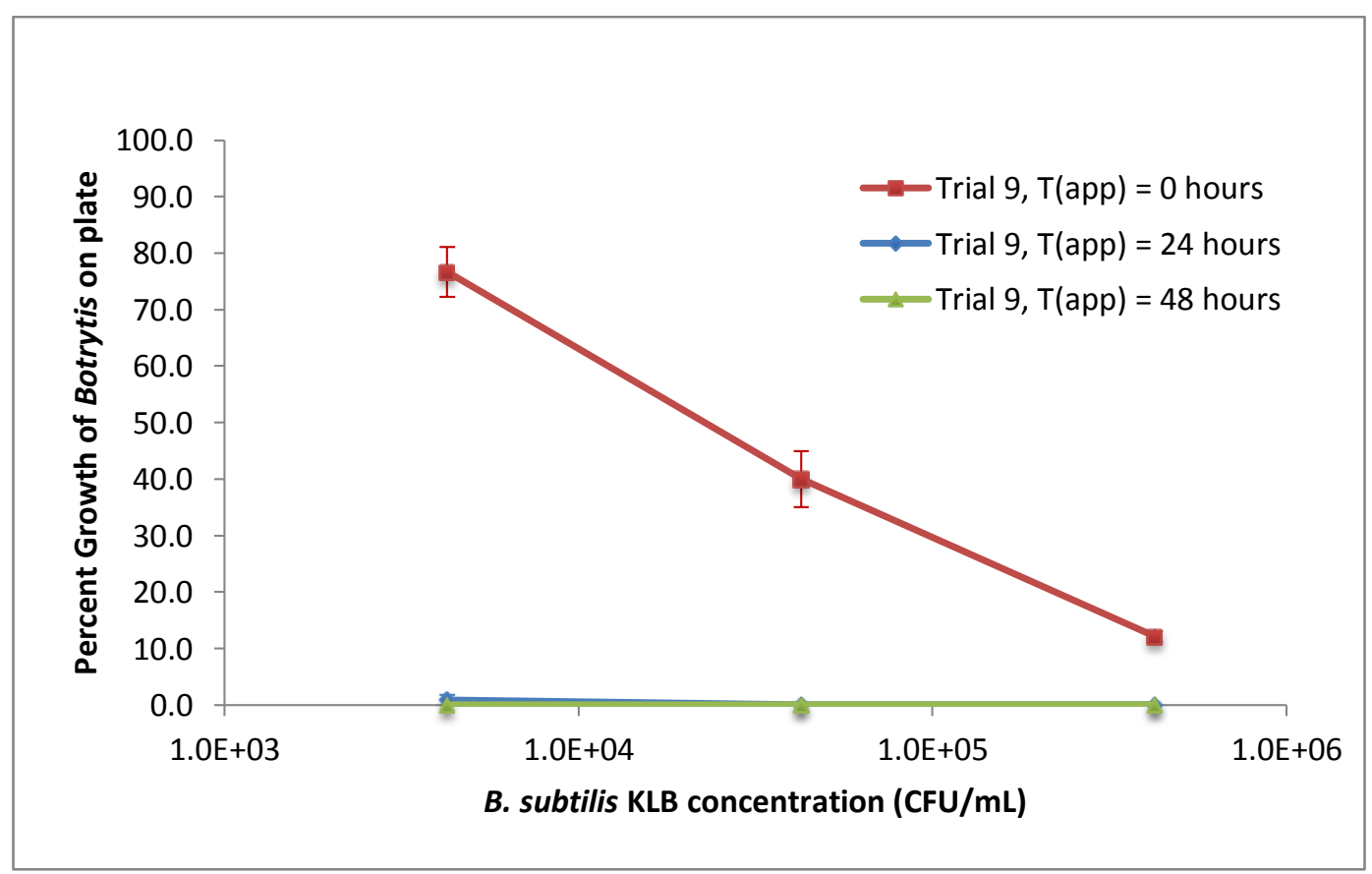

Figure 4-25. B. subtilis KLB Trial 9 data from Table 4-17. 
Trial 9 (Figure 4-25 and Table 4-17) was based on the culmination of all eight previous trials. Application times of 0,24 , and 48 hours were tested. KLB concentrations used were within the threshold range for complete inhibition of Botrytis at the respective application times. At application times of 24 and 48 hours, complete or nearly complete inhibition was seen at all KLB concentrations, from $4.3 \times 10^{3} \mathrm{CFU} / \mathrm{mL}$ to $4.3 \times 10^{5}$ $\mathrm{CFU} / \mathrm{mL}$. At application time of 0 hours, a strong inverse relationship between Botrytis growth and KLB concentration was evident, with growth ranging from 12 percent at $4.3 \mathrm{x}$ $10^{5} \mathrm{CFU} / \mathrm{mL}$ to 77 percent at $4.3 \times 10^{3} \mathrm{CFU} / \mathrm{mL}$. This suggested that inoculating KLB prior to inoculating Botrytis, either at application time of 24 or 48 hours, contributed to inhibition of Botrytis growth.

\subsubsection{Statistical Data of Trials 1-9 Combined}

The two goals were to predict $B$. subtilis KLB concentration thresholds for complete Botrytis inhibition as well as to predict the relationship between Botrytis growth and KLB concentration at different application times. One possibility is that at a greater application time, Botrytis inhibition is less dependent on KLB concentration. At higher application times, KLB colonies will have matured and formed inhibition zones to inhibit Botrytis growth.

All data from the nine trials were transferred onto Minitab. An equation was predicted to estimate percent growth of Botrytis as a function of Botrytis application time and log 
concentration of KLB. The data were fitted using linear regression on a semi-log plot (Figure 4-26).

Botrytis growth data of $6.6 \times 10^{5}$ and $6.6 \times 10^{6} \mathrm{CFU} / \mathrm{mL}$ of KLB (Trial 3, Figure 4-18) at application time of 24 hours were omitted because complete Botrytis inhibition was already seen at a lower KLB concentration of $4.3 \times 10^{5} \mathrm{CFU} / \mathrm{mL}$ (Trial 9, Figure 4-25). These outliers may have skewed the equation to predict higher KLB concentration thresholds.

Complete Botrytis inhibition was seen on many plates below the threshold KLB concentrations, but these data were not omitted because at least one of the plates in triplicate contained Botrytis growth. An example is in Trial 3 (Figure 4-18), in which Botrytis growth percentages were 0, 0.7, and 2.6 percent at application time of 0 hours and $6.6 \times 10^{5} \mathrm{CFU} / \mathrm{mL}$ of KLB. 


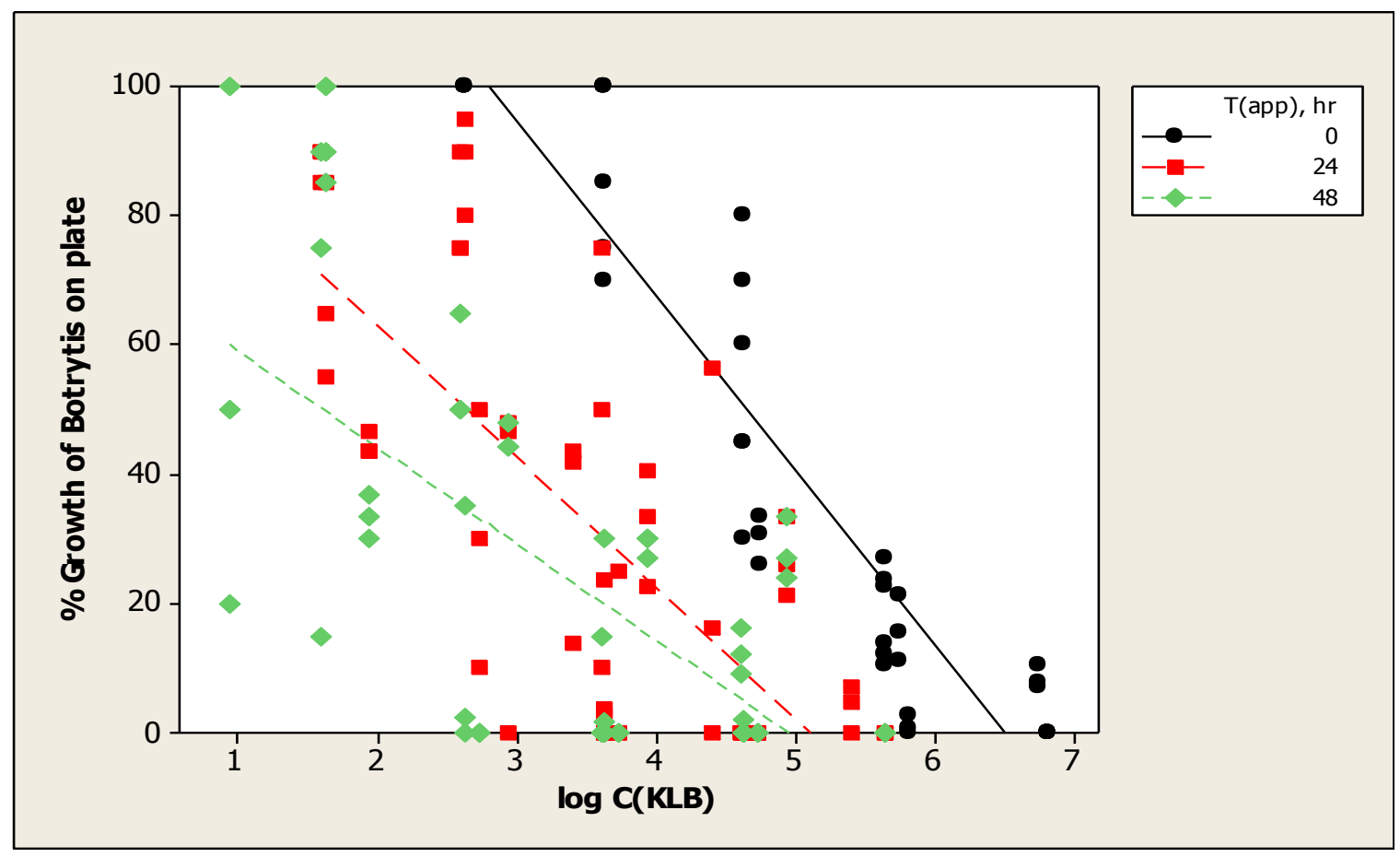

Figure 4-26. Linear regression graphs of all three Botrytis application times of 0, 24, and 48 hours from data of all nine trials.

The equation to model Figure 4-26 data was as follows:

Predicted Percent Growth of Botrytis on plate $=$

$127-0.928 \mathrm{~T}_{\text {app }}-18.6 \log \mathrm{C}_{\mathrm{KLB}}\left(\mathrm{R}^{2}=0.55\right.$, from Appendix $\left.\mathrm{A}\right)$

The predicted KLB concentration thresholds are shown as y-intercepts in Figure 4-26, where percent growth of Botrytis on plate is 0 percent. At the three application times, the predicted threshold KLB concentrations are as follows:

$\mathrm{T}_{\mathrm{app}}=0$ hours: $\mathrm{C}_{\mathrm{KLB}}=3.2 \times 10^{6} \mathrm{CFU} / \mathrm{mL}$

$\mathrm{T}_{\text {app }}=24$ hours: $\mathrm{C}_{\mathrm{KLB}}=1.3 \times 10^{5} \mathrm{CFU} / \mathrm{mL}$

$\mathrm{T}_{\text {app }}=48$ hours: $\mathrm{C}_{\mathrm{KLB}}=9.1 \times 10^{4} \mathrm{CFU} / \mathrm{mL}$ 
The predicted threshold KLB concentration at application time of 0 hours was more than one log greater compared to predicted thresholds at application times of 24 and 48 hours. KLB colonies were already established on the plates at 24 and 48 hours as opposed to at 0 hours, in which KLB was inoculated at the same time as Botrytis.

The model in Figure 4-27 predicts the relationship between Botrytis growth and log KLB concentration at different application times. Figure 4-27 is a truncated version of Figure 4-26, in which all data at less than $2.5 \times 10^{3} \mathrm{CFU} / \mathrm{mL}$ of KLB were removed. The reason for truncation was to focus on KLB concentrations closer to the predicted thresholds. In addition, future in vivo strawberry field trials will likely involve higher KLB concentrations to completely inhibit Botrytis growth.

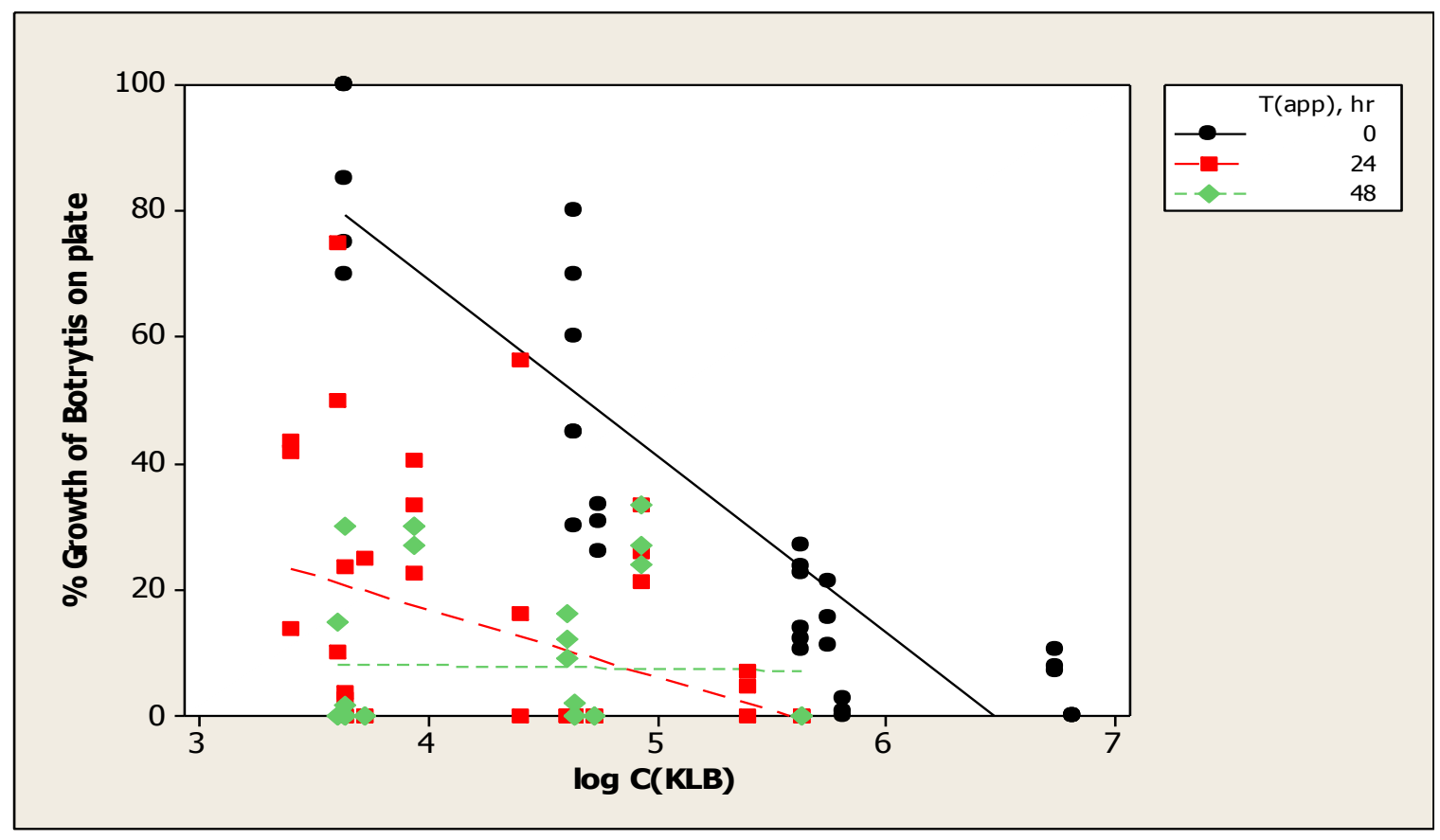

Figure 4-27. Truncated version of Figure 4-26 with only data containing $B$. subtilis KLB concentrations greater than $2.5 \times 10^{3} \mathrm{CFU} / \mathrm{mL}$. 
The equation to model the truncated data in Figure 4-27 was as follows: Predicted Percent Growth of Botrytis = $143-2.93 \mathrm{~T}_{\mathrm{app}}-22.1 \log \mathrm{C}_{\mathrm{KLB}}+0.453$ interaction $\left(\mathrm{R}^{2}=0.50\right.$, from Appendix $\left.\mathrm{A}\right)$

The interaction term predicts whether at least one of the slopes is "different" from the others. The slope is explained as the reduction in the percent growth of Botrytis on plate per $\log$ increase in KLB concentration. Since the interaction term was significant (Pvalue $<0.05$, ) at least one of the three slopes is predicted to be "different" from the others (Appendix A). The interaction terms between 0 and 48 hours, and 0 and 24 hours were significant, which means that the slope at application time of 0 hours was "different" from the others. The interaction term between 24 and 48 hours was not significant, which means there was not enough evidence to conclude that the two slopes are "different" from each other. In other words, the dependence of KLB concentration on Botrytis inhibition was different at application time of 0 hours compared to at 24 and 48 hours. 


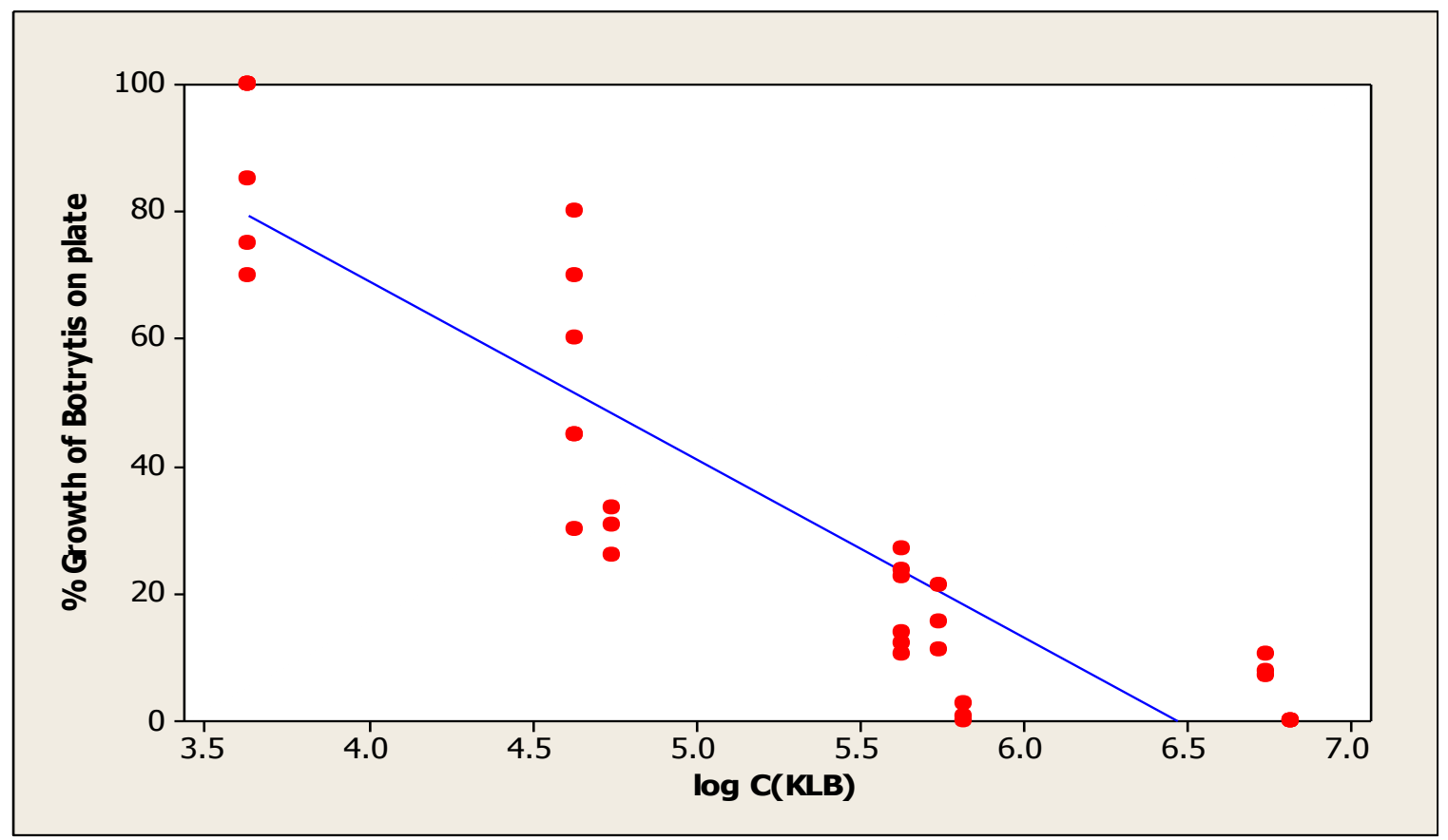

Figure 4-28. Linear regression graph with truncated data from application time of 0 hours.

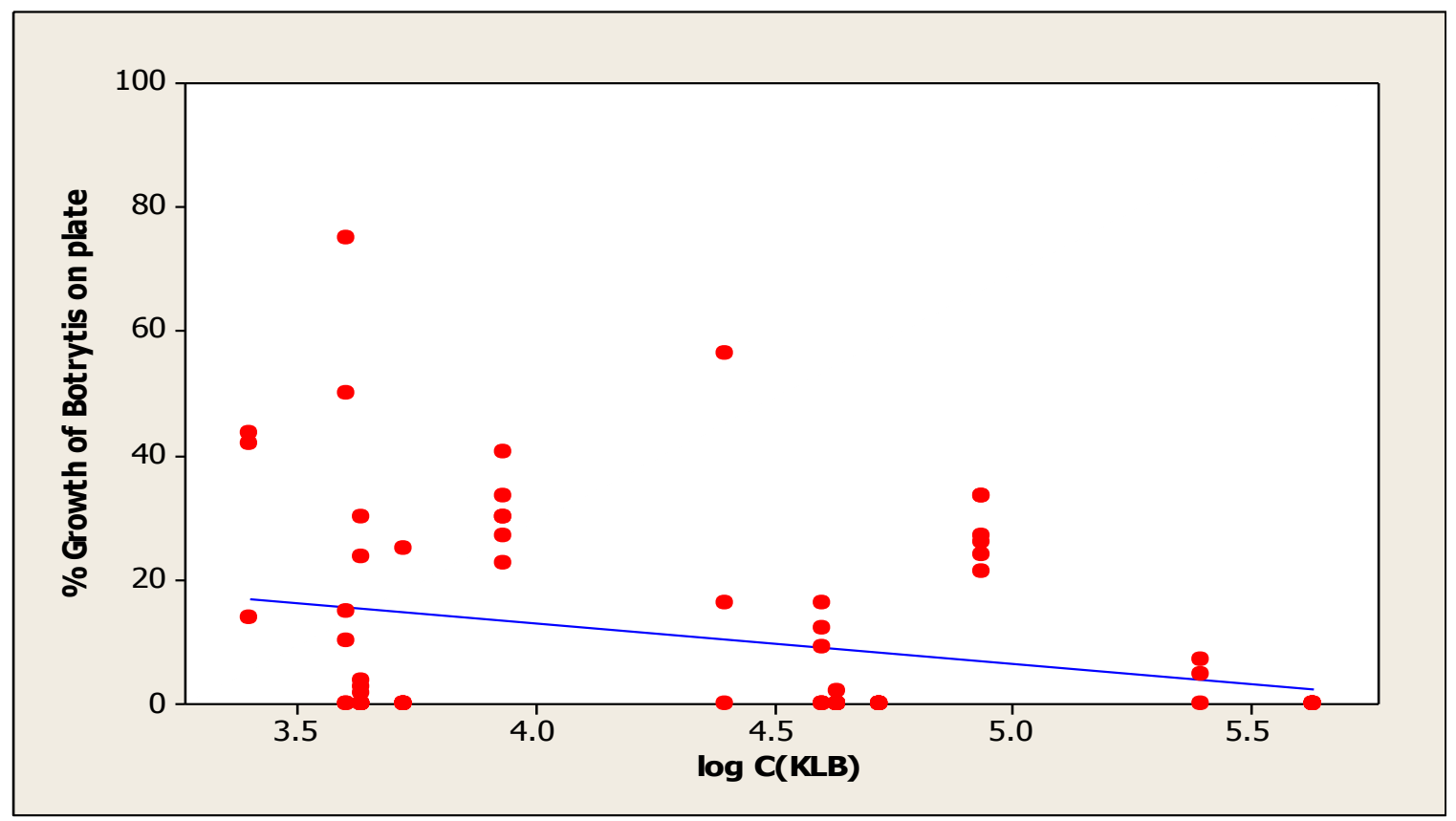

Figure 4-29. Linear regression graph with combined truncated data from application times of 24 and 48 hours. 
Two regression equations were predicted, one at application time at 0 hours and the other with combined data at 24 and 48 hours. The two equations were as follows (from Appendix A):

$\mathrm{T}_{\mathrm{app}}=0$ hours (Figure 4-28):

Predicted Percent Growth of Botrytis on plate $=181-28.0 \log \mathrm{C}_{\mathrm{KLB}}\left(\mathrm{R}^{2}=0.81\right)$ $\mathrm{T}_{\text {app }}=24$ and 48 hours (Figure 4-29):

Predicted Percent Growth of Botrytis on plate $=38.9-6.49 \log \mathrm{C}_{\mathrm{KLB}}\left(\mathrm{R}^{2}=0.07\right)$

At application time of 0 hours, a one-log increase in KLB concentration resulted in a 28 percent decrease in Botrytis growth. At application times of 24 and 48 hours, a one-log increase in concentration resulted only in a 6.5 percent decrease in growth. However, the $R^{2}$ value for the equation at application times of 24 and 48 hours is only 0.07 (Figure 4-29). One of the reasons for the low $R^{2}$ value is because at lower KLB concentrations, Botrytis growth widely varied from plate to plate. Some plates completely inhibited Botrytis growth while other plates contained substantial growth especially at lower KLB concentrations. KLB colonies in some plates varied in size, in which larger colonies typically contained a larger inhibition zone. Therefore, KLB concentration did not matter as long as KLB colonies had time to grow. 


\subsection{Initial Carbon Source Screening Results}

Tapioca and molasses were screened as commercially available carbon source alternatives for growth of $B$. subtilis KLB. Experiment 1 was conducted twice (Trials 1.1 and 1.2) and consisted of the two carbon sources at 5, 15, and $25 \mathrm{~g} / \mathrm{L}$. Experiment 2 was conducted four times (Trials 2.1 to 2.4 ) and consisted of only tapioca at 5, 15, and $20 \mathrm{~g} / \mathrm{L}$. Only tapioca was used in Experiment 2 because cell counts were significantly higher compared to molasses. Each data point in Figure 4-30 and Figure 4-31 was the average of nine data points - three flasks for each carbon source concentration multiplied by three plates for each flask. The incubation temperature was $30^{\circ} \mathrm{C}$, time of incubation was 48 hours, and agitation speed was $120 \mathrm{rpm}$.

Table 4-18. Cell counts in triplicate for Experiment 1, Trial 1.1.

\begin{tabular}{|c|c|c|c|c|c|c|}
\hline \multirow[b]{3}{*}{ Flask } & \multicolumn{6}{|c|}{ B. subtilis KLB (x 107 CFU/mL) } \\
\hline & \multicolumn{3}{|c|}{ Molasses } & \multicolumn{3}{|c|}{ Tapioca } \\
\hline & $5 \mathrm{~g} / \mathrm{L}$ & $15 \mathrm{~g} / \mathrm{L}$ & $25 \mathrm{~g} / \mathrm{L}$ & $5 \mathrm{~g} / \mathrm{L}$ & $15 \mathrm{~g} / \mathrm{L}$ & $25 \mathrm{~g} / \mathrm{L}$ \\
\hline \multirow{3}{*}{1} & 53 & 16 & 60 & 27 & 700 & 306 \\
\hline & 60 & 14 & 26 & 29 & 450 & 386 \\
\hline & 160 & 1 & 13 & 38 & 500 & 500 \\
\hline \multirow{3}{*}{2} & 2 & 94 & 103 & 10 & 500 & 174 \\
\hline & 3 & 47 & 150 & 35 & 600 & 164 \\
\hline & 9 & 16 & 400 & 51 & 650 & 312 \\
\hline \multirow{3}{*}{3} & 38 & 130 & 250 & 16 & 322 & 185 \\
\hline & 12 & 49 & 130 & 19 & 356 & 135 \\
\hline & 2 & 27 & 39 & 64 & 362 & 153 \\
\hline Avg 1 & 91 & 10 & 130 & 31 & 550 & 346 \\
\hline Avg 2 & 5 & 52 & 218 & 32 & 583 & 217 \\
\hline Avg 3 & 17 & 69 & 140 & 33 & 347 & 158 \\
\hline Avg total & 38 & 44 & 162 & 32 & 493 & 240 \\
\hline
\end{tabular}




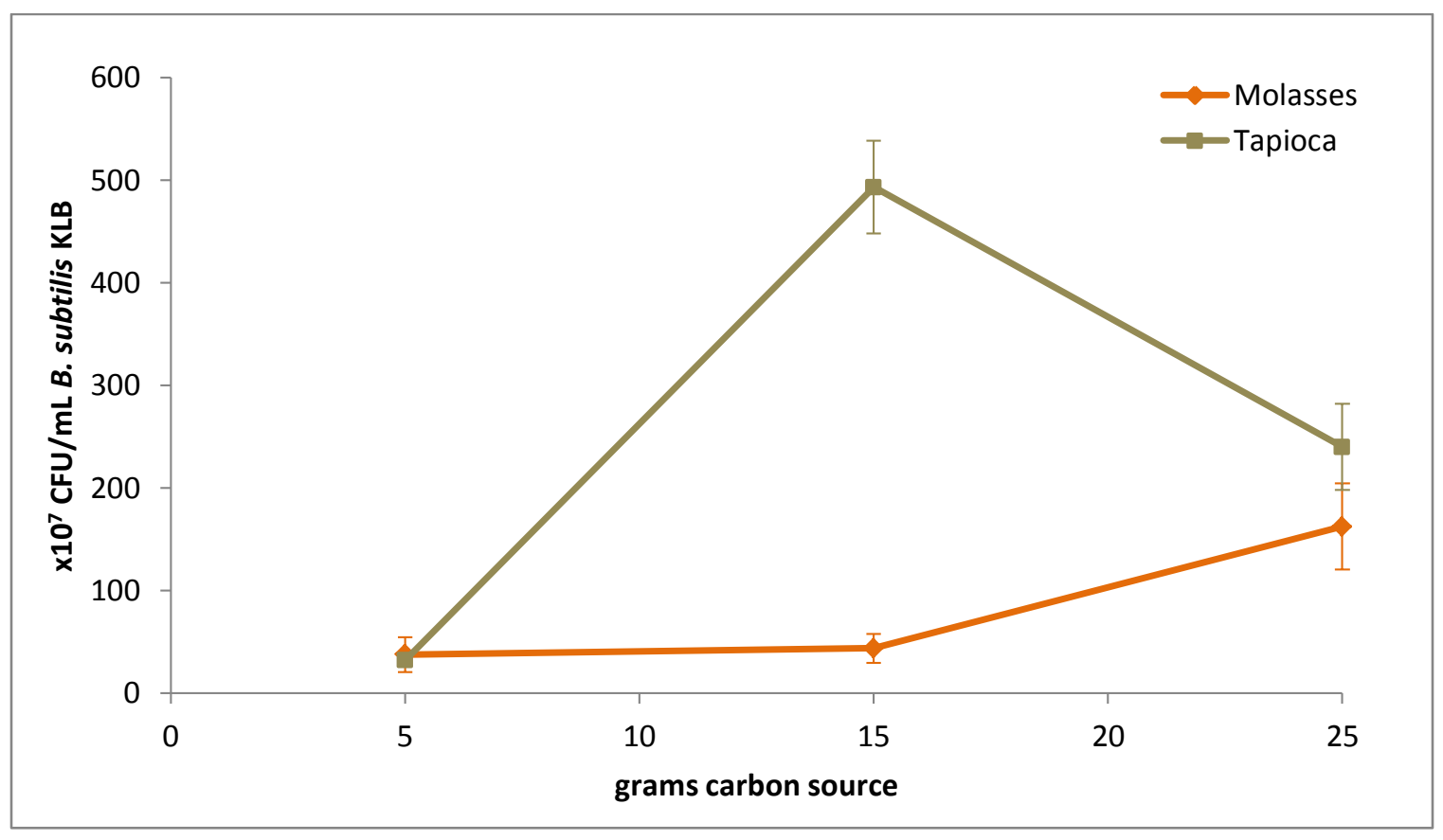

Figure 4-30. Cell counts of KLB grown on molasses and tapioca from Table 4-18 (Experiment 1, Trial 1.1).

Table 4-19. Cell counts in triplicate for Experiment 1, Trial 1.2.

\begin{tabular}{|c|c|c|c|c|c|c|}
\hline \multirow[b]{3}{*}{ Flask } & \multicolumn{6}{|c|}{ B. subtilis KLB (x 107 CFU/mL) } \\
\hline & \multicolumn{3}{|c|}{ Molasses } & \multicolumn{3}{|c|}{ Tapioca } \\
\hline & $5 \mathrm{~g} / \mathrm{L}$ & $15 \mathrm{~g} / \mathrm{L}$ & $25 \mathrm{~g} / \mathrm{L}$ & $5 \mathrm{~g} / \mathrm{L}$ & $15 \mathrm{~g} / \mathrm{L}$ & $25 \mathrm{~g} / \mathrm{L}$ \\
\hline \multirow{3}{*}{1} & $\mathrm{n} / \mathrm{a}$ & 1 & 220 & 37 & 296 & 380 \\
\hline & $\mathrm{n} / \mathrm{a}$ & 0 & 57 & 17 & 270 & 38 \\
\hline & $\mathrm{n} / \mathrm{a}$ & 0 & 19 & 356 & 140 & 171 \\
\hline \multirow{3}{*}{2} & 107 & 62 & 21 & 77 & 119 & 38 \\
\hline & 37 & 0 & 12 & 137 & 45 & 138 \\
\hline & 53 & 0 & 3 & 185 & 215 & 192 \\
\hline \multirow{3}{*}{3} & 2 & 5 & 99 & 26 & 50 & 16 \\
\hline & 18 & 1 & 34 & 19 & 25 & 32 \\
\hline & 12 & 1 & 18 & 8 & 20 & 3 \\
\hline Avg 1 & 107 & 0 & 54 & 137 & 235 & 112 \\
\hline Avg 2 & 66 & 21 & 12 & 133 & 126 & 123 \\
\hline Avg 3 & 11 & 2 & 50 & 18 & 32 & 17 \\
\hline Avg total & 38 & 8 & 39 & 96 & 131 & 84 \\
\hline
\end{tabular}




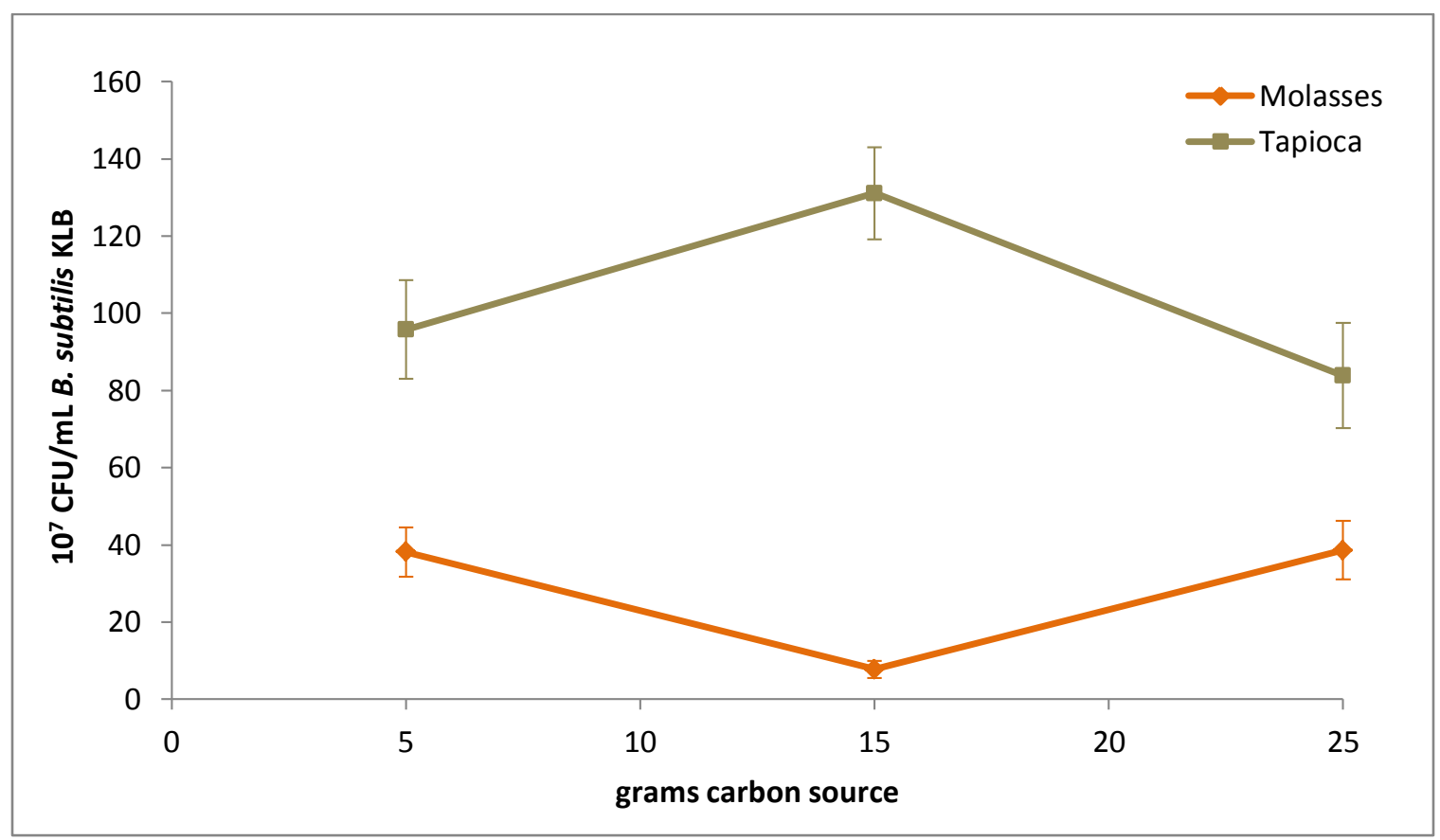

Figure 4-31. Cell counts of KLB grown on molasses and tapioca from Table 4-18 (Experiment 1, Trial 1.2).

Cell counts for Trial 1.1 (Table 4-18 and Figure 4-30) for both carbon sources were about five times higher compared to those for Trial 1.2 (Table 4-19 and Figure 4-31).

Conditions of Trial 1.1 and 1.2 were identical, with the exception that the starting concentrations of KLB inoculum varied since the trials were conducted on different days. Trial 1.1 tapioca averaged 493 colonies per plate at a $10^{-7}$ dilution, or $4.9 \times 10^{9} \mathrm{CFU} / \mathrm{mL}$, while molasses averaged $4.4 \times 10^{8} \mathrm{CFU} / \mathrm{mL}$. Trial 2 tapioca averaged $1.3 \times 10^{9} \mathrm{CFU} / \mathrm{mL}$ while molasses averaged $8 \times 10^{7} \mathrm{CFU} / \mathrm{mL}$. Nonetheless, in Trial 1.1 at $15 \mathrm{~g} / \mathrm{L}$ of carbon source, tapioca yielded a cell concentration of 11.1 times the concentration of molasses (Figure 4-30). In Trial 1.2 at $15 \mathrm{~g} / \mathrm{L}$, tapioca yielded 16.3 times the concentration of molasses (Figure 4-31). 
Table 4-20. Cell counts in triplicate for tapioca, Experiment 2, Trials 2.1-2.4.

\begin{tabular}{|c|c|c|c|c|c|c|c|c|c|c|c|c|}
\hline \multirow[b]{3}{*}{ Flask } & \multicolumn{12}{|c|}{ B. subtilis KLB (x $\left.10^{7} \mathrm{CFU} / \mathrm{mL}\right)$} \\
\hline & \multicolumn{3}{|c|}{ Trial 2.1} & \multicolumn{3}{|c|}{ Trial 2.2} & \multicolumn{3}{|c|}{ Trial 2.3} & \multicolumn{3}{|c|}{ Trial 2.4} \\
\hline & $\begin{array}{c}5 \\
\mathrm{~g} / \mathrm{L} \\
\end{array}$ & $\begin{array}{l}15 \\
\mathrm{~g} / \mathrm{L}\end{array}$ & $\begin{array}{c}20 \\
\mathrm{~g} / \mathrm{L}\end{array}$ & $\begin{array}{c}5 \\
\mathrm{~g} / \mathrm{L} \\
\end{array}$ & $\begin{array}{l}15 \\
\mathrm{~g} / \mathrm{L}\end{array}$ & $\begin{array}{l}20 \\
\mathrm{~g} / \mathrm{L}\end{array}$ & $\begin{array}{c}5 \\
g / L \\
\end{array}$ & $\begin{array}{l}15 \\
\mathrm{~g} / \mathrm{L}\end{array}$ & $\begin{array}{l}20 \\
\mathrm{~g} / \mathrm{L}\end{array}$ & $\begin{array}{c}5 \\
g / L \\
\end{array}$ & $\begin{array}{l}15 \\
\mathrm{~g} / \mathrm{L}\end{array}$ & $\begin{array}{l}20 \\
g / L\end{array}$ \\
\hline \multirow{3}{*}{1} & 46 & 480 & 71 & 2 & 0 & 284 & 0 & 286 & 29 & 320 & 150 & 81 \\
\hline & 75 & 159 & 14 & 2 & 0 & 136 & 0 & 123 & 73 & 30 & 32 & 10 \\
\hline & 206 & 201 & 24 & 0 & 1 & 45 & 3 & 22 & 128 & 80 & 30 & 23 \\
\hline \multirow{3}{*}{2} & 23 & 15 & 257 & 0 & 246 & 193 & 36 & 11 & 264 & 50 & 451 & 186 \\
\hline & 3 & 26 & 79 & 0 & 249 & 45 & 80 & 25 & 90 & 40 & 250 & 81 \\
\hline & 3 & 21 & 82 & 1 & 104 & 40 & 101 & 102 & 34 & 270 & 11 & 9 \\
\hline \multirow{3}{*}{3} & 96 & 259 & 297 & 194 & 240 & 87 & 65 & 300 & 0 & 0 & 490 & 321 \\
\hline & 26 & 500 & 72 & 48 & 93 & 36 & 50 & 62 & 0 & 0 & 137 & 181 \\
\hline & 66 & 600 & 31 & 8 & 42 & 17 & 47 & 108 & 0 & 0 & 30 & 188 \\
\hline Avg 1 & 109 & 280 & 103 & 1 & 0 & 98 & 1 & 144 & 69 & 143 & 71 & 120 \\
\hline Avg 2 & 10 & 21 & 139 & 0 & 200 & 93 & 72 & 46 & 129 & 120 & 237 & 92 \\
\hline Avg 3 & 63 & 453 & 133 & 83 & 125 & 47 & 54 & 157 & 0 & 0 & 219 & 230 \\
\hline $\begin{array}{l}\text { Avg } \\
\text { total }\end{array}$ & 60 & 251 & 125 & 28 & 108 & 79 & 42 & 115 & 66 & 88 & 176 & 147 \\
\hline
\end{tabular}




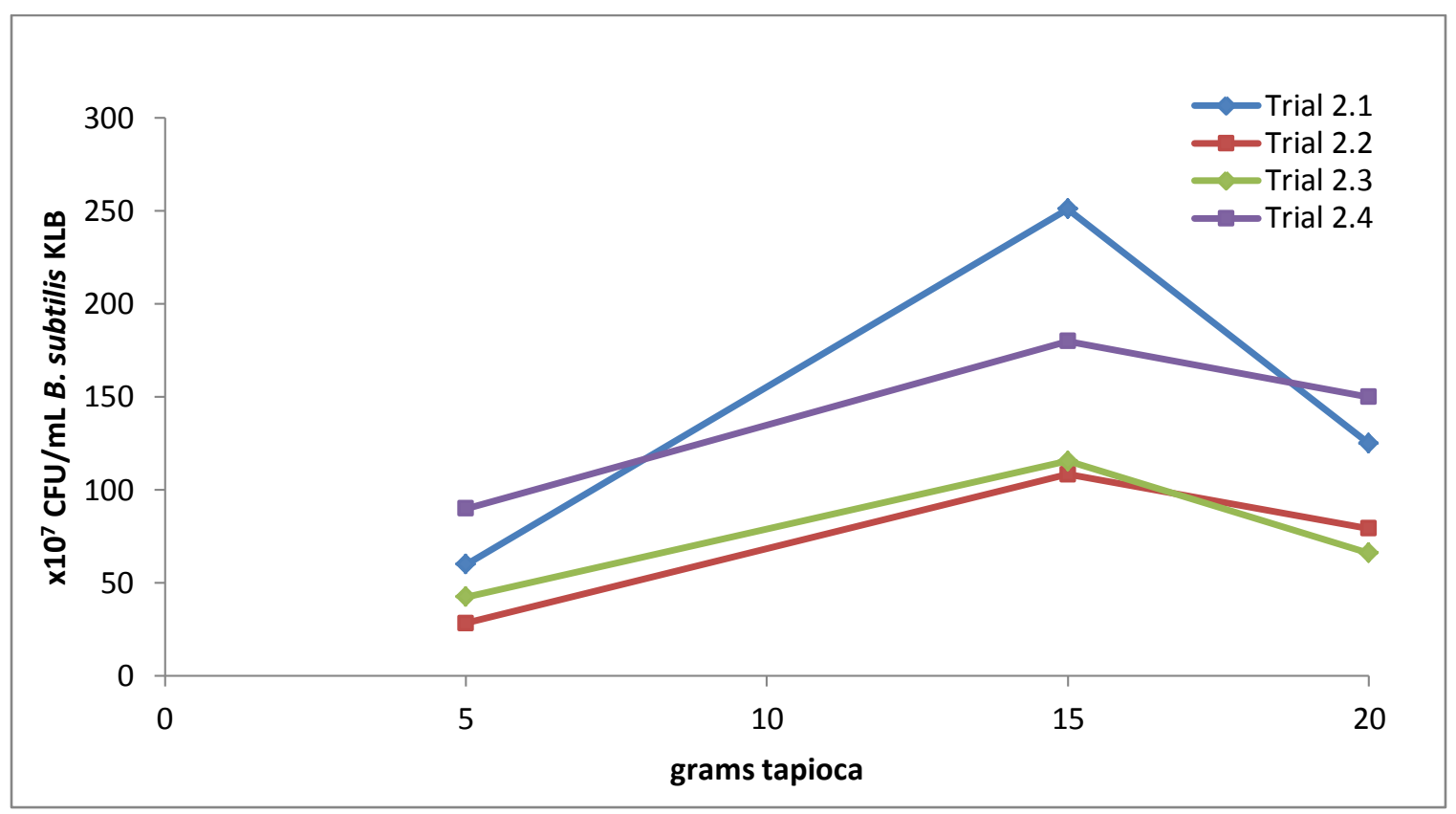

Figure 4-32. Cell counts of KLB grown on tapioca from Table 4-20 (Experiment 2, Trials 2.1-2.4).

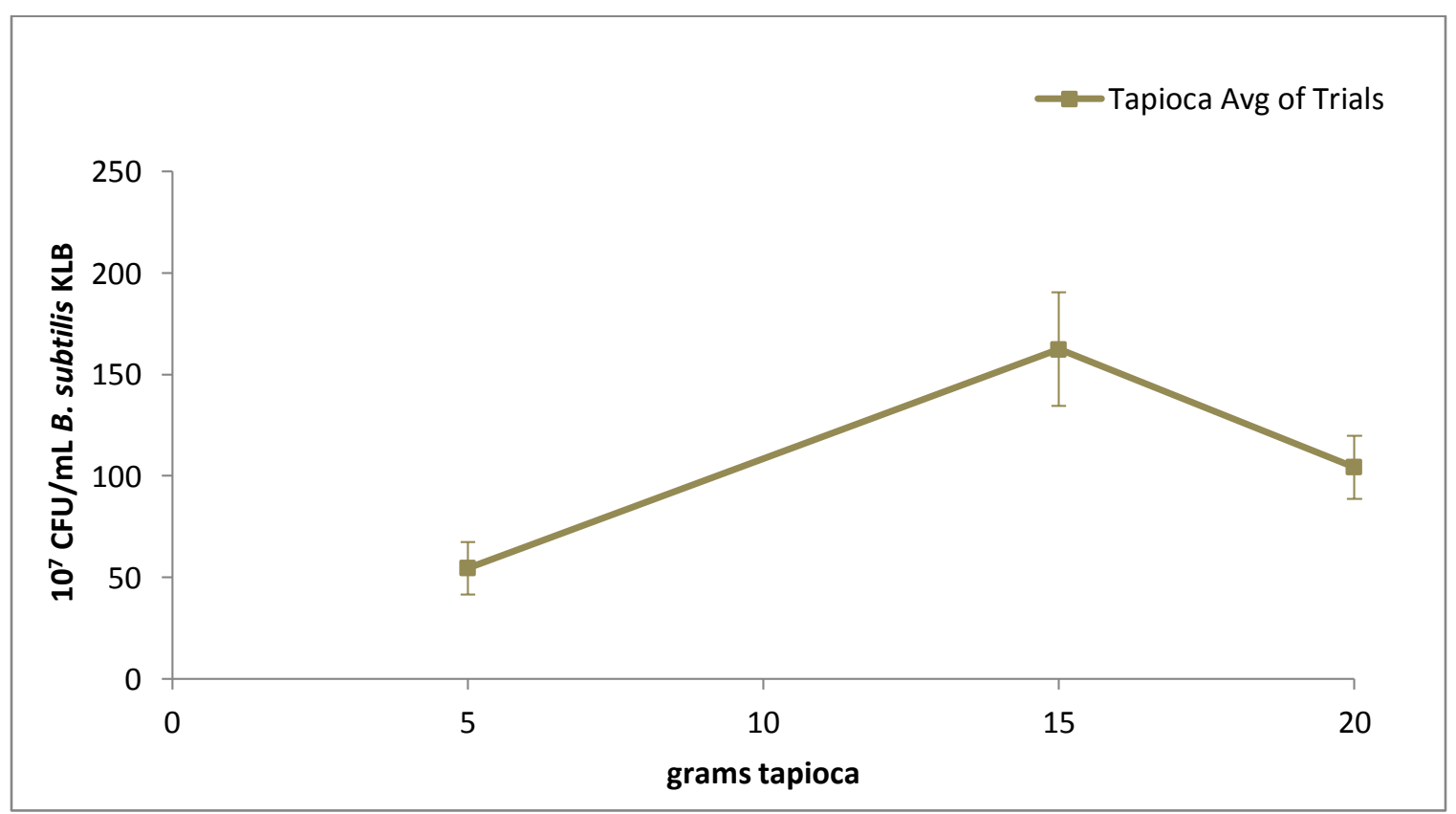

Figure 4-33. Average cell counts of KLB grown on tapioca from Table 4-20 (Experiment 2, Trials 2.1 to 2.4). 
Conditions of Trials 2.1 to 2.4 (Table 4-20 and Figure 4-32) were identical, with the exception that the starting concentrations of KLB inoculum varied since the trials were conducted on different days. Experiment 2 consisted of tapioca at 5, 15, and $20 \mathrm{~g} / \mathrm{L}$ based on Experiment 1 data as well as the optimal tapioca concentration of $16.7 \mathrm{~g} / \mathrm{L}$ for production of B. amyloliquefaciens B128 spores (Rao, 2007). Although this experiment focused on determining an optimal tapioca range for viable cell production instead of spores, Trials 2.1 to 2.4 show that between the three tapioca levels, $15 \mathrm{~g} / \mathrm{L}$ of tapioca produced the highest average cell concentration with 164 colonies per plate at a $10^{-7}$

dilution, or $1.6 \times 10^{9} \mathrm{CFU} / \mathrm{mL}$. At $5 \mathrm{~g} / \mathrm{L}$ of tapioca, the average cell concentration was 5.5 x $10^{8} \mathrm{CFU} / \mathrm{mL}$ and at $20 \mathrm{~g} / \mathrm{L}$ it was $1.1 \times 10^{9} \mathrm{CFU} / \mathrm{mL}$ (Figure 4-33).

\subsection{Botrytis Growth Curve Experiment Results}

Cell growth over time of both $B$. subtilis $\mathrm{KLB}$ and $\mathrm{BiOWiSH}^{\mathrm{TM}}$-Aqua were compared using $\mathrm{OD}_{600}$. 


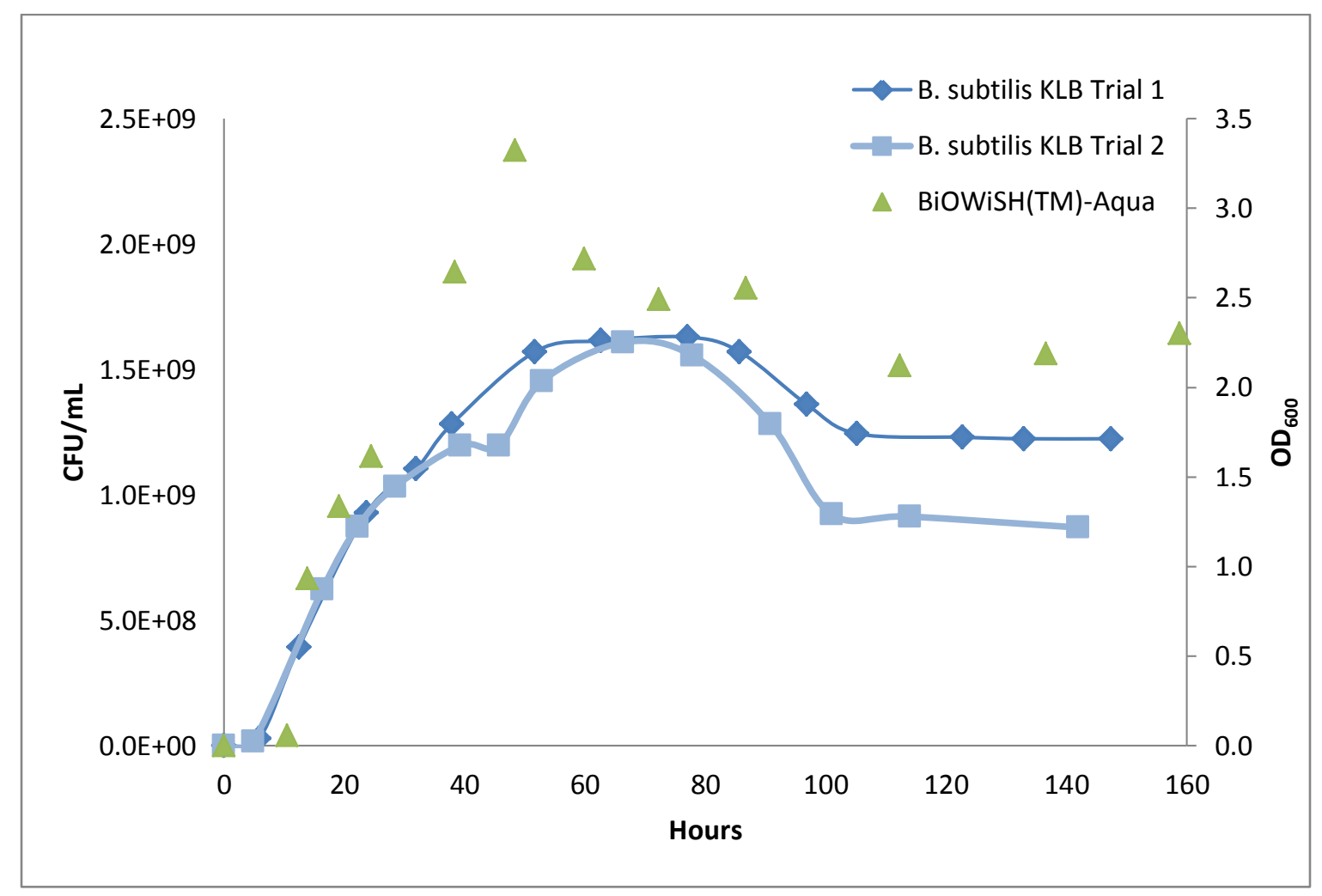

Figure 4-34. The $\mathrm{OD}_{600}$ values of $B$. subtilis $\mathrm{KLB}$ and $\mathrm{BiOWiSH}^{\mathrm{TM}}$-Aqua with corresponding KLB cell counts.

The primary y-axis (left) shows KLB cell counts and the secondary y-axis (right) shows $\mathrm{OD}_{600}$ of both KLB and $\mathrm{BiOWiSH}^{\mathrm{TM}}$-Aqua (Figure 4-34).

By using an enriched LB medium, the KLB lag phases were relatively short. The lag phases of the KLB trials lasted about 5-6 hours. The growth phase for both trials lasted until 50-55 hours. A slight dip in KLB concentration occurred in Trial 2 at 46 hours, but the next cell concentration at 53 hours increased, thus indicating the cells were still in growth phase. The maximum $\mathrm{OD}_{600}$ readings of the KLB trials were reached at around 66 hours, but the beginning of the stationary phase began earlier, possibly around 53 
hours. The two trials indicate that the stationary phases, where death of cells is approximately equal to growth of new cells, lasted between 24 and 36 hours. Cell concentrations of both trials at stationary phase were around $1.6 \times 10^{9} \mathrm{CFU} / \mathrm{mL}$. The death phases, where the deaths of cells exceed the growth of new cells, began between 78 and 86 hours. However, although cell concentration was expected to decrease at a constant rate during the death phase, the cell concentrations unexpectedly stayed constant based on $\mathrm{OD}_{600}$ readings after approximately 100 hours. $\mathrm{OD}_{600}$ reading may be inaccurate in this case because both dead and live cells, as well as spores, may have been taken into account in the OD readings.

The BiOWiSH ${ }^{\mathrm{TM}}$-Aqua grew rapidly starting at 10 hours, which resembled a lag phase. $\mathrm{OD}_{600}$ peaked at 48 hours at 3.3. $\mathrm{OD}_{600}$ was at a sharp and abrupt peak as it quickly dropped from about 3.3 to 2.7. In comparison to $\mathrm{KLB}$, the maximum $\mathrm{OD}_{600}$ of $\mathrm{BiOWiSH}^{\mathrm{TM}}$-Aqua at 3.3 was significantly greater than that of KLB at 2.2, or $1.6 \times 10^{9}$ CFU/mL. OD $_{600}$ fluctuated from 60 to 160 hours, with an upward trend in $\mathrm{OD}_{600}$ toward the end. No resemblance of a stationary or a death phase was present in the $\mathrm{BiOWiSH}^{\mathrm{TM}}$-Aqua data. The proportion of $\mathrm{KLB}$ in $\mathrm{BiOWiSH}^{\mathrm{TM}}$-Aqua was unknown. An explanation is that different organisms in $\mathrm{BiOWiSH}^{\mathrm{TM}}$-Aqua were growing at different times, hence the high $\mathrm{OD}_{600}$ values compared to KLB. 


\subsection{B. subtilis KLB as Biopesticide on Strawberry Fruit Bodies}

Strawberries and several beakers of water were placed in a chamber as shown in Figure

3-9. Temperatures ranged from $18-22^{\circ} \mathrm{C}$ and humidity ranged from $90-99 \%$.

Table 4-21. Average Botrytis infection rate (\%) four days after biopesticide inoculation.

\begin{tabular}{|c|c|c|c|c|c|}
\hline \multirow{3}{*}{ Trial } & \multicolumn{5}{|c|}{ Percent of strawberries molded 4 days after biopesticide inoculation } \\
\hline & \multicolumn{3}{|c|}{ B. subtilis KLB } & \multirow{2}{*}{$\begin{array}{l}\text { Serenade }{ }^{\circledR} \\
\text { (undiluted) }\end{array}$} & \multirow[b]{2}{*}{ Control } \\
\hline & No Dilution & 1:10 Dilution & $\begin{array}{c}\text { 1:100 } \\
\text { Dilution }\end{array}$ & & \\
\hline 1 & 33.3 & 83.3 & 33.3 & 33.3 & 16.7 \\
\hline 2 & 83.3 & 50.0 & 50.0 & 33.3 & 50.0 \\
\hline 3 & 100.0 & 100.0 & 100.0 & 83.3 & 100.0 \\
\hline 4 & 33.3 & 66.7 & 88.9 & 44.4 & 55.6 \\
\hline 5 & 50.0 & 100.0 & 87.5 & 75.0 & 100.0 \\
\hline $\begin{array}{l}\text { Avg infection } \\
\text { rate (\%) }\end{array}$ & 60.0 & 80.0 & 71.9 & 53.9 & 64.4 \\
\hline
\end{tabular}




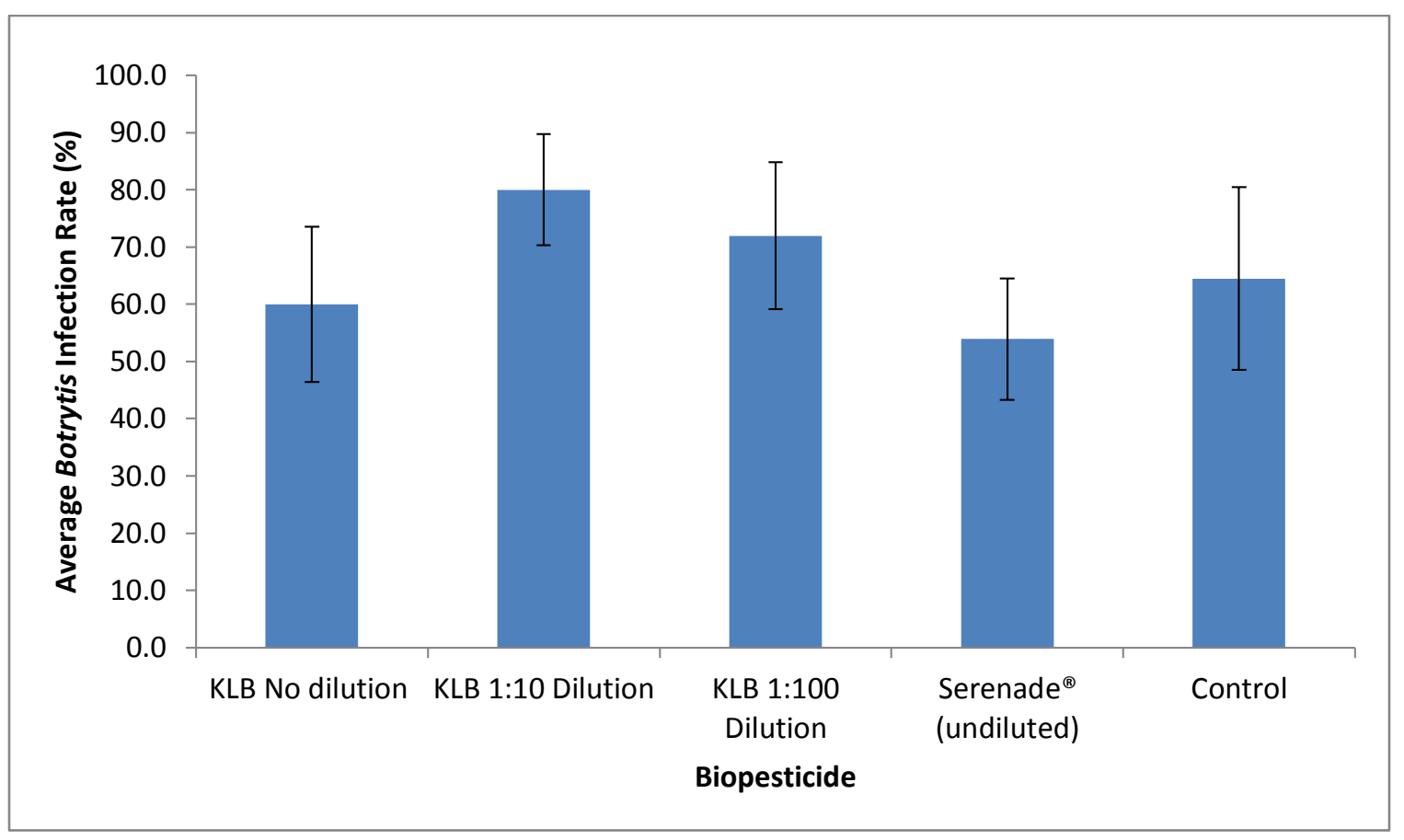

Figure 4-35. Average Botrytis infection rate (\%) four days after biopesticide inoculation from Table 4-21 data.

The original concentrations of $B$. subtilis KLB inoculum were approximately $5.0 \times 10^{8}$ CFU/mL. Commercial product Serenade ${ }^{\circledR}$ Garden Disease Control Spray (B. subtilis QST 713) was at the unknown original concentration. The control contained no biopesticide.

Table 4-21 and Figure 4-35 show the Botrytis infection rate (\%) of gray mold-infected strawberries four days after biopesticide inoculation. Trials 1 to 4 contained identical conditions with strawberry placement as shown in Figure 3-10 and described in Section 3.6.1. Trial 5 was conducted using the modified scheme in Figure 3-11 and described in Section 3.6.2. Infection typically began three days ( 72 hours) after biopesticide 
inoculation. Shortly after, the fruit body itself was broken down by the Botrytis (shown by a puddle of red juice).

The data in Table 4-21were analyzed using Analysis of Variance (ANOVA F-test) to determine whether average Botrytis infection rates between the five biopesticide groups were statistically different (Appendix B). The null hypothesis was average infection rates between the five groups were equal, and the alternative hypothesis was at least one average infection rate was different from the others. There was insufficient evidence $(\mathrm{F}=$ $0.64<2.87)$ to reject the null hypothesis at the five percent significance level. In other words, there was no statistical evidence that the average Botrytis infection rates between the five biopesticide groups were different. Therefore, none of the biopesticides had an effect on Botrytis infection rates of strawberries at $18-22^{\circ} \mathrm{C}$ and $90-99 \%$ humidity in a chamber. 


\section{CHAPTER 5: CONCLUSIONS}

\subsection{Experimental Conclusions}

The original goal of this research was to investigate the potential of $\mathrm{BiOWiSH}^{\mathrm{TM}}$-Aqua as a biopesticide against Botrytis. Results were measured as percent Botrytis growth on plate, which resulted in varied percentages of growth because every plate possibly contained a different cell composition. This led to results that were varied even within plates in triplicate. The lack of homogeneity of commercial product $\mathrm{BiOWiSH}^{\mathrm{TM}}$-Aqua was the probable cause of the vast differences. On average, $\mathrm{BiOWiSH}^{\mathrm{TM}}$-Aqua somewhat inhibited Botrytis growth, but was far from an optimal biopesticide.

The organism responsible for Botrytis inhibition was isolated from the $\mathrm{BiOWiSH}^{\mathrm{TM}}$ Aqua plates. Inhibition zones were seen around these specific colonies, which were identified as an isolate (B. subtilis KLB) courtesy of Alice Hamrick and Dr. Christopher Kitts. The closest sequence match was to B. subtilis BSn5 (100\% Max ident), which contains antimicrobial activity against plant pathogen Erwinia carotovora. It was probable that KLB produced an antibiotic substance, such as the antifungal lipopeptide fengycin, to inhibit Botrytis growth (Vanittanakom, 1986). Hang (2005) had similar success with another strawberry biopesticide, B. subtilis $\mathrm{S} 1-0210$, which produces antibiotic substance that diffuses into the agar medium and inhibits the mycelial growth of Botrytis. 
Once KLB was isolated, it was tested in place of $\mathrm{BiOWiSH}^{\mathrm{TM}}$-Aqua as the biopesticide used against Botrytis. KLB was much more successful and predictable in terms of Botrytis inhibition. In contrast to $\mathrm{BiOWiSH}^{\mathrm{TM}}$-Aqua, $\mathrm{KLB}$ showed a trend in which the longer KLB grew on plates before Botrytis inoculation, the less concentrated the KLB culture needed to be for complete Botrytis inhibition. The threshold was $3.2 \times 10^{6}$ $\mathrm{CFU} / \mathrm{mL}$ of KLB at application time of 0 hours, as opposed to $1.3 \times 10^{5} \mathrm{CFU} / \mathrm{mL}$ and 9.1 x $10^{4} \mathrm{CFU} / \mathrm{mL}$ at 24 and 48 hours, respectively. KLB concentration also mattered much less at higher application times. Botrytis growth was reduced by 28 percent for every log increase in KLB concentration at application time of 0 hours, as opposed to only 6.5 percent at 24 and 48 hours.

The probable cause of these trends was that KLB produced an antifungal agent during the application time before the inoculation of Botrytis. This means at application time 0 hours, Botrytis grew before the antifungal agent was produced because KLB started growing at the same time. Given that commercial product $\mathrm{BiOWiSH}^{\mathrm{TM}}$-Aqua is used for various applications due to the multitude of organisms, the potential of using KLB as a specialized product for strawberries was explored.

Subsequent experiments involved investigation of KLB for use as a commercial product directly on strawberries. First, commercially available carbon sources, liquid molasses and cooked tapioca balls, were tested to determine whether cell counts similar to those grown in LB could be achieved. While results varied between trials, every trial showed 
$15 \mathrm{~g} / \mathrm{L}$ of tapioca was the optimal amount of carbon source. This makes sense because tapioca is a starch (a polysaccharide consisting of many glucose molecules) and KLB is very closely related to B. amyloliquefaciens, which can metabolize tapioca using amylases to break down the starch (Rao, 2007). However, the tapioca made the solution very turbid because residue was very apparent. Flocculation may have contributed to the disparity in cell counts of each trial as shown in Figure 4-32.

Another experiment to characterize both $\mathrm{BiOWiSH}^{\mathrm{TM}}$-Aqua and the isolate was to compare their $\mathrm{OD}_{600}$ values at different times. Seen in Figure 4-34, the KLB growth curve was a characteristic growth curve with clearly defined lag, log, stationary, and death phases. In contrast, $\mathrm{BiOWiSH}^{\mathrm{TM}}$-Aqua growth was more random over time, with $\mathrm{OD}_{600}$ increasing even when KLB was well into its death phase. This indicates that different organisms grew at different times. $\mathrm{OD}_{600}$, which was used to calculate cell counts, did not identify particular cells. Rather, the $\mathrm{BiOWiSH}^{\mathrm{TM}}$-Aqua growth curve just showed the aggregate of all of the organisms growing and dying. While one organism was in the death phase, another organism may have been in the log phase. The proportion of $\mathrm{KLB}$ in $\mathrm{BiOWiSH}^{\mathrm{TM}}$-Aqua at any given time was not determined.

Using a biopesticide on post-harvest strawberries did not inhibit gray mold much. A similar result was described previously in which pre-application (on leaves and flowers) of a biopesticide was much more effective than post-application on ripe strawberries (Hang, 2005). Another problem was high humidity in the chamber at 90 to 99 percent, 
which promoted fungal growth. The data in Table 4-21 as well as the ANOVA show that there was no significant difference between using a biopesticide and not using a biopesticide on post-harvest strawberries. In other words, KLB worked well to inhibit Botrytis in plate (in vitro) but not on strawberries (in vivo).

\subsection{Future Research}

The success of in vitro experiments using $B$. subtilis KLB as a biopesticide against Botrytis suggests that KLB should be successful in field trials. Hang (2005) showed $B$. subtilis S1-0210 could reduce infection rates from 70 percent in an untreated control to under five percent using a wettable powder formation of the biopesticide for pretreatment. Field trials confirming these results should be conducted by comparing the following: using fumigation (chemical pesticide) only, using KLB only, and planning IPM by reducing chemical usage and increasing biological usage (biopesticides).

Post-harvest treatment testing by using KLB to increase shelf life of strawberry fruits can also be conducted. Lowering the temperature along with decreasing humidity may lead to more success in Botrytis inhibition.

Other tests related to the commercial feasibility of using KLB should be done. Some of the factors that determine whether KLB is an economic alternative are the ease of successfully growing the organism in large batches and the use of cheap commercial 
ingredients in the media (molasses and tapioca). While my experiments aimed at these concerns, the results were preliminary. More bench-top scale fermentation in a bioreactor needs to be conducted to determine whether scaling up from flasks can be successful in terms of cell counts while minimizing contamination.

Once field trials confirm the effectiveness of KLB on Botrytis inhibition, the main priority will be to conduct research on its commercial feasibility as a biopesticide against Botrytis to address the increasing need of alternative pesticides needed in the California strawberry industry. 


\section{BIBLIOGRAPHY}

Agrios, G.N. (1997). Plant Pathology. San Diego, CA: Elsevier Academic Press.

BiOWiSH ${ }^{\mathrm{TM}}$-Technologies. "BiOWiSH ${ }^{\mathrm{TM}}$-Aqua". n.d. Web March 17, 2012 http://www.biowishtechnologies.com/us/environment/wastewater-treatment/industrialwastewater/biowish-aqua/

Brennan T., "Biopesticides Registration Improvement Course: Integrated Pest Management (IPM)" EPA, NAFTA Technical Working Group on Pesticides. Web. 18 Dec. 2011. http://www.epa.gov/oppbppd1/biopesticides/nafta-bric/agenda/day-1/14-tombrennan.pdf

Burr T.J., Pearson R.C., and Schwartz M.R. ( 1985) "Small Fruit IPM Disease Identification Sheet No. 1: Botrytis fruit rot" New York State Agricultural Experiment Station (NYSAES), Geneva, A Division of the New York State College of Agriculture and Life Sciences, A Statutory College of the State University, Cornell University, Ithaca. www.nysipm.cornell.edu/factsheets/berries/botrytis.pdf

Chiou, A. L. and Wu, W. S. (2003), Formulation of Bacillus amyloliquefaciens B190 for Control of Lily Grey Mould (Botrytis elliptica). Journal of Phytopathology, 151: 13-18.

Cooley D. R., Wilcox, W.F., Kovach, J., Schloemann, S.G. (1996) "Integrated pest management programs for strawberries in the northeastern United States" Plant Disease 80(3): 228-237.

Fennimore S., Duniway, J. M., Browne, G. T., Martin. F. N., Husein, A., Westerdahl, B. B., Goodhue, R. E., Haar, M., Winterbottom, C. (2008) "Methyl bromide alternatives evaluated for California strawberry nurseries" California Agriculture 62(2): 62-67.

Guo M., Gao S. (2009) "Degradation of Methyl Iodide in Soil: Effects of Environmental Factors" Journal of Environmental Quality 38: 513-519.

Hang N.T.T., Oh S.O., Kim G.H., Hur J.S., Koh Y.J. (2005) "Bacillus subtilis S1-0210 as a Biocontrol Agent against Botrytis cinerea in Strawberries" The Plant Pathology Journal 21(1): 59-63.

Locascio S., Gilreath J.P., Dickson D.W., Kucharek T.A., Jones J.P, Noling J.W. (1997) "Fumigant Alternatives to Methyl Bromide for Polyethylene-mulched Tomato" HortScience 32(7): 1208-1211. 
Morrissey W.A. (2007) "Methyl Bromide and Stratospheric Ozone Depletion, Congressional Research Service (CRS) Report for Congress" http://www.cnie.org/NLE/CRSreports/07Jan/RS20863.pdf

Nagorska K., Bikowski M., Obuchowski, M. (2007) “Multicellular behavior and production of a wide variety of toxic substances support usage of Bacillus subtilis as a powerful biocontrol agent" Acta Biochimica Polonica Vol. 54 No. 3/2007, 495-498.

Nicholson W.L. (2002) "Roles of Bacillus endospores in the environment" Cell Mol. Life Sci. 59: 410-416.

Rao Y.K., Tsay K.J., Wu W.S., Tzeng Y.M. (2007) "Medium optimization of carbon and nitrogen sources for the production of spores from Bacillus amyloliquefaciens B128 using response surface methodology" Process Biochemistry 42 (2007) 535-541.

Rodgers, P. B. (1993), "Potential of biopesticides in agriculture" Pestic. Sci., 39: 117129. doi: $10.1002 /$ ps.2780390205

Stein T. (2005), "Bacillus subtilis antibiotics: structures, syntheses, and specific functions" Molecular Microbiology 56(4): 845-857.

Thomas W.B. (1996) "Methyl Bromide: Effective Pest Management Tool and Environmental Threat" Supplement to Journal of Nematology 28(4S): 586-589.

U.S. Department of Agriculture (USDA) (1999) "Crop Profile for Strawberries in California" University of California Integrated Pest Management Project, University of California, Davis, http://www.ipmcenters.org/CropProfiles/docs/castrawberries.html

U.S. Environmental Protection Agency (EPA) (2011) "Ozone Layer Protection Regulatory Programs: List of Critical Uses” Web. 20 Jan. 2012.

http://www.epa.gov/ozone/mbr/cueuses.html

U.S. Environmental Protection Agency (EPA) (2000) "Pesticides: Regulating Pesticides. Bacillus subtilis Strain QST 713 (006479) Fact Sheet" http://www.epa.gov/oppbppd1/biopesticides/ingredients/factsheets/factsheet_006479.htm

Vanittanakom N., Loeffler W., Koch U., Jung G. (1986) "Fengycin - a novel antifungal lipopeptide antibiotic produced by Bacillus subtilis F-29-3" J Antibiot (Tokyo) 39(7): 888-901.

Zhang Z., Schwartz S., Wagner L., and Miller, W. (2000) "A greedy algorithm for aligning DNA sequences" J Comput Biol 7(1-2): 203-14. 


\section{Appendix A}

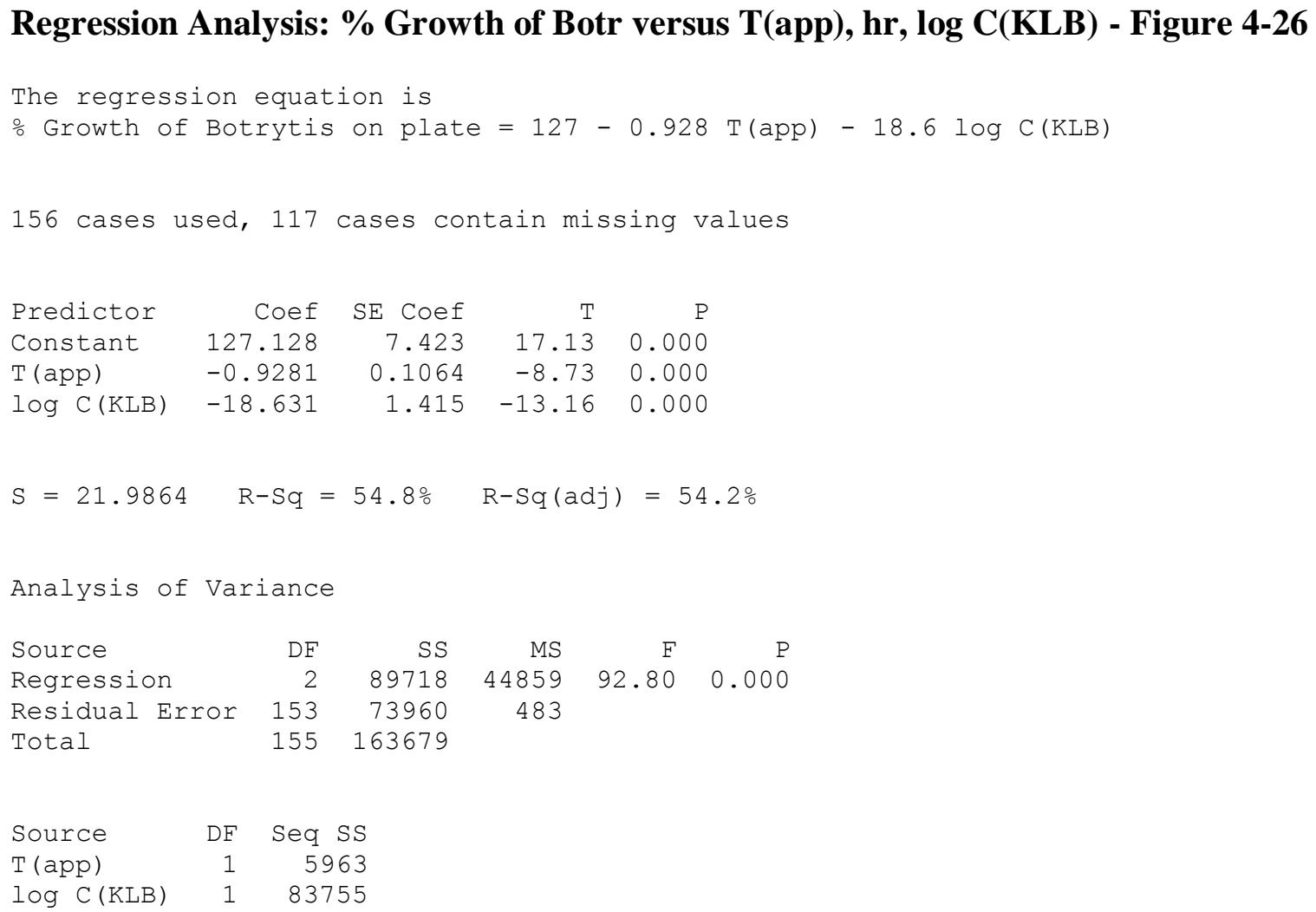

Regression Analysis: \% Growth of Botr versus T(app), hr, $\log$ C(KLB) Figure 4-27

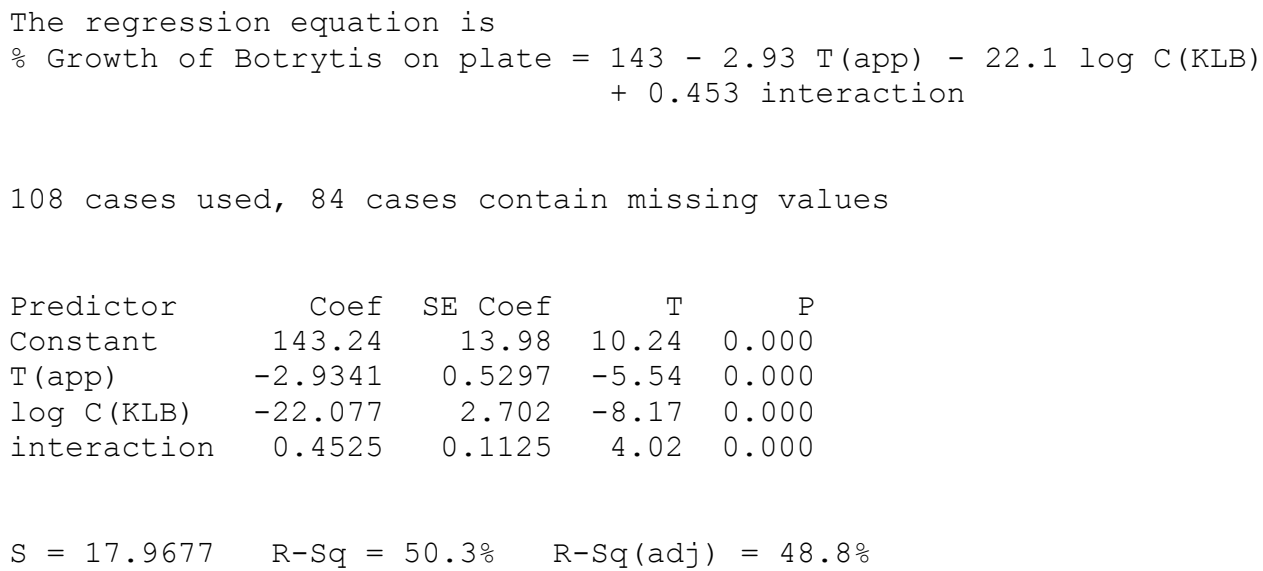




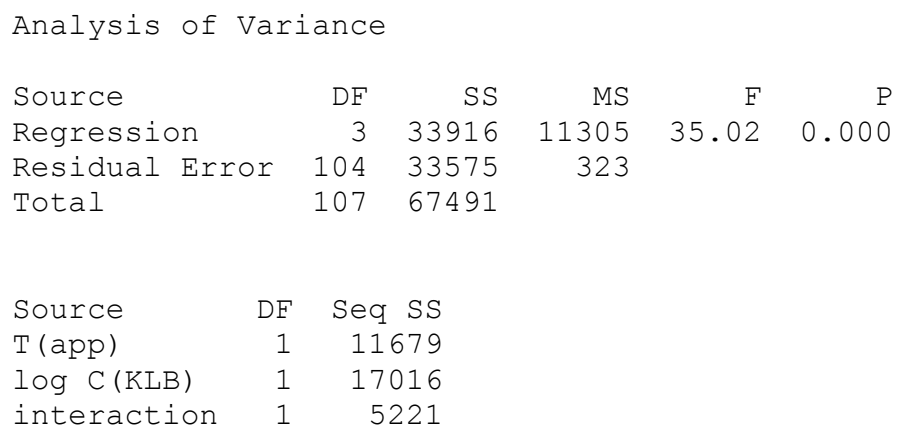

Regression Analysis: \% Growth of Botrytis on plate versus log C(KLB), Tapp $=0$ hours - Figure 4-28

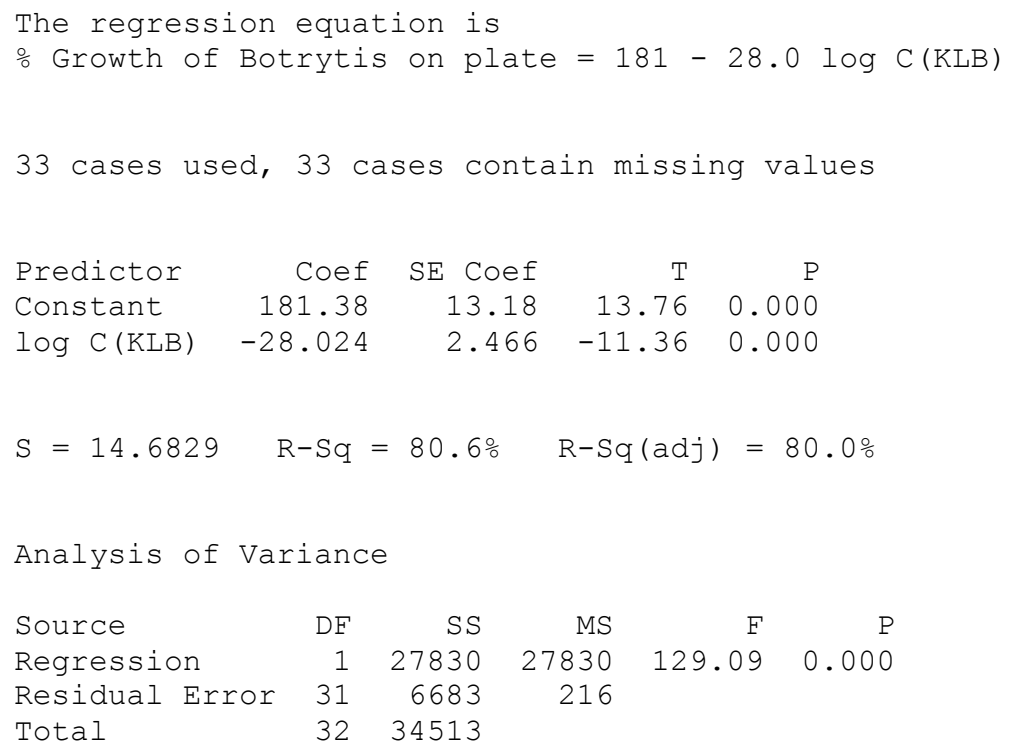

Regression Analysis: \% Growth of Botrytis on plate versus $\log C(K L B)-$ Figure 4-29

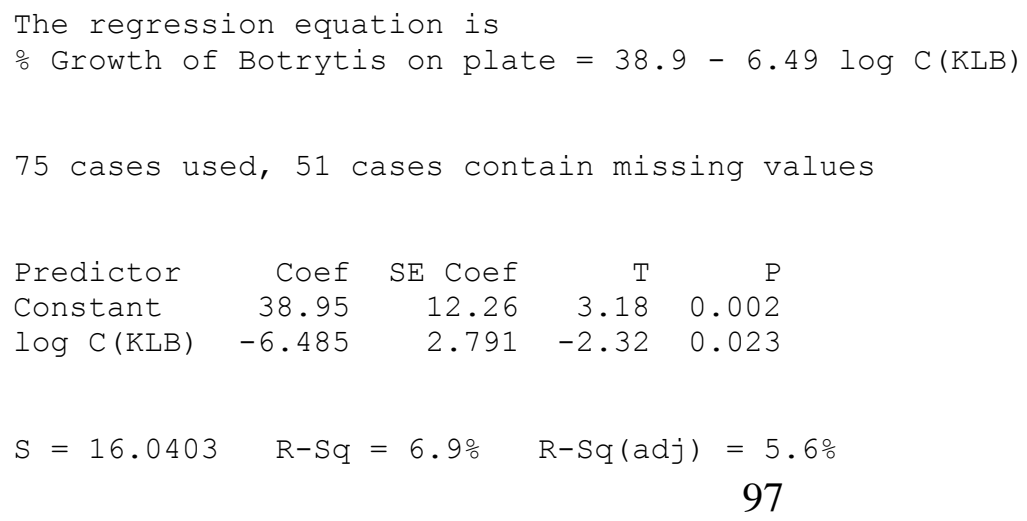




Analysis of Variance
$\begin{array}{lrrrrr}\text { Source } & \text { DF } & \text { SS } & \text { MS } & \text { F } & \text { P } \\ \text { Regression } & 1 & 1389.7 & 1389.7 & 5.40 & 0.023 \\ \text { Residual Error } & 73 & 18782.2 & 257.3 & & \\ \text { Total } & 74 & 20171.9 & & & \end{array}$

\section{Appendix B}

One-way ANOVA: KLB Undiluted, KLB 1:10, KLB 1:100, Serenade, Control Figure 4-35

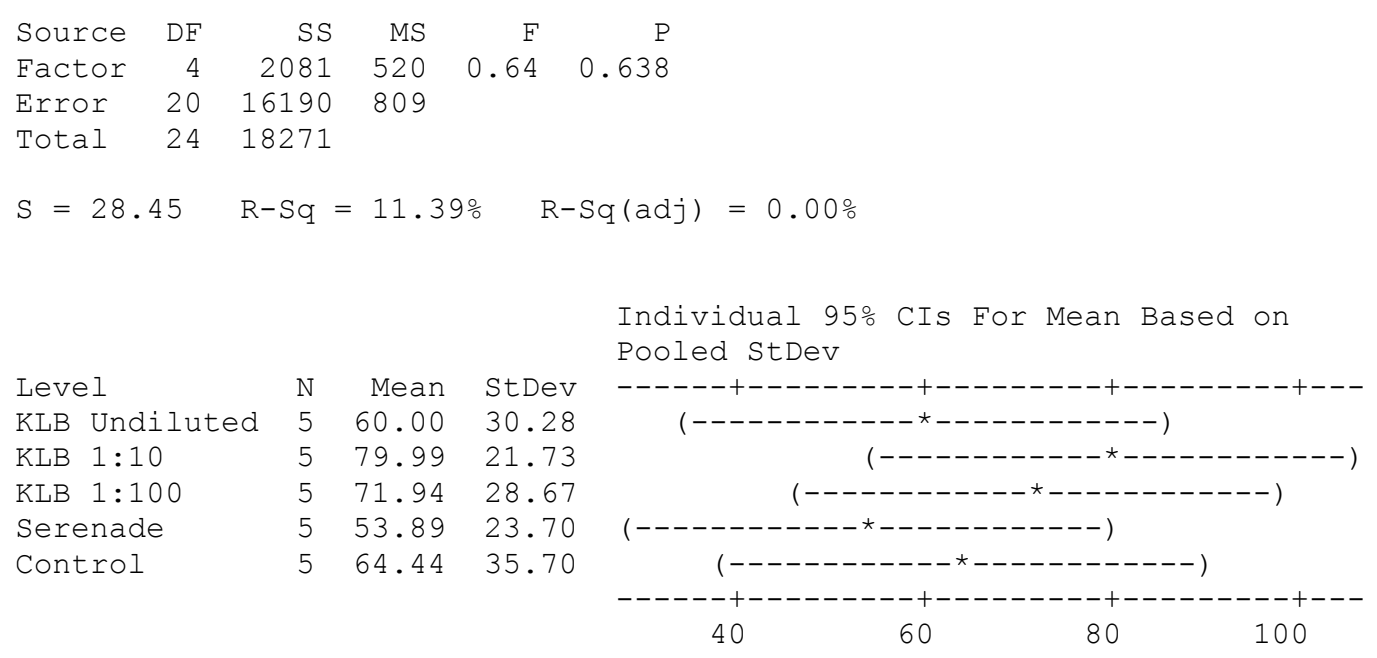

